Integration of advanced geriatric nurses: A mixed methods study of role and scope of practice

Silje Havrevold Henni

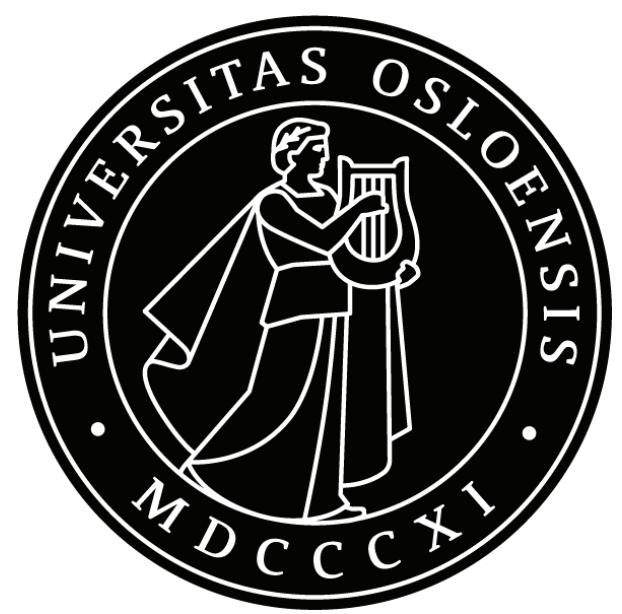

Dissertation for the degree philosophiae doctor (PhD)

Department of Nursing Science

Faculty of Medicine

University of Oslo

April 2020 
(C) Silje Havrevold Henni, 2020

Series of dissertations submitted to the Faculty of Medicine, University of Oslo

ISBN 978-82-8377-704-8

All rights reserved. No part of this publication may be reproduced or transmitted, in any form or by any means, without permission.

Cover: Hanne Baadsgaard Utigard.

Print production: Reprosentralen, University of Oslo. 


\section{Contents}

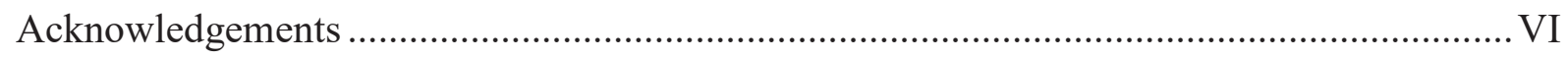

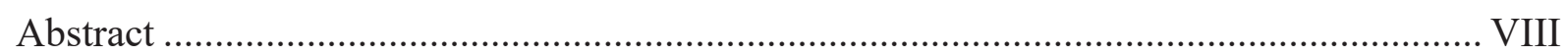

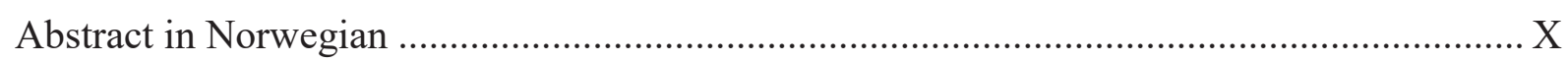

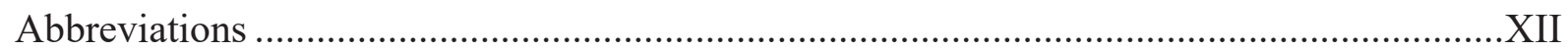

List of publications .......................................................................................... XII

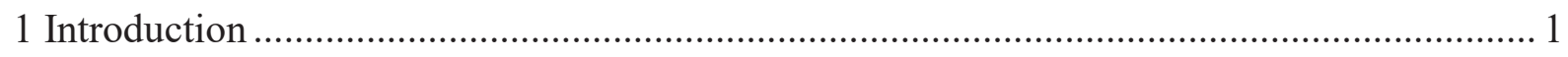

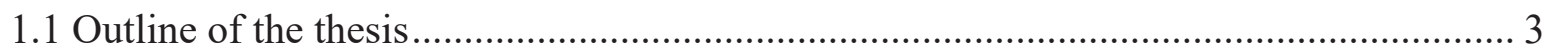

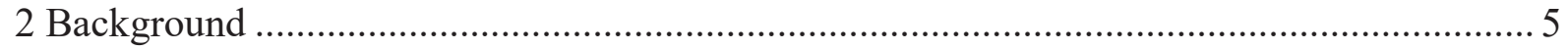

2.1 The Norwegian healthcare system with a focus on primary care................................... 5

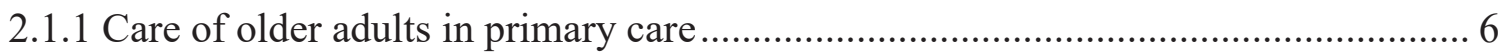

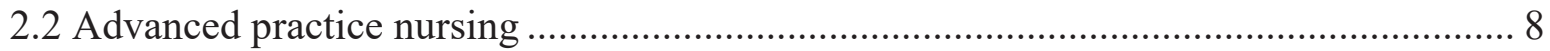

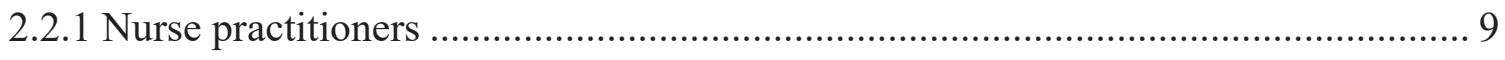

The role transition process from registered nurse to nurse practitioner .......................... 9

Role and scope of practice of nurse practitioners working in primary care................. 10

Nurse practitioners' contribution to healthcare ........................................................... 13

2.2.2 Advanced practice nursing in Norway ............................................................. 15

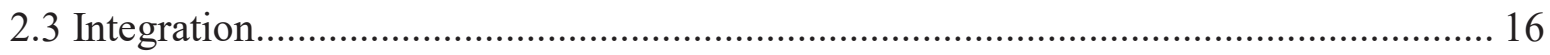

2.4 Placement of the PhD project in the research field .................................................... 19

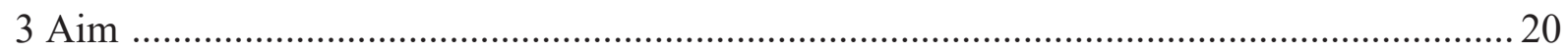

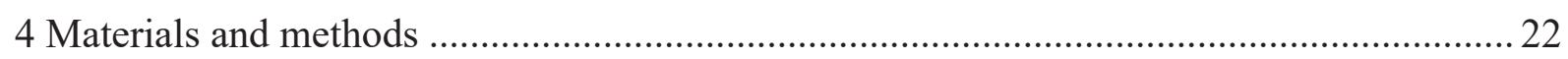

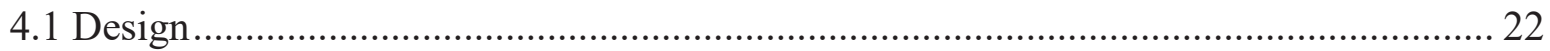

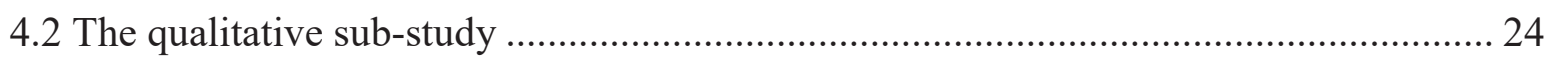

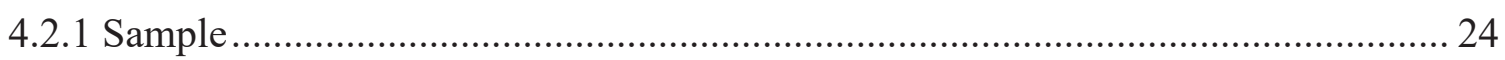

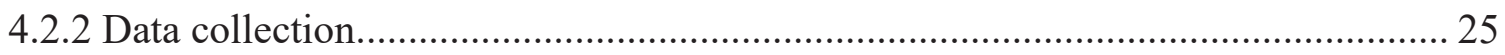

4.2.3 Analysis Sub-study I ............................................................................... 26

4.3 The quantitative sub-study ................................................................................. 27

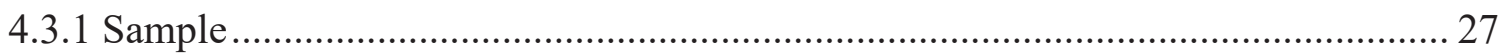

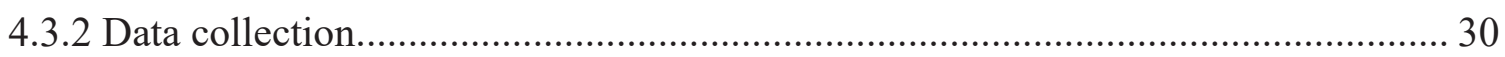

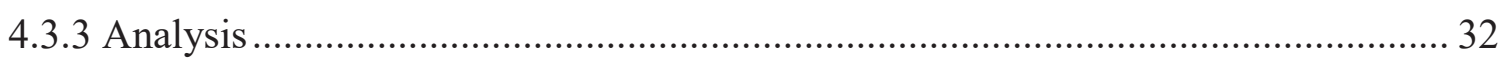

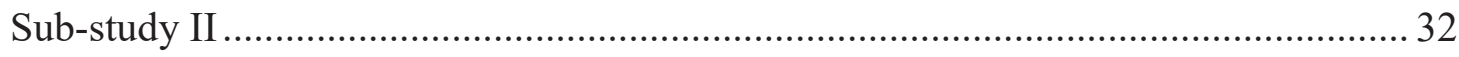

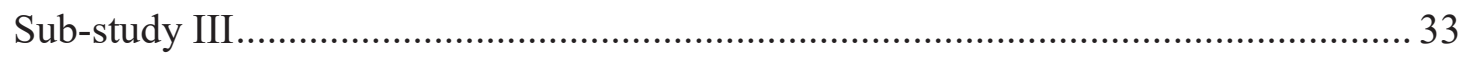

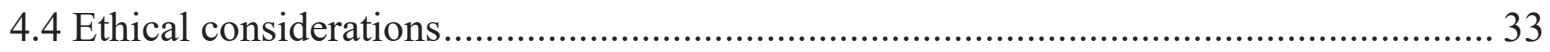


5 Results .35

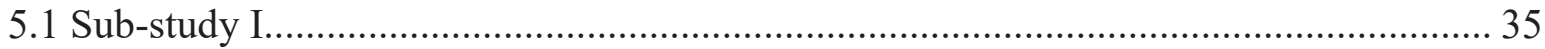

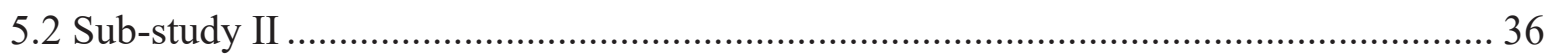

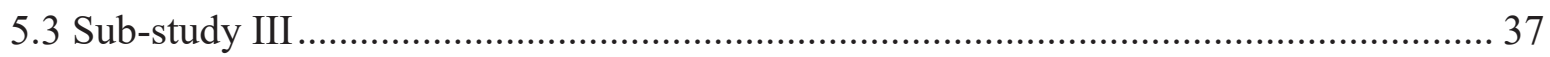

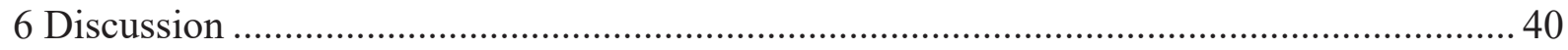

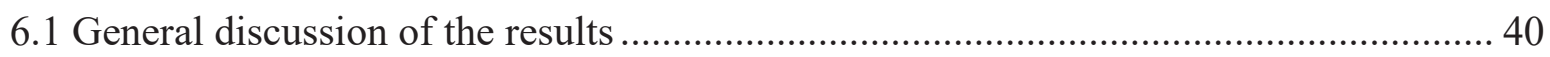

6.1.1 Role and scope of practice of advanced geriatric nurses ................................... 40

6.1.2 Factors that may affect the integration of advanced geriatric nurses into the

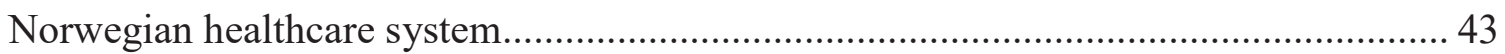

Factors that may facilitate the integration of advanced geriatric nurses ..................... 44

Factors that may hinder the integration of advanced geriatric nurses ......................... 45

6.1.3 The importance of the study for the further development of advanced practice

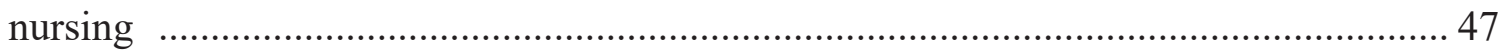

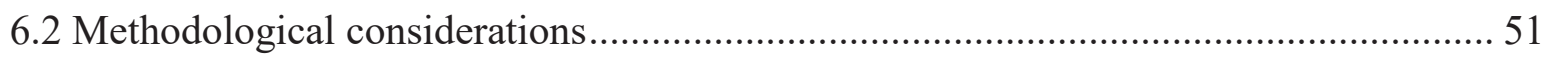

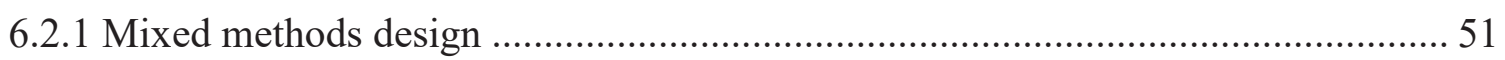

6.2.2 Sampling procedures and representativeness .................................................. 52

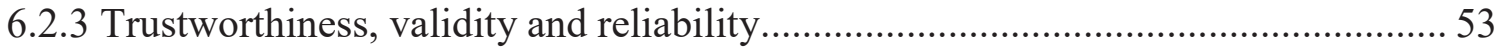

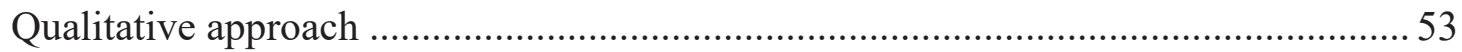

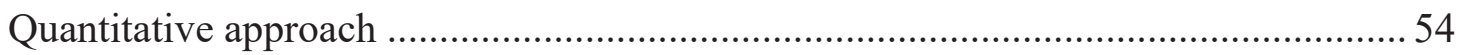

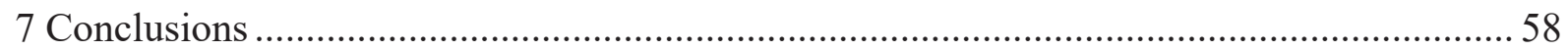

7.1 The significance of the study in today's health debate on advanced practice nursing... 58

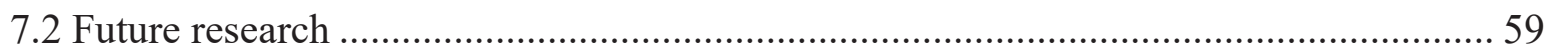

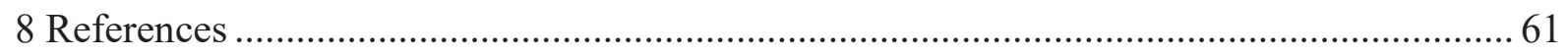

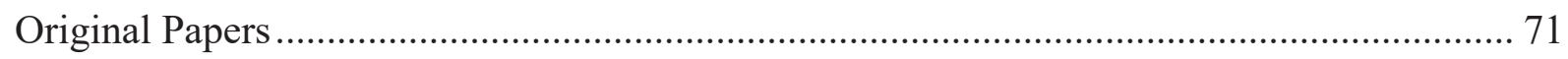

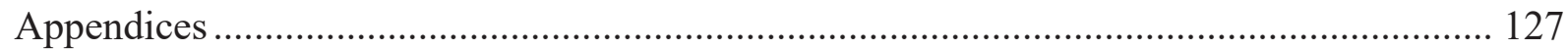




\section{Figures}

Figure 1 Flowchart of the exploratory sequential mixed methods design used in this study.. 22

Figure 2 Flowchart of factors that may affect the AGN's level of integration

\section{Tables}

Table 1 Overview of the three sub-studies that are the basis for this study

Table 2 Characteristics of the participants in the qualitative sub-study $(\mathrm{N}=21) \ldots \ldots \ldots \ldots \ldots . . . . .25$

Table 3 Examples of how the transcribed text was coded and grouped into subcategories .... 27

Table 4 The subcategories that constitute the main categories 27

Table 5 Characteristics of the respondents in the quantitative sub-study $(\mathrm{N}=218)$..... .29 


\section{Acknowledgements}

Working on this thesis has been an exciting process but also an extremely challenging one. I would like to express my gratitude to all who contributed; you have all been vital in bringing this project to its completion.

First, I am sincerely grateful to all the advanced geriatric nurses and their colleagues who participated in this study. It would not have been possible without your involvement.

I would like to thank my main supervisor, Professor Christina Foss, for generously sharing her research experience and knowledge with me, not only on the journey to my $\mathrm{PhD}$ but also throughout my Master of Nursing Science programme. Christina, thank you for your detailed comments on multiple drafts and for being available 24/7 - even during the holidays!

I would also like to thank my co-supervisor, Professor Marit Kirkevold, for hiring me as a $\mathrm{PhD}$ candidate at the Department of Nursing Science. It has been a privilege to immerse myself in advanced practice nursing. I also thank you for your helpful feedback on multiple drafts, fruitful discussions and for willingly sharing all your knowledge about advanced practice nursing with me.

I am grateful to my co-supervisor, Postdoc Konstantinos Antypas. Kostas, you noticed when I had my emotional ups and downs over the last few years and have been there for me when I needed emotional support or just a laugh! I also thank you for the stimulating conversations and feedback on multiple drafts.

I would also like to express my gratitude to Anne Schad Bersaker for statistical support and incredibly fun discussions. My supervision with you has been awesome - I have always walked out of our meetings with a smile on my face!

To my dearest Dagmara Bossy: on one of my first days at the department, you said, "Let's go talk to Marit. There's an extra desk in my office; from now on, it's our office!" Thereafter, you opened your home and heart to me and introduced me to two fabulous girls: Tove Guttulsrud Sjøberg and Lena Kristine Lien. Dagmara, it is not possible to thank you enough. Tove and Lena, you have supported both Dagmara and me through our doctoral work. You have believed in us and never complained about our endless chatting about our studies. Thank you! 
I also owe a debt of gratitude to 'De nye Akademikerne Annen Etage' and the rest of the staff at the Department of Nursing Science, where I have spent most of my time the last few years. We have had loads of stimulating conversations, and you have all been interested in my work, and for that, I am immensely grateful. Our kitchen talks have been extremely important to me. My heartfelt thanks go to all my family and friends for encouraging and supporting me throughout the entire $\mathrm{PhD}$ process. Thank you, Christoffer. I sincerely appreciate your support. Lastly, thank you, Mum, for always believing in me, supporting me, for never getting tired of endless chatting about my studies and for never letting me forget that Dad would have been proud of me! 


\section{Abstract}

Background: Older adults constitute an important population group receiving primary care services. Registered nurses (RNs) need comprehensive knowledge and skills to adequately address the complex needs of frail older adults. Despite the need for RNs with advanced qualifications, integrating the new advanced roles for RNs into interdisciplinary teams has proved to be challenging. Previous research on the integration of new advanced roles for RNs indicates that the degree to which they are integrated into their workplaces affects how they use their knowledge and skills. Integration is therefore seen as important in this study, which focuses on the introduction of advanced geriatric nurses (AGNs) into the Norwegian healthcare system.

Aims: The overall aim of this study was to investigate the role of AGNs, what AGNs and their collaborators see as an appropriate scope of practice for these nurses and how AGNs are being integrated into the Norwegian healthcare system. The aim was investigated through three sub-studies that: I) describe AGNs' experiences in their new role, II) investigate the level of agreement among AGNs, their colleagues and their leaders regarding which activities related to different functions are seen as appropriate for AGNs and III) investigate the degree to which AGNs are integrated into their workplaces.

Methods: The study employed an exploratory sequential mixed methods design. In 2016, each AGN in the total sample of AGNs in Norway $(\mathrm{N}=21)$ was interviewed about her/his role. In 2017, 23 AGNs and 195 of their colleagues (including leaders) answered a questionnaire focusing on the integration of AGNs and their scope of practice. The interview data were analysed by content analysis (Sub-study I). A series of cross-tabulations were conducted to identify the respondents' reporting of the appropriateness of different activities (Sub-study II). The survey data pertaining to the integration of the AGNs were analysed through cross-tabulations, Pearson's chi-squared test, Fisher's exact test and the KruskalWallis test (Sub-study III).

Results: The AGNs explained that they had developed a complex and extensive role and that they had developed a new 'gaze' based on a combination of their new knowledge and skills with their experience and interests. This new gaze provided them with the ability to see a wider range of medical, social and environmental problems in the older adults' situations compared to before they started the educational programme. The AGNs related that 
workplace conditions affected their opportunities to perform their role, and they explained that they had developed several strategies to overcome workplace conditions that negatively affected their performance in their new role (Sub-study I). The AGNs, their colleagues and their leaders perceived that all the activities described in the questionnaire related to coordination, teaching/supervision and research and development work and that almost half of the direct and one-third of the indirect care activities were appropriate for AGNs. The AGNs also perceived that just above two-thirds of the remaining direct and indirect care activities were appropriate for them, while in their colleagues' view, just under one-fourth of the remaining direct and indirect care activities were appropriate for AGNs. The leaders saw only one of the remaining direct care activities as appropriate for AGNs (Sub-study II). The majority of the AGNs experienced using their knowledge and skills to their full potential when providing direct care, but only a minority experienced doing so when providing indirect care, teaching/supervision and coordination. Around one-fourth of the colleagues participating in the study stated that the AGNs' scope of practice was completely clear and that they collaborated with the AGNs several times a week. Despite the undefined scope of practice and the scarce collaboration, the majority of the colleagues considered that the AGNs' role and scope of practice contributed highly positively to health services for older adults. Overall, the results indicate that the AGNs are not completely integrated into their workplaces (Sub-study III).

Conclusions: This study provides evidence that AGNs have a multifaceted role and a broad scope of practice, both of which are desired by AGNs, their colleagues and their leaders. The study also revealed a need for greater focus on how to integrate AGNs into the Norwegian healthcare system as AGNs experience that they do not use their knowledge and skills to their full potential and it seems that they are not always included in the daily practice of health services for older adults. In order for AGNs to be integrated, the results of this study indicate a need to address external and internal factors that may affect AGNs' level of integration and thus the use of their knowledge and skills. 


\section{Abstract in Norwegian}

Bakgrunn: Eldre utgjør en viktig befolkningsgruppe som mottar helsetjenester fra primærhelsetjenesten. Sykepleiere trenger omfattende kunnskap og ferdigheter for å imøtekomme de sammensatte behovene til skrøpelige eldre. Til tross for behovet for sykepleiere med avanserte kvalifikasjoner, har det vist seg å være utfordrende å integrere nye avanserte roller for sykepleiere inn i tverrfaglige team. Tidligere forskning knyttet til integrering av nye avanserte roller for sykepleiere indikerer at graden de er integrert på arbeidsplassen påvirker deres muligheter for å anvende sin kunnskap og ferdigheter. Integrering representerer derfor et viktig begrep i denne studien som fokuserer på introduksjonen av avanserte geriatriske sykepleiere (AGSer) i den norske helsetjenesten.

Hensikt: Den overordnede hensikten med denne studien var å undersøke rollen til AGSer, hva som blir sett på av AGSer og samarbeidspartnere som et passende ansvarsområde (scope of practice) for AGSer og hvordan AGSer er integrert i det norske helsevesenet. Hensikten har blitt undersøkt gjennom tre delstudier som: I) beskriver sykepleiernes erfaringer med sin nye rolle som AGSer, II) undersøker om AGSer, deres kolleger og ledere er enige om hvilke aktiviteter relatert til ulike funksjoner de oppfatter som hensiktsmessige for AGSer og III) undersøker hvilken grad AGSer er integrert i praksisfeltet.

Metode: Studien benyttet et sekvensielt utforskende mixed-metod design. I 2016 ble da samtlige AGSer $(\mathrm{N}=21)$ intervjuet om sin rolle. I 2017 svarte 23 AGSer og 195 av deres kolleger (inkludert ledere) på et spørreskjema med fokus på integrering av AGSer og ansvarsområdet til AGSer. Intervjudataene ble analysert ved bruk av innholdsanalyse (delstudie I). En serie med kryss-tabeller ble utført for å undersøke respondentenes svar angående hvilke aktiviteter er hensiktsmessige for AGSer (delstudie II). Spørreskjemadataene med fokus på integrering ble analysert ved bruk av kryss-tabeller, Pearsons kjikvadrattest/Fishers eksakt test og Kruskal-Wallis test (delstudie III).

Resultater: AGSene beskrev at de hadde utviklet en kompleks og omfattende rolle og at de hadde utviklet et nytt «blikk» basert på at de kombinerte sine nye kunnskaper og ferdigheter med sine erfaringer og interesser. Det nye blikket ga AGSene ferdigheter til å se et bredere spekter av medisinske, sosiale og miljømessige utfordringer i eldres situasjon sammenlignet med før de startet på utdanningen. AGSene fortalte at forhold på arbeidsplassen påvirket deres muligheter til å bruke den nye rollen. AGSene beskrev at de hadde utviklet flere strategier for 
å håndtere forhold på arbeidsplassen som negativt påvirket bruken av deres nye rolle (delstudie I). AGSene, deres kolleger og lederne mente at alle aktivitetene oppgitt i spørreskjemaet knyttet til koordinering, undervisning/veiledning og forsknings- og utviklingsarbeid, og nesten halvparten av de direkte og en tredjedel av de indirekte omsorgsaktivitetene var hensiktsmessige for AGSer. AGSene mente også at rett over to tredjedeler av de gjenværende direkte og indirekte omsorgsaktivitetene var hensiktsmessige for dem, mens kollegene så i underkant av en fjerdedel av de gjenværende direkte og indirekte omsorgsaktivitetene som hensiktsmessige for AGSer. Lederne så bare en av de gjenværende direkte omsorgsaktivitetene som hensiktsmessig for AGSer (delstudie II). Et flertall av AGSene erfarte at de brukte sine kunnskaper og ferdigheter fullt ut når de utførte direkte omsorg, mens et mindretall erfarte at de brukte sine kunnskaper og ferdigheter fullt ut når de utførte indirekte omsorg, undervisning/veiledning og koordinering. Rundt en fjerdedel av kollegene uttalte at AGSene sitt ansvarsområde var tydelig og at de samarbeidet med AGSene flere ganger i uken. Til tross for at ansvarsområdet ikke var klart og kjent for de fleste av kollegene, og at samarbeidet var begrenset, mente flertallet at AGSene i høy grad bidro til helsetjenesten. Totalt sett tyder resultatet på at AGSene ikke er fullstendig integrert på arbeidsplassene sine (delstudie III).

Konklusjon: Denne studien viser at AGSer har en mangefasettert rolle og et vidt ansvarsområde og at denne mangefasetterte rollen og ansvarsområdet er ønsket av AGSer, deres kolleger og deres ledere. Studien viser også at det er behov for å ha et større fokus på hvordan integrere AGSer i den norske helsetjenesten ettersom AGSer erfarer at de ikke bruker sine kunnskaper og ferdigheter fullt ut og det virker som om de ikke alltid er integrert $\mathrm{i}$ helsetjenesten for eldre. Resultatene fremhever behovet for å adressere eksterne og interne faktorer som kan påvirke integrering av AGSer og dermed også deres bruk av kunnskap og ferdigheter. 


\section{Abbreviations}

AGNs Advanced geriatric nurses

APNs Advanced practice nurses

NPs Nurse practitioners

OECD Organisation for Economic Co-operation and Development

RNs Registered nurses 


\section{List of publications}

I. Henni SH, Kirkevold M, Antypas K, Foss C. The role of advanced geriatric nurses in Norway: A descriptive exploratory study. Int J Older People Nurs. 2018;13(3):e12188.

II. Henni SH, Kirkevold M, Antypas K, Foss C. Perceptions of the scope of practice of nurse practitioners caring for older adults: Level of agreement among different healthcare providers. Scand J Caring Sci. 2020; Article accepted on 25 March, 2020.

III. Henni SH, Kirkevold M, Antypas K, Foss C. The integration of new nurse practitioners into care of older adults: A survey study. J Clin Nurs. 2019;28(1516):2911-23. 



\section{Introduction}

This $\mathrm{PhD}$ project is part of a larger research project called 'New steps in the municipal health and care staircase: Educating for new roles and innovative models for treatment and care of frail elders'. The Research Council of Norway, under the PraksisVEL programme, funded the research project. The project was started based on the introduction of a new advanced role for registered nurses (RNs) in Norway: advanced geriatric nurses (AGNs). A master's degree programme in advanced practice nursing to educate AGNs was introduced in Norway to meet needs that have evolved in the wake of a number of healthcare reforms, such as the hospital reform, the municipal home healthcare reform, the nursing home reform and the coordination reform, which promote patients living as long as possible in their own homes and receiving care within the most cost-effective level, which is primary care (1-4). These healthcare reforms and the fact that average hospital stays in Norway have been significantly reduced have resulted in increased pressure on primary-care healthcare providers to meet the needs of patients with advanced medical needs (5). The reforms have thus resulted in a need to increase the knowledge and skills of healthcare providers in primary care. The overall goal of the main project was to develop, describe and evaluate new primary-care service models for sick older adults and to develop and evaluate relevant advanced education for a new type of role for primary-care-based RNs. This $\mathrm{PhD}$ project focuses on the introduction of AGNs into the Norwegian healthcare system.

Advanced roles for RNs have been introduced into healthcare systems in many countries to work with different patient groups within different healthcare systems (6-8). Many factors can explain the international interest in the development of advanced practice nursing roles. The main factors described in the literature are changing demands for care, the need to promote a high quality of care, growing health costs, improvement of career prospects for RNs and a shortage of physicians $(9,10)$. Two survey studies examining international trends for the development of advanced practice nursing roles have found that the most widespread advanced role for RNs internationally is that of the nurse practitioner (NP) (7, 8). The role and scope of practice of the AGN are inspired by those of the NP. AGNs are specialised in the care of older adults, which is in line with the international and Norwegian literature that emphasises the need for RNs with advanced knowledge related to the care of older adults (1, 9, 11-17). 
Globally, the NP role varies based on the patient group they are educated to care for, the depth and scope of the knowledge taught at the various educational institutions, the length of the various education programmes and the special needs that exist in each country (6). Despite these variations, the purpose of NP education programmes is to qualify RNs for an expanded scope of practice and a wider field of responsibility. All NPs are expected to have expertise above the level of a bachelor's in nursing and to focus on direct clinical practice, guidance and coaching of patients and relatives, consultation, evidence-based practice, leadership, collaboration and ethical decision-making (18). NPs are further expected to focus not only on the patient's symptoms and diseases but also on the complex and unique situation that is characteristic of each patient for whom they provide care $(19,20)$. NPs are also expected to have the expertise to perform advanced health assessments and to possess clinical management skills, including pharmacological management $(18,21,22)$.

International research has shown that the introduction of a new NP role into workplaces that already have established healthcare positions and defined roles, scopes of practice and work patterns is not straightforward, and several factors influence how successfully the role is integrated $(13,23-31)$. A clearly defined role and scope of practice of a new NP at the workplace is described as an important factor in the literature, while a lack of clarity around the role and scope of practice is found to hinder integration $(23,29,31)$. Research indicates that the extent to which NPs are integrated into their workplaces may affect their opportunities to practice to their full potential $(13,23,31-33)$. The development of an NP role and scope of practice that leads to the best possible care and outcomes for the patients is described in the literature as a challenging process (32). Some of the first NPs in the United States, who helped define the NP role in the years 1965-1979, reported that they had to take the NP role from a somewhat ambiguous entity and develop its form and substance (34). The NPs stated that it was difficult to be pioneers in the new role and that they met resistance and scepticism from both RNs and physicians about whether they were capable of performing activities that RNs usually do not perform. The first RNs in Finland (35) and Sweden (36) to take on an advanced nursing role also reported that it was challenging to be pioneers in the new and demanding role as they started with a lack of role models and a clear job description. The Finnish RNs also reported that it took a long time to establish a position and that they experienced loneliness and social isolation in the role-development process 
Despite the fact that the NP role is established in several countries, a literature review (32) found that it is challenging to introduce new NP roles in different settings. Different countries have different healthcare systems and cultures, which may affect the introduction of the role. For example, it is likely that the way the Norwegian healthcare system is organised will influence the introduction of the AGN role in Norway. This study therefore focuses on the introduction of the first AGNs in Norway by investigating the AGNs' role, what is seen by AGNs and collaborators as an appropriate scope of practice for AGNs and how the AGNs' are being integrated into the Norwegian healthcare system. Overall, the current study contributes potentially valuable knowledge for the further development of advanced practice nursing in Norway and other countries that are developing new NP roles.

\subsection{Outline of the thesis}

The Norwegian healthcare system and advanced practice nursing are part of the practice context framing this study. In the background chapter, it is therefore necessary to provide a depiction of not only the Norwegian healthcare system with a focus on primary care but also the role and scope of practice of NPs that form the basis for the development of the Norwegian AGN educational programme. The thesis continues with a description of advanced practice nursing in Norway and subsequently presents my understanding of the concept of integration. Then, the current study is situated in the research field to illustrate its contribution to previous research, and the overall aim, specific aims and research questions of Sub-studies I, II and III are introduced. The methods applied to achieve the aims and answer the research questions of the three sub-studies are then presented. The results of the sub-studies are published in three different papers and are also presented separately in this thesis as each substudy has a different focus, but the results are presented together in the discussion chapter as the findings of each sub-study can contribute to a broader understanding of the subjects discussed there. As AGNs have been newly introduced into the Norwegian healthcare system, the discussion chapter begins with a description of the AGNs' role and scope of practice and a discussion of whether they share similar characteristics with the role and scope of practice of NPs as described by the research field internationally. There follow a presentation and discussion of factors found in this study that may facilitate or hinder the integration of AGNs into the Norwegian healthcare system as the integration of new NP roles into interdisciplinary teams has proved to be challenging. The establishment of advanced roles for RNs is of current interest in Norway, so further discussion is presented regarding how this study can be of value to the further development of advanced practice nursing in Norway. The discussion chapter 
ends with a clarification of the methodological strengths and weaknesses of this study, and the thesis concludes with its implications. 


\section{Background}

\subsection{The Norwegian healthcare system with a focus on primary care}

In recent decades, a series of reforms have been introduced in European countries aimed at strengthening primary care. According to Kringos et al. (12), these European reforms have been driven by certain challenges, such as changing demands due to the rising trend to discharge patients from hospitals at an early stage of the rehabilitation process and an increased focus on cost control. In addition, it is well known that the proportion of the elderly will increase in the coming years and that many older adults have chronic diseases that are often associated with a need for complex healthcare. These challenges have resulted in the need for RNs with advanced knowledge and skills in primary care who are prepared to perform new tasks and complex patient care (12). White papers from European countries endorse the need for RNs who have advanced knowledge and skills to meet the complex care needs of older adults, especially those who have multiple chronic diseases, as the responsibility for patients with chronic diseases has increased in primary care contexts (11, 12). New master's degree programmes in advanced practice nursing have therefore been introduced in several European countries to increase the knowledge and skills of RNs $(9,37$, $38)$.

Norway has followed the European policy trend of introducing health reforms to strengthen primary care. One of the first health reforms to do so was the hospital reform enacted in Norway in 1975 (4). The reform emphasised that healthcare services should be provided at the lowest effective level of care, that is, at the level closest to the patient that can provide adequate healthcare service. A municipal home healthcare reform was introduced in 1984, followed by a nursing home reform in 1988 (1). These reforms also emphasised that healthcare services should be decentralised to the municipalities, which represent the lowest effective level of care. As a consequence of the reforms, the Norwegian healthcare system is now organised on three levels - national, regional and local (39). At the national level, the government is in charge of the determination of health policy, legislation and funds. At the regional level, hospital care is organised by four hospital regions. However, some hospitals, such as Rikshospitalet University Hospital, perform specialised tasks and therefore have a nationwide responsibility in addition to a regional responsibility. At the local level, primary care is organised within the municipalities. The municipalities are responsible for providing 
health promotion and preventive care, curative care and long- and short-term care in nursing homes and in the inhabitants' homes. Inhabitants are provided with health and care services based on individual assessments of their needs. As a consequence of the current organisation of the healthcare system based on the health reforms, the municipalities have become responsible for a significantly higher number of patients with more extensive needs for services than before the health reforms were introduced. One of the most recent reforms in Norway that have affected the municipalities' responsibility is the coordination reform (3). The aim of this reform is to have the municipalities ensure a holistic care pathway that includes prevention, early intervention, early diagnosis, treatment and follow-up so that comprehensive patient care can be provided to the greatest possible extent within the most effective care level. This requires increasing the knowledge and skills among RNs working in primary care.

There have been public discussions in Norway about whether RNs have sufficient knowledge and skills to handle the increased pressure on the primary care sector and whether there is a need to strengthen the basic education of RNs. International and national research studies have found that primary care RNs caring for older adults often need more knowledge $(14,15)$, which indicates that there is a need to strengthen the nursing workforce in primary care. In 2006, the Norwegian government introduced what is called 'Kompetanseløftet 2015' (Competence increase 2015) (2). Kompetanseløftet 2015 was a strategic plan to increase the knowledge and skills of primary care RNs in 2015. One of the strategies therein was to offer postgraduate education for RNs in the care of older adults, dementia disorders, supervision and rehabilitation. In response to the health policy strategies, the University of Oslo started a master's degree programme in advanced practice nursing to educate AGNs. 'Live Your Whole Life', which is one of the latest health reforms in Norway, suggests that RNs who have graduated from master's degree programmes in advanced practice nursing are needed to fill new roles in health and care services and contribute to the closer follow-up of older adults with complex needs (16).

\subsubsection{Care of older adults in primary care}

The largest population group receiving primary care is older adults. In $2018,60 \%$ of those receiving primary care in Norway were over 67 years of age and of these, $40 \%$ were over 80 (40). Geriatric syndromes and multimorbidity combined with polypharmacy and often a limited social network make the care of older adults complex (41-43). Older adults may also 
have syndromes that cross organ systems and discipline-based boundaries, making care for them a knowledge-intensive field (44).

On a typical work shift in primary care services in Norway, a minority of the care providers are RNs, while the majority are auxiliary nurses and assistants. RNs are prepared at the bachelor's level, while auxiliary nurses are prepared at upper secondary school with two years at school and two years of practice placements in healthcare services. The assistants usually have little or no formal training in healthcare. Usually, employers provide the assistants with a few days of training before they provide services on their own to older adults. RNs in charge of the work shifts have to assess which of the older adults are in need of care that can only be provided by an $\mathrm{RN}$ and which are in need of care that can be provided by an auxiliary nurse or an assistant. RNs must also have sufficient skills to assess when older adults are in need of assessment and/or medical treatment by a physician. In addition, RNs participate in determining the older adults' care level, the type of services they should receive and the coordination of those services (45).

A Norwegian Delphi study suggests that care providers (RNs, auxiliary nurses and assistants) caring for older adults are in need of knowledge and skills related to the following areas: basic needs, health assessment, treatment of conditions, promotion and disease prevention, palliative care, communication, documentation, collaboration and relevant ethics and regulation (46). In addition, the Delphi study found that care providers should demonstrate responsibility, take action and have positive attitudes towards older adults. The researchers that conducted the Delphi study developed a questionnaire based on the results to measure the competencies among care providers in primary care (47). The survey showed that the care providers were sufficiently competent in all the areas identified as important but that the level of competence was insufficient in several other areas (15). The survey indicates that there is a need to improve the quality of the health and care services offered to frail older adults. It is likely that AGNs may contribute to improving the quality of the health and care services offered to frail elderly patients, as the master's degree programme that educates AGNs is designed to meet the increased need for advanced care of such patients (48). 


\subsection{Advanced practice nursing}

Advanced practice nursing is an umbrella term often used to describe RNs practicing at a higher level than they traditionally do $(6,49)$. The term was introduced in the United States in the 1980s (50). The term advanced practice nurse (APN) refers to

a registered nurse who has acquired the expert knowledge base, complex decisionmaking skills and clinical competencies for expanded practice, the characteristics of which are shaped by the context and/or country in which s/he is credentialed to practice. A master's degree is recommended for entry level (21, para. 2).

In recent years, there has been a global trend to educate APNs. It is estimated that approximately 70 countries either have APN roles or are considering introducing these roles (51). The literature describes four established APN roles and their respective competencies (52-55):

- Certified nurse-midwives: perform health promotion, disease prevention and individualised wellness education to women from adolescence beyond menopause. More specifically, they provide gynaecologic and family-planning services, preconception care, care during pregnancy, childbirth and the postpartum period, care of normal newborns and treatment of women and their partners for sexually transmitted infections.

- Certified registered nurse anaesthetists: make independent judgements concerning comprehensive anaesthesia and pain care across the life span in outpatient, inpatient and office-based settings.

- Clinical nurse specialists: provide leadership and evidence-based nursing practice in a speciality area of nursing. More specifically, they work as coordinators and case managers, educators and supervisors to RNs and other healthcare providers and facilitators of change and innovation in healthcare systems mostly in hospitals but also in primary care.

- Nurse practitioners: perform comprehensive assessments, promote health and treat and prevent illness and injury in primary and hospital care.

As described in the introductory chapter, the Norwegian AGN role is inspired by the NP role. Therefore, a description of the knowledge base regarding the role and scope of practice of 
NPs is provided below as it is essential to understand the foundation of the development of the AGN education programme and AGNs' role and scope of practice in Norway.

\subsubsection{Nurse practitioners}

The NP role was first modelled informally by Frontier Nursing Service in the 1930s in the United States and implemented in that country in the mid-1960s in outpatient paediatric clinics (50) and in Canada in rural and inner-city areas (56). A shortage of primary care physicians is the argument given for introducing NPs in both the United States and Canada $(50,56)$. The NP role came to Europe in the early 1970s, where it first appeared in the United Kingdom (9), but according to Pearson and Peels (57), it was not until the 1990s that the role started to be promoted in the United Kingdom as a response to cost issues, the need to improve access to health services and the inadequate availability of physicians. The NP role, which has now been introduced in several European countries, such as Ireland, the Netherlands, Finland and Sweden, is still in its infancy in most countries $(9,54,58)$. In addition, the NP role has been introduced in Australia, New Zealand (6), Africa (59) and Asian countries (60-62). Its introduction in most European, Oceanian, African and Asian countries came as a response to the need to improve access to health services, the inadequate availability of physicians and the need to maintain health among specific groups $(6,9,54)$.

\section{The role transition process from registered nurse to nurse practitioner}

According to the literature, newly graduated NPs usually go through a role transition from RN to NP in the first year of practice (63-66). In 1997, based on interviews with new NP graduates, Brown and Olshansky (63) developed a theoretical model for NP role transition in primary care. These researchers describe the transition as a four-stage process in which NPs first go through a period of confusion when required to transfer to a new role as an NP (63, 64). Thereafter, they enter a period during which they start practicing, but they are still insecure and have pervasive performance anxiety. The third transition stage is when the anxiety starts to decrease, and the NPs develop increased confidence and competence. In the last stage, the NPs develop a feeling of enhanced self-esteem related to competence, and they have realistic and positive feelings about their future as an NP.

In 2015, two studies $(65,66)$ each carried out a conceptual analysis of NP role transition. Both conceptual analyses describe the attributes of the NP role transition similarly: the researchers explain that NP role transition is characterised by a change of the NPs' self and professional role. The change is described as a complex and individual process during which 
the NPs must let go of their old self and role as a professional RN and adapt to the workplace to take on the role of an NP. During this process, the NPs may experience a sense of loss of role due to straddling two roles. These conceptual analyses are consistent with Brown and Olshansky's $(63,64)$ theoretical model of the role-transition process and highlight the complexity of letting go of one's role as an RN and taking on the new role of NP.

Recently, researchers in the field have focused on barriers to and facilitators of NP role transition. Factors such as role ambiguity, lack of support and respect and workload have been identified as barriers to this transition (67-69). In addition, there can be power struggles between RNs and newly graduated NPs as well as between senior NPs and newly graduated NPs, which may also negatively affect the role transition (70). The research literature identified that among the facilitators of NP role transition were factors such as mentorship, social support (67-69), work-life balance and finding meaning in one's work (68). In addition, there may be specific local contextual factors that also impact on role transition, requiring researchers to explore the introduction of new roles, such as the AGN, in new contexts.

\section{Role and scope of practice of nurse practitioners working in primary care}

According to Hardy and Conway (71), healthcare professionals' roles are more or less fixed positions regarding which society has certain expectations and requirements. However, the authors point out that healthcare professionals' roles can change in line with any social development that sets new expectations and requirements. The literature asserts that the focus of all NP roles, regardless of the patient group they care for, is on direct care, which includes any aspects of nursing care for and in the presence of a particular patient $(18,21)$. The literature further explains that NPs are educated to perform advanced health assessments and that they have acquired diagnostic and clinical management skills. Carryer et al. (72) examined the 'core role' of NPs in Australia and New Zealand and found that this core role consists of three components: dynamic practice, professional efficacy and clinical leadership. The researchers explain that NP practice is dynamic because NPs adapt their practice to the specific context, that NPs demonstrate professional efficacy because they have an extended scope of practice and that they demonstrate clinical leadership through advocating for patients and the field of nursing. Two literature reviews (73-75) and several qualitative, quantitative and mixed methods studies from countries that have regulated the NP role $(28,76-83)$, and countries that have not $(20,58,84)$, have described the NP role and scope of practice. The 
studies vary in sample size and have included NPs, their colleagues, patients and family members as participants. The studies explain that the NP role can entail the provision of services related to preventive care $(28,78)$, primary/chronic care $(28,73,74,78,79,84)$, acute care $(28,73,84)$, palliative care $(79)$, support to patients and family members $(79,80)$ and the education of patients, families and staff $(73,79)$. The NP role is described in the literature $(20,28,78)$ as a holistic and health-promoting role in the sense that NPs engage with patients as partners in the management of their health. Common to all the studies (28, $72-74,78-80,84)$ that describe the NP role is the fact that the role is depicted as a multifaceted, complex role that is adapted to the practice setting of the NP. For example, Kaasalainen et al. (79) pointed out that NPs who provide palliative care also manage comorbidities and medications, control pain, support families and pronounce death. According to the literature $(85,86)$, most NPs caring for older adults work in primary care, either in an independent practice or in collaboration with physicians. Dick and Frazier (87) report that NPs caring for older adults assess the whole person, which, in addition to health assessments, includes considering safety, home management, social support, finances and psychosocial issues.

The scope of practice of NPs refers to the activities that an NP is educated to conduct and legislatively permitted to perform (88). In recent years, a scoping review (75) was published exploring the scope of practice of NPs working in primary care settings. All the studies in the scoping review described NPs as providing care to patients who are seen as vulnerable. Nevertheless, the researchers found that the scope of practice of NPs in the included studies varied from being targeted towards a specific diagnosis (COPD, stroke, diabetes etc.) to the management of patients' health and well-being needs regardless of diagnosis. For example, older adults can be seen as a vulnerable group, and research has found that NPs caring for older adults focus on maintaining their health through health-promoting treatments, chronic disease management and the diagnosis and treatment of minor acute illnesses $(85,89)$. Variation in NPs' scope of practice may be explained by the fact that the literature (7-9) stipulates that NPs' scope of practice varies from setting to setting because there is a variation in education, regulation, licensing and credential requirements both within and between countries. In many countries, NPs have a scope of practice that traditionally belongs to the medical field, performing activities that are usually in the physicians' domain $(7,13,90)$. Examples of such activities are diagnosis, treatment, prescription of medications, referring patients to other healthcare providers and admitting patients to hospitals (21). The fact that 
NPs in some countries have been given authorisation to prescribe medications has resulted in great interest in the research field to investigate NPs' prescribing practices (91-99). Four studies $(93,95,96)$ focused on NPs' prescribing practices to older adults. One of these studies (96) found that NPs' prescribing patterns are not influenced by their educational preparation, work experience or work setting characteristics. Another of the studies (95) found that prescribing NPs routinely evaluate the necessity of medications and whether there are other non-medication alternatives, and if they choose to prescribe medications, they prescribe a low dosage and increase the dosage slowly. Furthermore, in New Zealand, NPs prescribe lower rates of potentially inappropriate medicines to older adults than other prescribers (93). The remaining study (91) examined the trends of NP prescribing to older adults in Ontario, Canada, during the 2000-2010 period and found that the number and proportion of NPs actively prescribing to older adults increased during the study period. In Sweden, where NPs do not have the authority to prescribe medications, NPs and their colleagues, including physicians, have stated that they want NPs to have the right to prescribe them $(58,100)$. Recently, in Norway, it has been debated in public discussions whether AGNs and other NPs should be candidates for the authority to prescribe medications. Physicians participating in the debate are divided about giving prescription authority to NPs. At present, whether the NPs in Norway will be granted the authority to prescribe medications remains undecided.

According to Hamric (18) and Thomas et al. (22), NPs should possess the competencies to perform activities related to direct clinical practice, guidance and coaching of patients and relatives, consultation, evidence-based practice, leadership, collaboration and ethical decisionmaking. During the literature search of the current study, several studies were identified (9, $21,38,58,80,86,87,101-104)$ that mentioned in the results section various activities that NPs perform. For example, NPs caring for the elderly perform activities such as coordination of older adults' health-related services (87), facilitation of participation in decision-making processes (80) and provision of informal and formal teaching to colleagues (104). Two mixed methods studies $(81,83)$ and two quantitative studies $(76,82)$ have also examined the activities performed by NPs working in primary care. Three of these studies $(76,81,83)$ focused on NPs caring for older adults, while the remaining study (82) included NPs caring for different patient groups including older adults. The four studies report that NPs perform several activities, such as educating healthcare providers about treatment plans and plans of care $(76,81)$, physical assessments, prescription of medication, research and auditing (82), ordering and/or reviewing tests and medications as well as referrals to and/or coordinating 
care with other healthcare providers (83). All four studies grouped different related activities into named functions, such as direct care, indirect care and supervision/teaching. In this study, we understand function as a group of related activities that constitute a larger activity; for example, the different types of activities that an NP performs to coordinate the care provided to older adults constitute a larger function known as coordination. The various functions of NPs can be understood as an operationalisation of their scope of practice. As pointed out by Gardner et al. (82), there seems to be no standard definition of the activities the different researchers have included in their studies and grouped into named functions.

To summarise, the previous research in this field gives the impression that NPs' role and scope of practice vary and that it is difficult to draw conclusions across different contexts. Furthermore, the NP role is seen as multifaceted and the scope of practice as broad with several different functions. The literature review in this section gives the impression that NPs can have different responsibilities and perform different activities depending on each NP's practice setting. A thorough description of the role and scope of the practice of NPs and the practice setting is therefore necessary to fully understand the appropriate role and scope of practice in different practice settings. There is therefore a need for research to explore the NP role and scope of practice in different countries, including in Norway, which neither has a formal description of the role nor a clearly delineated scope of practice.

\section{Nurse practitioners' contribution to healthcare}

When new healthcare roles are introduced into a country's healthcare service, it is important to examine their contribution to healthcare. In this light, several reviews $(73,104-108)$ have focused on NPs' contribution to healthcare. The studies included in the reviews varied in sample size, design, methods and the outcome examined. Most of the studies examined outcomes regarding the management of chronic conditions, patients' functional status, hospitalisation and emergency department visits, time spent with patients, the satisfaction of patients, family and staff, patients' mortality rates and cost savings. The reviews found that compared to physicians, NPs provide better or equivalent management of chronic conditions $(73,104-106)$. The reviews also found that NPs improved patients' functional status, reduced hospitalisations and emergency department use (73, 104-106), increased time spent with patients that resulted in better documentation and care for each patient $(73,105,108)$ and improved family $(73,104-107)$, patient $(73,104-106,108)$ and staff satisfaction $(73,104$ 106). In addition, the mortality rate of patients seeing NPs was found to be equivalent to those 
seeing physicians $(73,105,106)$. Four reviews $(73,104,105,107)$ that examined cost savings reached different conclusions on whether NPs are associated with these savings. Three of the reviews $(73,105,107)$ suggest that NPs are associated with reduced costs, while one $(104)$ was unable to reach a conclusion about NPs' impact on cost-effectiveness as the studies included in the review varied in terms of cost savings. The reviews that concluded that NPs were associated with reduced costs $(73,105,107)$ based their conclusions on nine different studies. The reviews do not account for the designs of the studies they included, how costs were measured nor whether the risk of bias in the included studies was assessed. The one review that was unable to reach a conclusion about NPs' impact on cost-effectiveness (104) included 24 studies with randomised controlled or quasi-experimental designs, but the review does not report whether the risk of bias in the included studies was assessed. Cost was most commonly reported in the included studies as an indirect measure of service utilisation, patients' length of stay in hospital and/or resource utilisation. As Chavez et al. (104) suggest, there is a need for more well-designed and rigorous studies in relation to costs in order to determine NPs' impact on cost-effectiveness.

Three single studies in the Netherlands $(109)$ and Sweden $(110,111)$ have recently appeared that examine NPs' contribution to healthcare in countries where the NP role has been newly introduced. The Dutch study (109) examined how substituting one NP for one physician in a team where five physicians usually work together in an out-of-hours primary care setting impacted the number of patients treated and the physicians' caseload. The study found that NPs roughly managed the same types of patients and provided the same care as physicians. Overall, the substitution of a physician with an NP in the team did not lead to a meaningful increase in the other physicians' caseloads. The study therefore concludes that administrators in areas with a lack of physicians can consider employing an NP to offer timely care to patients with acute problems. One of the Swedish studies (110) focused on patients' experiences of the healthcare provided by NPs and found that patients trusted the NP and that their needs were satisfied, specifically because the NPs had a holistic focus. The other Swedish study (111) focused on leaders', physicians' and RNs' expectations of NPs as a way to meet the increasing needs of older adults. The study found that the participants thought NPs could be a resource as they could help provide healthcare more effectively. The participants believed NPs could satisfy older adults' needs and cover some patients for physicians, with the result that the physicians could have more time to see other patients. The idea of NPs acting, in some cases, as substitutes for physicians is in line with the focus in the research 
field of equating care provided by NPs and physicians. The continued interest in examining NPs' contribution, even though several reviews on the topic have been published, highlights the importance of understanding the effect of introducing a new role into a country's healthcare service.

\subsubsection{Advanced practice nursing in Norway}

The master's degree programme that prepares AGNs at the University of Oslo was founded in 2011 and was the first master's degree programme in advanced practice nursing in Norway. It is a part-time programme with 120 European Credit Transfer and Accumulation System credits. The first AGNs graduated in 2014. The programme focuses on care to older adults, builds on international research and experience and encompasses nursing theories, medical subjects and clinical knowledge. The students have a 450-hour practicum with preceptors during their education. Since the first AGNs graduated, the government has supported the establishment of master's degree programmes in advanced practice nursing based on the NP role $(1,112)$, and, in 2015, a wage subsidy was established for RNs who pursued a master's degree in advanced practice nursing (113).

Based on the literature review in this section, it makes sense to assume that the AGNs' role and scope of practice should be more advanced compared to other RNs caring for older adults. However, AGNs do not have an accreditation as AGNs, and there is no difference in national regulations between the scope of practice of AGNs and other RNs caring for older adults. Healthcare providers' duties in Norway are regulated by law (114). The law does not specify healthcare providers' scope of practice, but it requires that they act in accordance with professional standards and provide care based on their professional qualifications.

Nevertheless, some activities, such as the referral of patients in the healthcare system and the prescription of medicines, medical equipment and oral nutrition supplements, are regulated by law. Apart from prescriptions of contraception for women over 16 years of age, which midwives and public health nurses are authorised to prescribe, no other RNs have the authority to prescribe medicines, medical equipment or nutrients or refer patients within the healthcare system in Norway.

Until recently, there were no regulations in Norway regarding what should be included in the curriculum of advanced practice nursing programmes. Since the University of Oslo started the first master's degree programme in advanced practice nursing, five other master's degree programmes in advanced practice nursing have been established in Norway (the University of 
South-Eastern Norway, Lovisenberg Diaconal University College, NTNU Ålesund, Inland Norway University of Applied Sciences and Østfold University College). As with the master's degree programme in advanced practice nursing that prepares AGNs, the other master's degree programmes in advanced practice nursing in Norway are inspired by the NP role and focus on several areas, including acute care, emergency care, family care, primary care and chronic diseases. In 2017, the Ministry of Health and Care Services suggested that advanced practice nursing education should be regulated. The Norwegian Directorate of Health, under the direction of the Ministry of Health and Care Services, has developed a programme description for a master's degree programme focusing on family care (care for patients across their lifespan) in close collaboration with the Ministry of Education and research (115). According to the The Norwegian Directorate of Health (115), this master's degree programme is based on international NP programmes, but they do not specify which NP programmes provided the basis for this programme description. The Ministry of Education and research sent the programme description for a public hearing in the spring of 2019 and was put into effect on 01.02.2020 (116). The Norwegian Directorate of Health also recommended that graduates from the master's degree programme be accredited as NPs. A regulation for authorisation, developed by the Ministry of Health and Care services, was sent for a public hearing in early autumn of 2019 and was put into effect on 01.02 .2020 (117). Because of the new regulation $(116,117)$, the master's degree programme in advanced practice nursing at the University of Oslo, which prepares AGNs, admitted its last student in the autumn of 2019. The educational programme at the University of Oslo is planning changes in line with the new programme description for a programme focusing on family care. It is uncertain whether the new master's degree programme in family care will meet the need for NPs specialised in the care of older adults or if there is still a need for AGNs. The issue will be discussed in Chapter 6 in light of the results of the three sub-studies.

\subsection{Integration}

International research has shown that the introduction of a new NP role into workplaces is a challenging process and that several factors influence how successfully the new role is integrated (13, 23-31). Blau (118) has developed an empirically based theory of the integration of individuals into a group that is much cited within the social sciences. According to Blau $(118$, p. 546), a person is 'considered to be integrated in a group if the other members find him sufficiently attractive to associate with him freely and accept him in their midst as one of them'. Yet, according to Blau (118), integration is a complex process; he theorised that 
a person who wants to be accepted (integrated) into a group must first prove that $\mathrm{s} / \mathrm{he}$ can provide valued services and then that $\mathrm{s} / \mathrm{he}$ is approachable. To test the theory, Blau (118) conducted an empirical study that showed that individuals who are seen as attractive associates and are approachable have the best chance of winning acceptance in a group. As highlighted by Blau (118), while the empirical data do not prove the theory, they support the inferences based on it.

The concept of integration is seldom defined in the research literature about NP integration, and most of the identified research neither defines nor states what is meant by the term (13, $23,24,31,32,119-122)$. Only two studies $(123,124)$ were identified that state what they mean by integration in this literature. According to one of them (123), full integration of an NP into a healthcare system occurs when the NP role is used to its full potential across the entire healthcare system. The definition does not include any requisite that the colleagues of the NP must accept the NP as one of them, which Blau (118) highlights in his integration theory. However, it is likely that in order for NPs to practice to their full potential across the entire healthcare system, they have to collaborate with their colleagues and be recognised as members of their healthcare team by them. The other study that stated what was meant by integration (124) reported that NPs are integrated into the workplace when they have the autonomy to fully enact their scope of practice, their roles are recognised, they are included as a vital team member, have an established role contribution and have developed role alliances. The description includes both acceptance by colleagues, which is highlighted by Blau (118) as important for integration, and the use of the NP role across the entire healthcare system, which is highlighted by DiCenso et al. (123) as important for integration. Based on Burgess et al. (124), DiCenso et al. (123) and Blau (118), I have developed the following understanding of integration: an AGN is integrated into the workplace when s/he experiences using her/his knowledge and skills to their full potential at the workplace and when $\mathrm{s} / \mathrm{he}$ is accepted by colleagues and thereby included in their daily practice of health services for older adults.

The research indicates that the level to which NPs are integrated into their workplaces may affect their opportunities to practice to their full potential $(13,23,31-33)$, which is consistent with DiCenso et al.'s (123) understanding of integration. A thorough review of the literature identified no studies that have specifically examined how integration affects NPs' practice opportunities. However, one study (125) examined the differences in organisational structures and outcomes between NPs with less than three years of experience and more than three years 
of experience in their current job in primary care. The study found that the two groups of NPs are used differently by their employers as the NPs with more than three years of experience are more likely to be assigned their own patient load than those with less than three years. In addition, the study showed that a significantly higher percentage of NPs with less than three years of experience explained that their role is not understood by their colleagues and the patients they care for. As pointed out by the researchers themselves, the results indicate that the group of NPs with less than three years of experience is less integrated than the other group as they face more challenges within their employment settings than the more experienced NPs. Consistent with previous literature $(26,31,122)$, the results of the study indicate that time is an important factor in the integration process. Time has also been found to be an important factor in changing one's role from RN to NP as it is time-consuming to go through a role transition $(65,66)$. A possible explanation for why the group with less than three years of experience faced more challenges within their employment settings than the more experienced NPs might be that three years of practice is not sufficient time to go through a role transition and become fully integrated at the workplace.

Contandriopoulos et al. (31) performed an analysis based, on the one hand, on a realist review of the literature related to barriers and facilitators that affect the integration of NPs and, on the other hand, qualitative case studies in six primary care teams in rural and urban areas of Quebec, Canada. The researchers identified several barriers and facilitators and structured them into a framework of five factors to guide NP integration into primary care teams. I) The first factor is the planning process and the work done to introduce the new NP into the team. II) The second factor is team consensus on the role and scope of practice, which can be achieved by the involvement of staff members in the planning process for an NP's arrival. III) The third factor is the collaborative culture at the workplace, as collaboration can lead to practice wherein the workers recognise each other's roles and contributions. IV) A fourth identified factor is leaders' and staff members' acceptance and support of the new role. V) The fifth and final factor is the organisational structure in the workplace, as this may influence the NP's opportunities to practice all the dimensions of the role. The researchers explain that the factors can take effect as facilitators for integration when addressed appropriately and barriers when not addressed appropriately. Contandriopoulos et al. (31) suggest that the framework can be used as practical advice about which factors need to be addressed appropriately in order to integrate NPs into primary care teams. Other studies (13, 23-30) that have examined barriers and facilitators to the integration of NPs also seem to 
support the framework as they identified that barriers to and facilitators of the integration of NPs are related to the same areas as indicated by Contandriopoulos et al. (31).

To summarise, countries that are working to integrate NP roles into their healthcare services can learn from international research the factors to be aware of in the integration process and how to achieve a successful integration of the new NP role. Nevertheless, the framework of Contandriopoulos et al. (31) was developed based on case studies and literature from countries where the NP role is an established part of the national healthcare service. Therefore, there may be other factors that may also have an effect on NP integration in countries where the NP role has been recently introduced, requiring research to explore NP integration in countries such as Norway, where the NP role is a new role in the healthcare system.

\subsection{Placement of the PhD project in the research field}

The majority of the research presented in this chapter describes the NPs' role and scope of practice in countries that have regulations for NPs. The majority of the research presented also focuses on NPs caring for all types of patients that receive primary care. This study focuses on the role and scope of practice of NPs caring for older adults in Norway, a setting without existing NP regulations.

As shown, integration is a frequently used concept in the research literature on NPs $(13,23$, $24,31,32,119-122)$, although the concept is seldom defined or operationalised. The lack of a definition of integration has resulted in the research literature neither addressing how the concept of integration is understood nor what characterises NPs who are and are not integrated into the workplace. This study uses the theory of integration as well as the research literature on the integration of NPs to define and operationalise integration. The concept of integration guides the development of this study's aim, research questions and data collection tools.

The knowledge about the role and scope of practice of AGNs and how they are integrated into the Norwegian healthcare system generated by this study could be useful for Norwegian politicians and healthcare leaders in facilitating the integration of this new role in Norway. It may also be useful for other European countries without regulations for the NP role and scope of practice that are in a similar developmental stage of establishing new NP roles. 


\section{Aim}

The overall aim of this study was to investigate the role of AGNs, what AGNs and their collaborators see as an appropriate scope of practice for these nurses and how AGNs are being integrated into the Norwegian healthcare system. This is achieved through three sub-studies, which are reported in three papers, by I) qualitatively describing the AGNs' experiences in their new role, II) quantitatively investigating the level of agreement among AGNs, their colleagues and their leaders regarding which activities related to different functions are seen as appropriate for AGNs and III) quantitatively investigating the level to which the AGNs are integrated into their workplaces. An overview of the three sub-studies is presented in Table 1. 


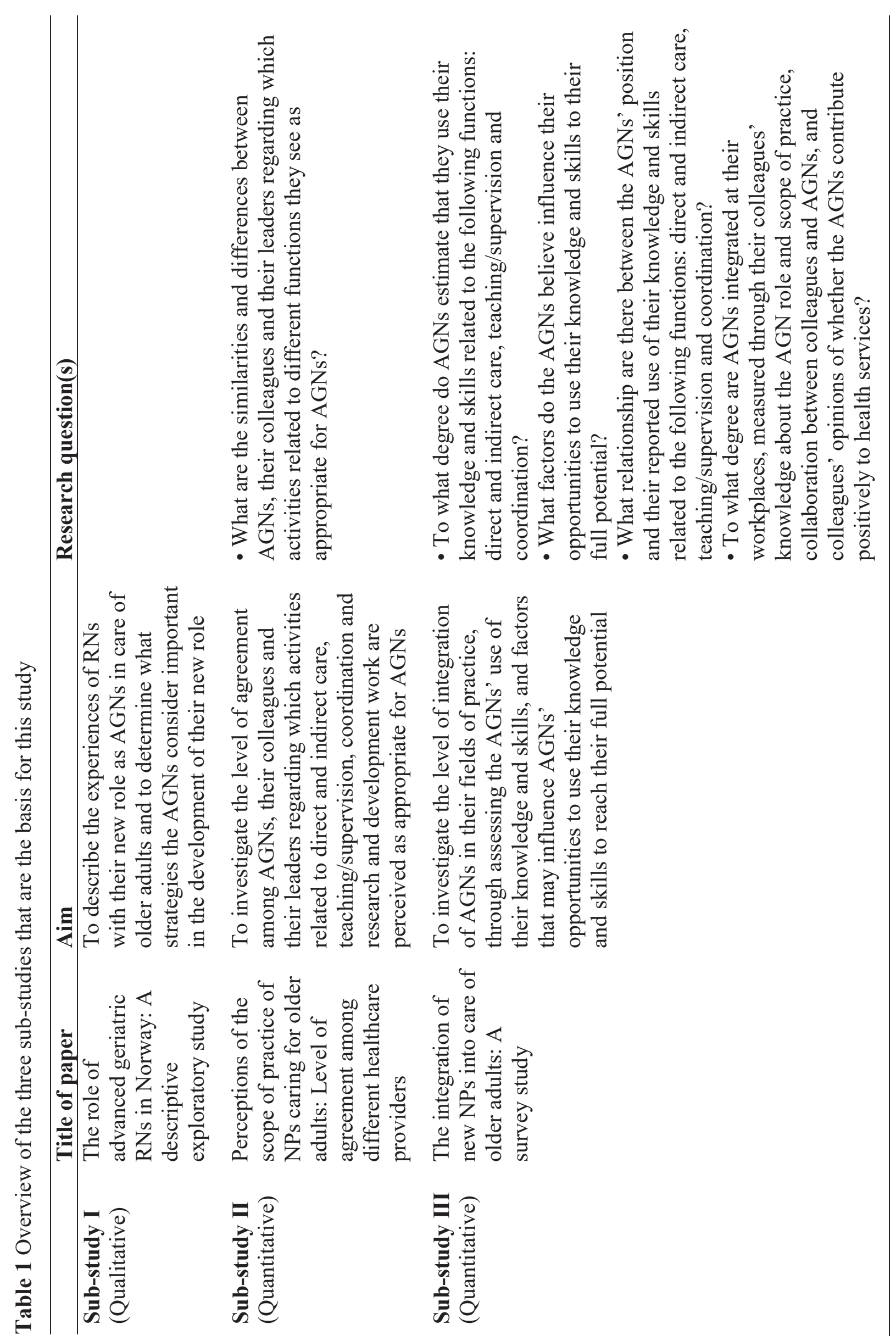




\section{Materials and methods}

\subsection{Design}

In this study, an exploratory sequential mixed methods design was employed: the surveydevelopment variant $(126,127)$. This design was implemented through four main steps. The first step involved the collection and analysis of the qualitative data. Subsequently, based on the qualitative results and relevant literature, two questionnaires were developed and administered, followed by the collection and analysis of the quantitative data. The last step was to interpret the results depending on how the two sets of data matched, deviated from or complemented each other (Figure 1).

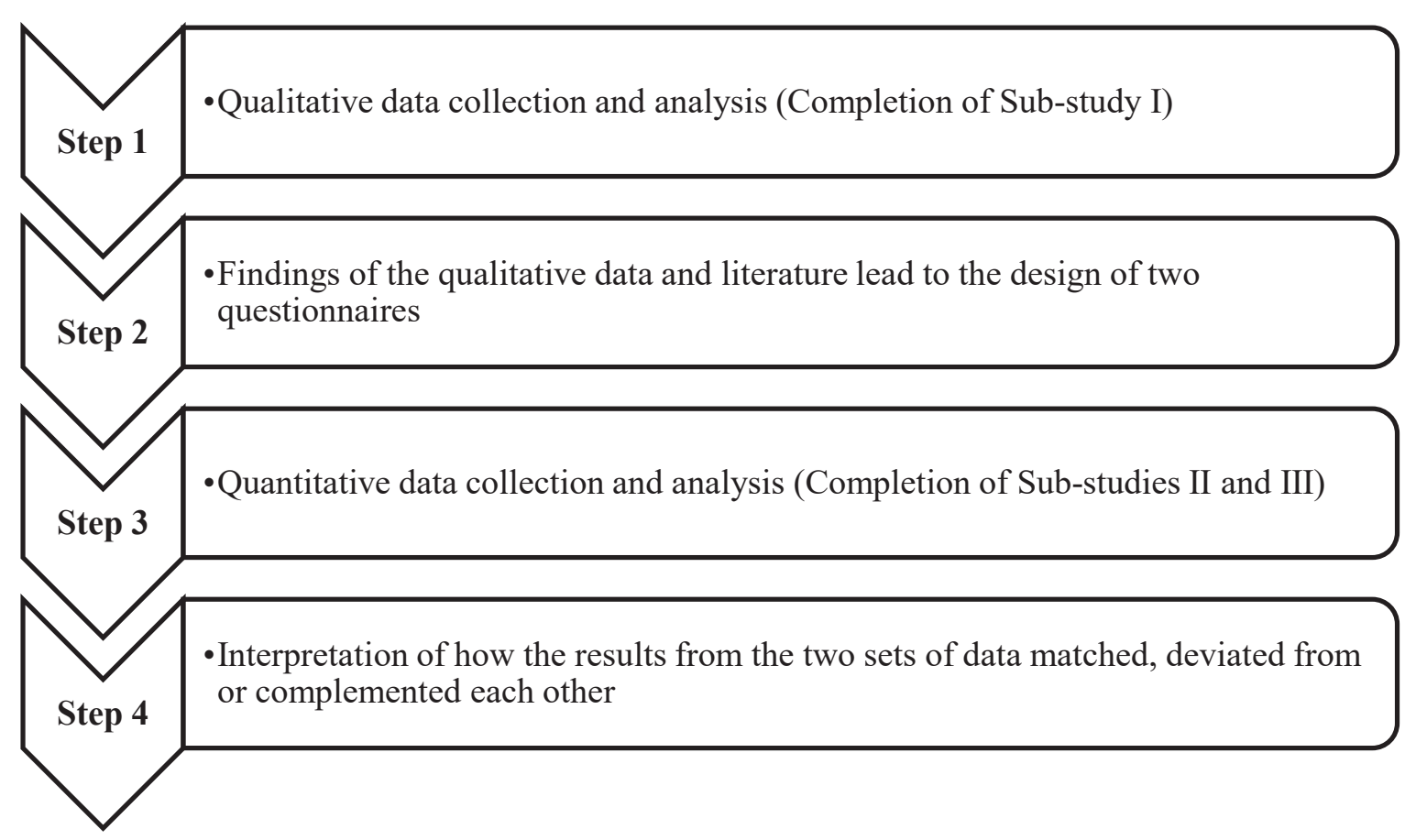

Figure 1 Flowchart of the exploratory sequential mixed methods design used in this study Creswell and Plano Clark (126) report that an exploratory sequential mixed methods design is especially useful in situations when the researcher has to develop a questionnaire because none is available, which was the case in the present study. The intent in using the exploratory sequential mixed methods design was that experiences from the qualitative sub-study could help to develop questionnaires aimed at collecting quantitative data $(126,127)$. In addition to helping develop questionnaires to collect quantitative data, the qualitative sub-study has been seen as a standalone sub-study as it collects valuable information that contributes to achieving the overall aim of this study. 
The concept of mixing methods was introduced in the 1960s, and, according to Leech and Onwuegbuzie (128), mixed methods have since become popular in numerous disciplines, including nursing, psychology, education and sociology. Studies report that a plethora of mixed methods designs have been developed since the concept of mixing methods was introduced $(128,129)$. Johnson et al. (130) examined how researchers within the field of mixed methods research define the approach and found that they apply different definitions. Based on these different definitions, Johnson et al. (130) developed the following general definition:

Mixed methods research is the type of research in which a researcher or team of researchers combines elements of qualitative and quantitative research approaches (e.g., use of qualitative and quantitative viewpoints, data collection, analysis, inference techniques) for the broad purposes of breadth and depth of understanding and corroboration (130, p. 123).

Tashakkori and Teddlie (131) report that there has been a paradigm debate among researchers about the mixing of methods. In the debate, researchers who can be categorised as paradigm 'purists' argue that it is not possible to combine quantitative and qualitative methods due to the incompatibility of the positivist (quantitative) paradigm and the naturalistic or constructivist (qualitative) paradigm underlying the respective methods. According to Williams et al. (132), Roy Bhaskar developed the paradigmatic perspective of critical realism, which supports the belief that quantitative and qualitative methods can be combined, as a response to the polarisation of the positivist and constructivist paradigms. The critical realism perspective argues that reality exists independent of people's cognition and that the social world can only be understood if people understand the structures that cause something to happen and lead to an observable phenomenon $(132,133)$. The idea that there is one external reality makes the perspective different from the constructivist paradigm, which argues that reality is individually constructed, which means that there are multiple realities. On the other hand, critical realism is critical of our ability to have certain knowledge of reality and accepts the possibility that there may be alternative valid accounts of any phenomenon. Therefore, it is distinct from the positivist point of view, which argues that the goal of science is to discover and describe the truth (= certain knowledge) about phenomena in the world, often conceptualised as causal relationships between independent phenomena (causes) and 
dependent phenomena (effects) (133). In this thesis, a position of critical realism has been adopted to allow us to understand what influences the AGNs' level of integration.

In addition to mixing methods, this study mixed data sources (AGNs, their colleagues and their leaders). The mixing of data sources can be used to compare the perspectives of people who hold different points of view, but it does not necessarily lead to a single, totally consistent picture (134). As pointed out by Contandriopoulos et al. (31), consensus among all the members in a workplace on the role and scope of practice is important in order to integrate an NP role into the workplace. In this study, it is therefore valuable to include all the occupational groups working at the AGNs' workplaces.

\subsection{The qualitative sub-study}

\subsubsection{Sample}

As I sought to describe the experiences of RNs in their new role as AGNs independent of whether or not they had a designated AGN position at their workplace, the total sample of RNs $(\mathrm{N}=21)$ who had graduated from the master's degree programme in advanced practice nursing at the University of Oslo was invited by email to participate in the study in spring 2016. Table 2 shows the characteristics of the 21 (100\%) AGNs who participated in the qualitative sub-study. 
Table 2 Characteristics of the participants in the qualitative sub-study $(\mathrm{N}=21)$

\begin{tabular}{lr}
\hline Variables & AGNs \\
\hline Gender & 20 \\
Female & 1 \\
Male & \\
Age & 13 \\
$30-50$ years & 8 \\
$>50$ years & \\
Years practicing as an RN & 4 \\
$<10$ years & 9 \\
$10-19$ years & 3 \\
$20-29$ years & 5 \\
$30-39$ years & \\
Number of years worked in current position & 4 \\
$<1$ years & 12 \\
$1-5$ years & 2 \\
$6-10$ years & 3 \\
$>10$ years & \\
Year graduated with a master's in advanced geriatric nursing & 11 \\
2014 & 9 \\
2015 & 1 \\
2016 & \\
\hline
\end{tabular}

Table from Henni et al. (135, p. 5).

\subsubsection{Data collection}

I developed a semi-structured interview guide to achieve the aim of Sub-study I and to obtain the insights necessary to develop questionnaires to collect the quantitative data. The interview guide has one open-ended question at the beginning to invite the AGNs to share their experiences of what they considered important for their role; there follow several topics relevant to role development and integration (Appendix 1). The interview guide was based on previous studies about the relationship between the role played by NPs and their integration $(23,31,32,136)$ in order to make sure that topics that have been important internationally were examined in Norway. The decision to base the interview guide on previous studies was based on previous ad hoc conversations with some AGNs. The AGNs that I spoke with stated that it was challenging to develop and integrate the role at their workplaces; therefore, the interview guide is based on the knowledge base about the integration of NPs. The interview guide was tested by one AGN, and the pilot interview was included in the study because no modifications were made to the guide after the pilot interview was conducted.

I interviewed the total population of AGNs between February and August 2016. Each AGN was interviewed one time at a venue that was convenient for the AGN. The interview started 
with the open-ended question that was formulated in a way to give the AGNs the opportunity to respond in whatever direction they wanted and to use whatever words they felt necessary to express what they had to say. The topics in the interview guide were not binding but served as a reminder of which topics should be covered in the interview. The follow-up questions from the interview guide were only asked if the AGNs did not mention the topics themselves when they were allowed to speak freely at the beginning of the interview. The interviews were audio-recorded and lasted between 30 and 60 minutes, yielding a total of 16 hours and 44 minutes of raw data material. In addition, I took notes during the interviews to help in the formulation of new questions when the informant said something that I wanted to check out later in the interview.

\subsubsection{Analysis Sub-study I}

I first transcribed all the interviews verbatim in their entirety to ensure that the written text had as much detail as possible. The written transcripts were checked against the audiotape to ensure that the text was transcribed accurately. The transcripts were analysed twice. The first time through, 'conventional content analysis', as described by Hsieh and Shannon (137), was applied to the data material to meet the aim of Sub-study I. Then, a second analysis was conducted to identify and develop questions and response categories to the questionnaires used to collect the quantitative data in this study. In this section, only the analysis process conducted to meet the aim of Sub-study I is described as the development of the questionnaires used in this study will be covered in Section 4.3.2.

I began the conventional content analysis by familiarising myself with the data material. My main supervisor and I familiarised ourselves with the data material by reading the transcripts and coding all the material that appeared to describe the role. We did this separately and met to discuss our interpretations. The coding procedure was done inductively, as we allowed codes and names for the codes to flow from the data. The names of the codes emerged from condensed data that describe the content of the text. Codes that were similar were then grouped into subcategories (Table 3), which were, in turn, grouped into two main categories (Table 4). I used NVivo version 11 (138) to structure codes and categories from the material. The entire research group discussed the analysis process and interpretation, and consensus was reached within the entire research team regarding the results presented in Paper I. 
Table 3 Examples of how the transcribed text was coded and grouped into subcategories

\begin{tabular}{lll}
\hline Transcribed text & Codes & Sub-categories \\
\hline $\begin{array}{l}\text { I'm responsible for all teaching and training of } \\
\text { nurses, auxiliary nurses and assistants (No. 8). }\end{array}$ & Teach colleagues & $\begin{array}{l}\text { Different } \\
\text { functions }\end{array}$ \\
$\begin{array}{l}\text { I've been involved in the drug project and the } \\
\text { management and patient safety project (No. 5). }\end{array}$ & Project participant & \\
$\begin{array}{l}\text { They'll [nurses] call me in situations where they } \\
\text { don't quite know what to do (No. 15). }\end{array}$ & Resource person & \\
$\begin{array}{l}\text { I think we can work more systematically in relation } \\
\text { to comprehensive surveys (No. 17). }\end{array}$ & $\begin{array}{l}\text { Comprehensive } \\
\text { survey }\end{array}$ & New expertise \\
$\begin{array}{l}\text { Many patients have often multiple drugs, I } \\
\text { sometimes make suggestions to the physician “This } \\
\text { is contraindicated, may it cause the patients } \\
\text { problem?” (No. 7). }\end{array}$ & Pharmacology \\
$\begin{array}{l}\text { I document that I can hear with auscultation ... and } \\
\text { then there are many nurses who don't know what } \\
\text { auscultation is (No. 11). }\end{array}$ & Auscultation & \\
\hline
\end{tabular}

Table from Henni et al. (135, p. 4).

Table 4 The subcategories that constitute the main categories

\begin{tabular}{ll}
\hline Sub-categories & Main categories \\
\hline See new problems & Dimensions of the AGN-gaze \\
New expertise & \\
Contribute to practice & \\
Different functions & \\
Different positions & Important strategies to develop the role \\
Use the new knowledge & \\
Engage managers in discussion & \\
Demonstrate knowledge to others & \\
Establish a collaborative relationship with others &
\end{tabular}

Table from Henni et al. (135, p. 5).

\subsection{The quantitative sub-study}

\subsubsection{Sample}

The AGNs, their colleagues and their leaders were included in the sample in the quantitative sub-study. I included all the different occupational groups that are traditionally involved in the care provided to older adults to provide a comprehensive view of the perspectives of the occupational groups that constitute the healthcare teams which the AGNs are a part of. This inclusion has the potential to provide a multifaceted perspective as it represents the perspectives of different healthcare providers that may have different understandings about 
the AGNs' role and scope of practice based on their education. The mixing of data sources was used in the quantitative sub-study to compare the perspectives of the different occupational groups.

In autumn 2017, all 26 AGNs who had graduated from the master's degree programme in advanced practice nursing at the University of Oslo were invited by email to participate in the study. In order to invite the AGNs' colleagues to participate in the study, the AGNs were asked to provide their workplace and their leader's contact information. Twenty-four of the AGNs provided the information. A few of the AGNs worked at hospital outpatient clinics. Even though this thesis focuses on primary care, these AGNs were included in the study as the hospital outpatient clinics have a primary care focus. Of those who responded to the invitation email, 21 AGNs worked in a clinical position, and three worked as instructors at nursing educational programmes or were involved in research. All the AGNs were included in the study as they had worked in clinical positions after graduating from the master's degree programme in advanced practice nursing. The remaining two AGNs that did not provide their leader's contact information did not want their colleagues to participate in the study, and one of them did not want to receive a questionnaire.

In order to maximise the sample of colleagues, I discussed the recruitment process of their colleagues with some AGNs and their leaders. There was a consensus that there was a greater possibility that individuals would answer the questionnaire if their leaders recruited them, instead of an unknown researcher (me). The leaders pointed out that they did not have the capacity to recruit more than 30 people each. I therefore emailed a formal enquiry to the leaders of the AGNs who worked in a clinical position to recruit 30 colleagues from the AGNs' workplace that were willing to answer a questionnaire. The leaders were informed that they could list themselves as one of the 30 people if they were willing to answer the questionnaire. I provided the leaders with the following inclusion criteria to create variation in the sample:

- The participants must be involved in the care of older adults in the municipality/institution where the AGN works.

- The sample should include participants from all system levels and with different job titles.

- There should be a minimum of one to two people from all healthcare providers involved in the care of older adults at the workplace. 
Sixteen of the leaders recruited participants personally or delegated the recruitment to the AGN or another person employed at the workplace. Three leaders did not agree to recruit participants and reported limited capacity as the reason they declined to participate in the study. At four workplaces, fewer than 30 colleagues were recruited. The recruiters stated that the reason was a lack of capacity and colleagues to recruit. At five workplaces, there was great commitment to participate in the study, and the recruiter therefore recruited more than 30 colleagues. In total, the leaders collected 465 email addresses for individuals who were willing to participate in the study. I sent out the questionnaires to 25 AGNs and 465 colleagues by email at the start of January 2018. Follow-up emails were sent out two, four and six weeks after the initial email. Table 5 shows the characteristics of the $23(88.5 \%)$ AGNs and the 195 (42\%) colleagues who answered the questionnaires.

Table 5 Characteristics of the respondents in the quantitative sub-study $(\mathrm{N}=218)$

\begin{tabular}{|c|c|c|}
\hline Variables & $\begin{array}{c}\text { AGNs } \\
(\mathrm{n}=23)\end{array}$ & $\begin{array}{c}\text { Colleagues } \\
(\mathrm{n}=195)\end{array}$ \\
\hline \multicolumn{3}{|l|}{ Gender } \\
\hline Female & $21(91.3)$ & $175(89.7)$ \\
\hline Male & $2(8.7)$ & $20(10.3)$ \\
\hline Age [years] & $45.4[9.4]$ & $44.3[11.5]$ \\
\hline \multicolumn{3}{|l|}{ Type of work organisation } \\
\hline Primary care & $21(91.3)$ & $185(94.9)$ \\
\hline Hospital care & $2(8.7)$ & $10(5.1)$ \\
\hline \multicolumn{3}{|l|}{ Job title } \\
\hline Leader & $1(4.4)$ & $38(19.5)$ \\
\hline AGN & $9(39.1)$ & \\
\hline Physician & & $5(2.6)$ \\
\hline Specialist RN & $8(34.8)$ & $3(1.5)$ \\
\hline $\mathrm{RN}$ & $5(21.7)$ & $64(32.8)$ \\
\hline Occupational therapist & & $18(9.2)$ \\
\hline Physical therapist & & $10(5.1)$ \\
\hline Auxiliary nurse & & $30(15.4)$ \\
\hline Assistant & & $7(3.6)$ \\
\hline Executive officer & & $10(5.1)$ \\
\hline Other & & $10(5.1)$ \\
\hline Worked in current position [years] $\dagger$ & $7.8[7.7]$ & $6.4[6.6]$ \\
\hline \multicolumn{3}{|l|}{ Work hours } \\
\hline Day, evening and night & & $10(5.1)$ \\
\hline Day and evening & $9(39.1)$ & $73(37.4)$ \\
\hline Day & $14(60.9)$ & $112(57.5)$ \\
\hline
\end{tabular}

Values are expressed as mean $[S D]$ or $n(\%)$.

$\uparrow$ The AGNs range from 1-27 years and the colleagues from 0-37 years. The range explains why the $S D$ is larger than the average years the colleagues had worked in their current position.

Modified table from Henni et al. (139, p. 2916). 


\subsubsection{Data collection}

Prior to the study, I conducted a literature search to identify relevant, existing psychometrically tested questionnaires that could be used to collect data to meet the aim of Sub-studies II and III, but no such questionnaires were identified. I therefore developed one questionnaire for the AGNs (Appendix 2) and another for the colleagues (Appendix 3). The questionnaires are based upon previous studies on factors that affect the integration of NPs $(23,31)$, common activities for NPs internationally $(9,21,38,81-83,86,101,102)$ and the qualitative interviews with the AGNs from Sub-study I. I examined the interviews thoroughly to ensure that the AGNs' experiences related to integration and scope of practice were taken into account. Based on the interviews, the following activities were added to the questionnaires: collection of blood samples, prescription and assessment of blood samples, drug performance review in collaboration with the patient's physician, evaluation of patient services, prescribing and ordering medical supplies, working in committees/project groups, contributing to routines and procedures consistent with laws, rules and guidelines and surveying which domains need increased competence at the workplace. The AGNs' interviews contributed to making the questionnaires' context specific to the Norwegian healthcare system and to NPs caring for older adults. Papers II and III contain a detailed description of the questions and response categories that are included in the different parts of the questionnaires and rationales for including the different questions.

The questionnaires consist of three sections with matching questions, but with the wording adjusted to the two target groups. In addition, both questionnaires include some additional questions that are not relevant to the other group. The first section contains questions about demographic background and work conditions. The second section contains questions about which activities within different functions are performed by and are appropriate for the AGNs, the AGNs' degree of use of their knowledge and skills within different functions and different reasons for any lack of knowledge and skills. The third section contains questions about factors that influence the integration of AGNs into healthcare. Papers II and III contain a thorough description of which parts of the questionnaires are used to meet the aims of the sub-studies.

The two questionnaires were uploaded to Nettskjema, which is a tool developed by the University of Oslo for designing and managing data collection for electronic surveys. Subsequently, the AGN questionnaire was pilot-tested by two AGNs, and the colleague 
questionnaire pilot was tested with one leader, one physician, one RN, one auxiliary nurse and one assistant. The testers were specifically asked to provide feedback about whether the questions and response categories were comprehensible, relevant and appropriate, whether the questionnaires were easy to fill out and whether they contained ambiguous questions and/or response categories. As recommended by Wilson (140), the testers tested the questionnaires in their electronic format as they were intended to be administrated electronically, and all of them, except for two, gave oral feedback to me simultaneously as they answered the questionnaire. The two testers that did not give oral feedback preferred to provide written feedback instead. After the testers filled out the questionnaire, they were given the opportunity to make additional comments regarding the questionnaires. The approach used to test the questionnaires is described as think-aloud interviewing (134). The think-aloud approach is appropriate to collect feedback from the testers as it aims to elicit how the questions and response categories are understood by the testers at the time of testing (134).

The responses of the testers resulted in two of the questions that they found difficult to answer being changed. The first change was related to questions about the AGNs' estimated use of knowledge and skills related to different functions (Table 3, Paper III). In addition to direct and indirect care, teaching/supervision and coordination, there was originally a question about the AGNs' estimated use of the knowledge and skills related to research and development work. I discussed that question with other AGNs in ad hoc conversations, and there was a consensus among them to remove the question. The AGNs I spoke to explained that they recognised research and development work as important and relevant to perform. Some AGNs expressed that they had the opportunity to use their knowledge and skills related to the function, but they chose not to use this opportunity, which caused difficulties in answering the question. The other change was related to the question about the degree to which the colleagues facilitated contact between patients and the AGN (Table 6, Paper III). The question originally had four response options. The colleagues had to grade their answers from a high degree to absolutely not. The testers thought it was hard to differentiate between a low degree and absolutely not in that specific context. Therefore, I decided to remove the response option for a low degree. A unanimous consensual validation by the entire research team regarding the questions and response categories that were included in the questionnaires was reached after all the testers' perceptions were taken into account. 


\subsubsection{Analysis}

The data were analysed with $\mathrm{R}$ version 3.4 .4 (141). To submit the questionnaires online, the respondents had to answer all the questions. There were therefore no missing data, and all the submitted questionnaires were included in the analysis. I prepared the data for analysis by inspecting them for irregularities and errors. One question had a free text field as one of several response categories. The statements from the text field corresponded well with the question's existing response categories. I therefore ticked off the response categories that were consistent with the statement. The demographic variables were categorical except for 'age' and 'years worked in current position'. I calculated the frequency and percentage distribution of the categorical variables and the mean and $S D$ for the continuous variables.

\section{Sub-study II}

In order to examine the similarities and differences among the AGNs, their colleagues and their leaders regarding which activities related to the different functions they see as appropriate for AGNs, I first separated the leaders' answers from those of the AGNs' other colleagues. This decision was based on the fact that in the interviews in Sub-study I, the AGNs asserted that the leaders are powerful actors because they are in a position to accommodate the AGNs in a role that enables the AGNs to properly utilise their knowledge and skills. The AGNs' experiences have also been confirmed in previous research $(23,30,31$, 135). In addition, previous studies have found that leaders play a central role in redesigning activity distribution and establishing new practices when a new NP role is introduced at a workplace (142).

In order to confirm that the respondents agreed that an activity was appropriate for AGNs, I established consensus criteria based on that used in Delphi studies (143, 144). Delphi studies use $75 \%$ as a measure for consensus, meaning that at least $75 \%$ of the sample must have the same answer on a variable. In this sub-study, consensus was defined to mean that $75 \%$ or more of the AGNs, $75 \%$ or more of the colleagues and $75 \%$ or more of the leaders responded that an activity was appropriate. Within-group consensus was defined as $75 \%$ or more of the respondents within one of the groups responding that an activity was appropriate. A series of cross-tabulations was then conducted to identify which of the activities related to direct and indirect care, coordination, teaching/supervision and research and development work the AGNs, colleagues, and leaders see as appropriate for AGNs. This analysis also provides an overview of the activities that the respondents have conflicting views about. 


\section{Sub-study III}

To answer the first two research questions related to the degree to which the AGNs estimated that they used their knowledge and skills related to different functions and which factors the AGNs believed influenced their opportunities to use their knowledge and skills to their full potential, the study relied upon descriptive data analysis. Specifically, I calculated the frequency and percentage distribution of the AGNs' reported use of the various function variables and the reason for not using knowledge and skills to a high degree variable. A series of cross-tabulations, Fisher's exact test and the Kruskal-Wallis test were subsequently conducted to identify if there was a pattern between the AGNs' position at their workplace and the AGNs' estimated use of their knowledge and skills within the following functions: direct and indirect care, coordination and teaching/supervision. Thereafter, I divided the colleagues into three groups based on their job title to check whether there were any differences between their reporting on the different variables used as a measurement on the AGNs' degree of integration (fourth research question). One group consisted of leaders as the AGNs stated that it was important for AGNs to have support from their leaders in the interviews in Sub-study I. In these interviews, the AGNs reported that RNs were the group of colleagues from whom they often encountered resistance (this is not reported in Paper I); the RNs and specialist RNs therefore constitute a separate group. The rest of the healthcare professions were grouped together (physicians, occupational therapists, physical therapists, auxiliary nurses, assistants, executive officers and colleagues who had other job titles than those included as response options) as the AGNs did not specifically mention other healthcare professions in the interviews. I conducted a series of cross-tabulations, Pearson's chi-squared test, Fisher's exact test and the Kruskal-Wallis test with the colleagues' knowledge about the AGNs' variables, the collaboration variables and the variable for the AGNs' contribution to examine if there were any differences between the three groups of colleagues. Pearson's chisquared test and Fisher's exact test were applied to investigate the associations between the variables and the Kruskal-Wallis test to investigate between-group differences. Analysis with a $p$-value of less than 0.05 was considered statistically significant.

\subsection{Ethical considerations}

This study was conducted in accordance with the ethical principles of medical research involving human subjects (145). The study was reported to the Norwegian Centre for Research Data. All the AGNs who participated in the interviews gave written consent; furthermore, the AGNs were informed that participation was voluntary and that they could 
withdraw their consent without explanation at any time. I also sent a formal enquiry to the leaders of the AGNs in order to obtain consent from their leaders to interview the AGNs. I did not obtain written consent for the questionnaires. Participants were informed in the email, which contained a hyperlink to the questionnaires, that participation was voluntary and that the submission of the questionnaire was viewed as consent to participate in the study.

There are only a few AGNs in Norway, and most of them have actively participated in social media to promote AGN education. Anonymous presentation was therefore important to ensure that none of the AGNs were linked to data that made it possible to identify them. I was therefore extra aware of presenting the characteristics of the AGNs as a unified group, and I went through all the citations before submitting the manuscript to ensure that the citations did not contain information that made it possible to identify who said them.

Another important aspect is methodological considerations; however, I will not discuss these considerations regarding this study in this section as they will be discussed in Section 6.2. 


\section{Results}

This chapter provides a summary of the main results from each of the three sub-studies.

\subsection{Sub-study I}

\section{Henni SH, Kirkevold M, Antypas K, Foss C. The role of advanced geriatric nurses in} Norway: A descriptive exploratory study. Int J Older People Nurs. 2018;13(3):e12188

The first sub-study presents the AGNs' experiences regarding their new role in the care of older adults and what strategies the AGNs consider important in the development of their new role. The qualitative interviews showed that the AGNs regarded their nursing role as complex and extensive. The AGNs stated that their AGN education provided them with new knowledge and skills from several fields (nursing, physiotherapy, medicine, geriatrics, pharmacy, etc.). The AGNs had developed what they described as a new 'gaze' based on a combination of their new knowledge and skills with previous experiences and personal interests. Through their new gaze, the AGNs gained a deeper and broader understanding of the older adults' life situations and the healthcare system. The new gaze further provided the AGNs with the ability to see a wider range of medical, social and environmental problems in the older adults' situation compared to before they started the educational programme. The AGNs stated that they were able to see the older adults' problems at an earlier stage and that the educational programme had provided them with the knowledge and skills to address these problems. Overall, they asserted that they worked to prevent medical and psychosocial problems. The AGNs clearly expressed that direct care was their core task, but they also described addressing quality development and the supervision and teaching of colleagues. The AGNs also told stories about how colleagues used them as an expert to be contacted for consultation in challenging patient cases. Just under half of the AGNs had entered new positions explicitly as AGNs, but those who had not entered a specific AGN position reported that they contributed to practice regardless of their position. The AGNs had experienced that their workplace conditions affected their possibilities to develop their role. It seemed like those who had a designated AGN position had a greater opportunity to prioritise their own agenda and work independently compared to those who did not. The opportunity to prioritise their own agenda was emphasised as important by all the AGNs, while several remarked that their leader had not done enough to customise an AGN position that optimised the use of their new knowledge and skills. 
The sub-study found that the AGNs had developed several strategies that they used to develop their role at their workplace. One strategy during their education was to engage their leader in discussion about how they could use their new knowledge and skills after graduation. The AGNs stated that support from leaders was important as it was the leaders who had the opportunity to facilitate an AGN role. Another strategy was to demonstrate their knowledge to other healthcare providers so that they could understand how AGNs can contribute to the care of older adults. The last strategy was to establish a collaborative relationship with others to avoid potential conflicts and to gain support from, for example, physicians, whom the AGNs often mentioned as important collaboration partners in their narratives. The establishment of a collaborative relationship with others was described as very important for the reason that the person the AGNs had established a relationship with could communicate the importance of the AGN role to others and thus help to make the role of the AGNs known.

The conclusions drawn from the sub-study are as follows. The AGNs exhibited the knowledge, enthusiasm, interest and self-esteem necessary to care for older adults' needs. The AGNs' main focus is on direct care, and they share their expertise with others through supervision and formal teaching. Overall, developing effective strategies that promote role integration is important in the development of new roles for AGNs caring for older adults. In particular, collaboration with leaders that resulted in a specific AGN position was experienced as an important strategy by the AGNs.

\subsection{Sub-study II}

\section{Henni SH, Kirkevold M, Antypas K, Foss C. Perceptions of the scope of practice of nurse practitioners caring for older adults: Level of agreement among different} healthcare providers. Scand J Caring Sci. 2020; Article accepted on 25 March, 2020

The second sub-study is concerned with the level of agreement among AGNs, their colleagues and their leaders regarding which activities related to direct and indirect care, teaching/supervision, coordination and research and development work are perceived as appropriate for AGNs. The sub-study showed that all the activities related to coordination, teaching/supervision and research and development work were seen as appropriate for AGNs by the AGNs, their colleagues and their leaders. In addition, they saw just under half of the direct care activities and one-third of the indirect care activities as appropriate for AGNs. 
Although the AGNs, their colleagues and their leaders saw several of the activities related to direct and indirect care as appropriate, they disagreed on the appropriateness of the activities that traditionally fall within the medical field and on some activities that traditionally fall within the nursing field. Examples of such activities are prescribing X-rays, prescribing and ordering medical supplies, prescribing a pre-agreed selection of drugs, collecting blood samples and inserting a permanent catheter. Just over two-thirds of the remaining medical and nursing activities related to direct and indirect care were seen as appropriate for AGNs by the AGNs. The colleagues saw just under one-fourth of the remaining nursing activities related to direct and indirect care as appropriate for AGNs, while the leaders saw only one of these activities as appropriate for AGNs. Although the colleagues and the leaders saw different activities as appropriate for AGNs, all the activities that the colleagues and the leaders saw as appropriate were also seen as appropriate by the AGNs. The colleagues and the leaders saw none of the remaining medical activities related to direct and indirect care as appropriate for AGNs. An overview of the specific activities included in the sub-study and the exact frequency and percentage distribution of AGNs, colleagues and leaders who reported that an activity was appropriate for AGNs are provided in Tables 2 and 3 in Paper II.

Overall, there seems to be a high degree of agreement on the appropriateness of various activities within the AGN group, while there is a lesser degree of agreement on the appropriateness of various activities within the colleague group and the leader group. The leaders had a lower degree of within-group agreement on the appropriateness of the various activities compared to the AGN group and the colleague group.

It may be concluded from this sub-study that the healthcare providers agreed on which activities related to teaching/supervision, coordination and research and development work are appropriate to include in the scope of the practice of AGNs. However, the findings of the sub-study highlight that conflicting views exist on some activities related to direct and indirect care.

\subsection{Sub-study III}

\section{Henni SH, Kirkevold M, Antypas K, Foss C. The integration of new nurse practitioners into care of older adults: A survey study. J Clin Nurs. 2019;28(15-16):2911-23}

The third sub-study is concerned with the AGNs' level of integration at their workplaces, assessed through the AGNs' use of their knowledge and skills, and factors that may influence 
AGNs' opportunities to use their knowledge and skills to reach their full potential. The substudy showed that $16(69.6 \%)$ AGNs reported using their knowledge and skills to their full potential when providing direct care. However, only a minority reported using their knowledge and skills to their full potential when providing indirect care $(\mathrm{n}=11,47.8 \%)$, teaching/supervision $(n=11,47.8 \%)$ and coordination $(n=5,21.8 \%)$. Twelve $(52.2 \%)$ AGNs stated that they believed the way the workplace was organised influenced their opportunities to use their knowledge and skills. A series of cross-tabulations, Fisher's exact test and the Kruskal-Wallis test showed that there was no significant relationship between the AGNs' position (designated AGN position or other non-designated AGN positions) and their use of knowledge and skills related to direct care and coordination, but there was a significant relationship with indirect care (Fisher's exact test: $p=0.046$, Kruskal-Wallis test: $H$ [1] $=$ $6.024, \mathrm{p}=0.014)$. The results of the cross-tabulations, Fisher's exact test and the KruskalWallis test also indicate that there was a relationship between the AGNs' position and teaching/supervision, as the Kruskal-Wallis test showed a significant relationship (H [1] = 5.754, $\mathrm{p}=0.016)$, and Fisher's exact test showed a nearly significant relationship $(\mathrm{p}=0.052)$. The degree to which the AGNs used their knowledge and skills in indirect care and teaching/supervision was higher among responders with a designated AGN position than among those in other positions.

The integration of AGNs into their workplaces was, in this sub-study, measured through the following variables: colleagues' knowledge about the AGN role and scope of practice, collaboration between colleagues and AGNs and colleagues' opinions whether the AGNs contribute positively to health services for older adults. The statistical tests showed no significant differences between the variables and the different groups of colleagues. I will therefore only report the frequency and percentage distribution of the colleagues as consolidated groups. An overview of the frequency and percentage distribution of the different groups of colleagues can be seen in Table 6 in Paper III. The results showed that 160 (82.1\%) colleagues knew which RN the AGN at their workplace was, but 109 (55.9\%) colleagues reported either they had not been informed at all about the AGNs' role or scope of practice or that the information provided was not sufficient. Forty-seven $(24.1 \%)$ colleagues considered that the AGNs' scope of practice was clear, and 52 (26.6\%) collaborated with the AGNs several times a week. Only 49 (25.1\%) colleagues reported that they facilitated contact between patients and the AGNs to a high degree. Finally, 131 (67.2\%) colleagues considered 
that the AGNs' role and scope of practice contributed highly positively to health services for older adults.

It was concluded from this sub-study that the AGNs use, to varying degrees, their knowledge and skills within different functions. Still, there is room for better utilisation of the AGNs' knowledge and skills through improved integration of AGNs into health services for older adults. 


\section{Discussion}

\subsection{General discussion of the results}

The overall aim of this thesis was to investigate the role of AGNs, what AGNs and their collaborators see as an appropriate scope of practice for these nurses and how the AGNs are being integrated into the Norwegian healthcare system. In the following sections, I will discuss the results of this study compared to the knowledge base on the role and scope of practice of NPs internationally. I will then discuss what affects the integration of AGNs into the Norwegian healthcare system as the results of Paper III show that there is a need for greater focus on how to integrate AGNs. I will also discuss how the results of this study can contribute to further development of advanced practice nursing in Norway as there is great interest in Norway in establishing advanced roles for RNs. In the discussion, I will draw on the results of the qualitative and quantitative studies and finally consider if and how the results from the two data sets match, differ or complement each other.

\subsubsection{Role and scope of practice of advanced geriatric nurses}

The knowledge base on the role and scope of practice of NPs presented in Section 2.2.1 indicates that internationally, the role is multifaceted and the scope of practice is broad. The research field indicates that NPs can have different responsibilities and perform different activities depending on their practice setting. Therefore, NPs may make different contributions to healthcare, depending on their specific role and scope of practice. Since AGNs are specialised in the care of older adults, their extended knowledge and skills in this area will influence their role and scope of practice and thus their contribution to healthcare.

Overall, this study indicates that AGNs have a multifaceted role and a broad scope of practice which are desired by the AGNs, their colleagues and their leaders. The specific contribution of the AGN role in providing healthcare services to older adults was not examined in this study, although the third sub-study found that the AGNs' colleagues and leaders agree that the AGNs' role contributes positively to the health services provided to older adults. Although the AGNs' contribution is seen positively by others, the first and third sub-studies found that the AGNs do not consider that they contribute to their full potential to the Norwegian healthcare system.

The interviews with the Norwegian AGNs depict the AGNs as RNs as having great dedication to the field of care of older adults, with experience and knowledge related to older adults' life 
situations, normal aging processes and signs of illness. The AGNs expressed how they are first and foremost clinically oriented and that they see direct care as their core function. According to Hamric (18) and the International Council of Nurses (21), the focus of all NPs, regardless of the patient group they care for, is direct care. The interviews further portray the AGNs as RNs as maintaining a strong focus on preventing medical and psychosocial problems and as possessing the knowledge and systematic clinical assessment skills to identify older adults' problems at an early stage. In addition, the AGNs stated that the master's degree programme provided them with the knowledge and skills necessary to address the problems they discovered. The international literature $(85,89)$ that describes the role of NPs caring for older adults also depicts a role with a strong focus on maintaining older adults' health through health promotion and disease management. Overall, the interviewees' portrayal of the AGNs' role is accordant with how Carryer et al. (72) describe the core role of NPs in Australia and New Zealand: as RNs who advocate for their patients and the field of nursing and who possess extensive knowledge and skills adapted to their specific practice context.

The first sub-study depicts AGNs as also focusing on interdisciplinary collaboration, systematic quality improvement and spreading their knowledge and skills through the clinical supervision and teaching of students and colleagues. The focus on the education of patients, families and staff was also described as a central part of the role of NPs who care for nursing home residents $(73,79,104)$. In the interviews, the AGNs gave several descriptions of how they worked to increase the knowledge and skills of the other healthcare providers in the workplace. For example, they provided extensive formal and informal teaching and clinical advice to their colleagues and students. The AGNs also reported that the colleagues asked them for advice in patient situations that they experienced as challenging, which indicates that the colleagues saw the AGNs as experts in the care of older adults. Teaching, supervision and research and development work activities were also seen as appropriate activities for AGNs not only by the AGNs but also by their colleagues and leaders (Sub-study II). The views of the AGNs, their colleagues and their leaders indicate that the AGNs felt competent to teach their knowledge and skills to their colleagues and that the colleagues and the leaders saw the AGNs as knowledgeable RNs from whom they wanted to learn. The need to increase professional competence in primary care in order to ensure that older adults' health and care needs are fulfilled is also highlighted in Norwegian white papers $(1-3,16)$. This study's description of AGNs' role and scope of practice shows that AGNs can contribute to 
increasing the general knowledge and skills of other healthcare providers in the workplace while working in a patient-oriented manner to fulfil older adults' needs.

One of the aims of the healthcare reform 'Live Your Whole Life' (16) is not only to provide older adults with a greater sense of security and predictability throughout the patient trajectory and during transitions between their own homes, hospitals and nursing homes but also to reduce the number of different health professionals caring for each patient. Internationally, it is found that NPs caring for older adults coordinate health-related services for their patients $(83,87)$. In the third sub-study, the AGNs, their colleagues and the leaders agreed that coordination of collaboration within and outside the organisation is appropriate for AGNs. The AGNs, their colleagues and the leaders agreed that AGNs can contribute to creating more coherent service provision for older adults and their relatives by contributing to the coordination of collaboration within and outside the organisation.

The international literature $(9,21,38,86,101,102)$ describes NPs' scope of practice as broad and notes that NPs caring for older adults can perform a range of activities. Some activities described in the literature traditionally belong to the medical field and are thus within the physicians' domain $(7,13,90)$. Norwegian AGNs do not have the authority to perform medical activities such as the prescription of medications, medical supplies, X-rays and fluid therapy. In the second sub-study, it was found that AGNs saw these activities as appropriate for their role, while a majority of their colleagues and leaders disagreed. Compared to the AGNs and their colleagues, the leaders also envisioned a more restricted scope of practice for AGNs. As discussed in Paper II, there may be several reasons why the AGNs' colleagues and leaders do not see some medical activities as appropriate for AGNs. For example, certain medical activities are normally performed by physicians in Norway, but the lack of national regulations allows AGNs to perform them. Task-shifting of medical activities from physicians to AGNs represents a change in the Norwegian healthcare system, and this change might be time-consuming to implement (146). Internationally, it is found that the lack of regulations results in NPs employed at different workplaces being assigned various types of activities (medical activities, nursing activities, etc.) $(9,30)$. It is reasonable to presume that the colleagues and leaders' view of the appropriateness of the different activities is affected by whether the AGN at the workplace performs the activities. Therefore, the fact that certain medical activities are normally performed by physicians in Norway and the lack of regulation might be reasons that the AGNs' colleagues and leaders do not see these medical activities as 
appropriate for AGNs. Another reason might be the lack of knowledge among the colleagues and leaders about whether the AGNs are capable of performing the medical activities as the colleagues and leaders had not received sufficient information about the AGNs' role and scope of practice (Sub-study III).

To summarise, Norwegian AGNs have a high focus on direct care, interdisciplinary collaboration and systemic quality improvement, which is similar to the role of NPs described internationally. Compared with the knowledge base about NPs' scope of practice internationally, it seems that AGNs have a relatively more restricted scope of practice.

\subsubsection{Factors that may affect the integration of advanced geriatric nurses into the Norwegian healthcare system}

The interviews with the AGNs reveal that they found the AGN role-development process challenging and that the opportunities to use their role depended on their workplace conditions. Cote et al. (147) assert in this regard that role optimisation appears to be influenced by elements related to NPs' workplace conditions. In the interviews, the AGNs highlighted the importance of developing effective strategies to foster role integration; such strategies are described in Sub-study I.

The concept of integration has guided the development of the present study's aim, research questions and data collection tools. As described in Section 2.3, my understanding is that an AGN is integrated into the workplace when s/he experiences using her/his knowledge and skills to their full potential at the workplace and when s/he is accepted by colleagues and thereby included in their daily practice of health services for older adults. The interviews with the AGNs reveal that they did not experience fully utilising their knowledge and skills, which they then confirm in the survey (Sub-study III). In addition, the AGNs' colleagues collaborate with the AGNs and facilitate contact between patients and AGNs to a limited degree (Substudy III), which indicates that the AGNs are not fully included in the daily practice of health services for older adults.

During the investigation of the role of AGNs, several factors were identified that may facilitate and several that may hinder the integration of AGNs into the Norwegian healthcare system. Internationally, factors that may facilitate or hinder the integration of NPs are discussed in the literature $(13,23,31)$, but international research is not conducted in settings where the NP role is introduced as a completely new role in a country's unregulated 
healthcare service. In addition, such research $(13,23,31)$ has not been conducted in settings where NPs are specialised in the care of older adults. In this section, I discuss the identified factors that may facilitate or hinder the integration of AGNs into the Norwegian healthcare system.

\section{Factors that may facilitate the integration of advanced geriatric nurses}

The importance of the regulation of advanced practice nursing in Norway for the development of a role that would utilise AGNs' knowledge and skills was highlighted in the qualitative interviews with the AGNs. The conclusion reached in one review was that a broad scope of practice authority tends to increase the number of NPs and growth of the NP workforce while promoting the growth and advancement of NP primary-care provision (155). The Ministry of Health and Care Services and the Ministry of Education and Research have recently established regulations for NP education in Norway in order to establish greater practice authority for NPs $(116,117)$. The establishment of regulations that lead to greater practice authority may promote the integration of the role of the AGN, as found internationally for the NP role (13).

The framework developed by Contandriopoulos et al. (31) suggests that NP integration depends on planning how to integrate the role, consensus within the team, establishing frames for collaboration and support between the NP and colleagues and the existence of an organisational structure that has been adjusted to accommodate the optimal use of the NP's knowledge and skills. International research has found that NPs' colleagues are supportive of the NP role $(84,100,148-154)$. During the interviews, the AGNs described how they had worked to establish a collaborative relationship with others to avoid potential conflict and gain support. Despite the AGNs' role and scope of practice being unknown among the colleagues, the colleagues seem to support the AGNs' role as they acknowledged that the role and scope of practice of the AGNs contributes positively to health service provision for older adults (Sub-study III). In addition, in their interviews, the AGNs rarely described having experienced opposition to their role and also expressed that they thought that other colleagues saw the benefit of having an AGN in the workplace. The colleagues' support of the AGN's role and the AGNs' efforts to gain support indicate that the factor of team support has taken effect as a facilitator for the integration of AGNs.

The AGNs described how they used different strategies to demonstrate their knowledge to others so that others could understand their abilities and how they can contribute to the care of 
older adults (Sub-study I). The AGNs also described how they worked to provide consultations to older adults and educate their colleagues and students to improve the care given to elderly patients. The AGNs' demonstration of knowledge to others and their efforts to improve care may be interpreted as an attempt to show their colleagues that they are associates who can contribute valued services to the care provided to older adults, which Blau (118) describes as essential for integration in his integration theory of individuals into a group. The AGNs specified in the interviews that it was important that they showed respect towards their colleagues when they demonstrated their knowledge so as not to leave others with the impression that the AGNs saw themselves as being 'above' other RNs in the workplace. According to Blau (118), showing a group that one considers oneself no better than the rest of the group can prevent the group from developing defensive tactics to hinder integration. During the interviews, the AGNs explained that the conflicts they had with some physicians disappeared after they spent time introducing themselves, being flexible and showing respect to establish a collaborative relationship with the physicians. The findings indicate that the AGNs have found a way to show their colleagues that they can contribute valuable services and that they are easily approachable, which Blau (118) describes as essential for a person to become integrated into a group. The AGNs' demonstration of their knowledge to others and their efforts to present themselves as approachable can therefore be seen as factors that facilitate their integration.

\section{Factors that may hinder the integration of advanced geriatric nurses}

Lack of regulation has been discussed as a barrier to integration in all three of the papers. In the interviews, the AGNs expressed that it was hard to develop an AGN role as there are no regulations, guidelines or frameworks in Norway that describe the intended AGN role. According to Maier et al. (13), a lack of regulation can lead to wide variations in the scope of practice and limit role clarity, which in turn prevents the integration of NPs. The AGNs explained in the interviews that their role and scope of practice was not clear among their colleagues, and a majority of the AGNs' colleagues also stated in the survey that the AGNs' scope of practice was unclear (Sub-study III). The lack of clarity around the role and scope of practice is found in the literature to hinder the integration of NPs $(23,29,31)$. Therefore, it is likely that the lack of regulations is hindering the integration of AGNs into Norwegian healthcare services. 
As discussed earlier in this chapter, team support appears to be a facilitator for the integration of AGNs. Both the first and third sub-studies indicate that the remaining factors (planning, team consensus, collaboration and organisational structure) from the framework of NP integration developed by Contandriopoulos et al. (31) were not addressed appropriately when the AGNs were introduced into Norwegian healthcare services. More specifically, the results of the first and third sub-studies indicate that planning has not been sufficient to make the necessary organisational adjustments to establish a role and scope of practice regarding which the AGNs and their colleagues have reached consensus. The lack of planning for how new NP roles should be integrated into the workplace seems to be an issue for NP integration $(23,30$, $31,69)$, and this lack of planning at the AGNs' workplaces does not differ from that at other workplaces that have hired an NP for the first time. However, contrary to the findings of international research (155-158), the majority of the colleagues in the present study were not in the habit of collaborating with AGNs or facilitating contact between patients and the AGN (Sub-study III). Overall, it appears as if there has not been sufficient planning on how to integrate AGNs, achieve role consensus, establish a collaborative relationship between AGNs and their colleagues and adjust the organisational structure in the workplace to accommodate an AGN role. It seems that these factors have acted as barriers to the integration of AGNs. Nevertheless, research shows that these factors can become facilitators for integration if addressed appropriately $(23,31)$.

Overall, the international literature has found that it is time-consuming to integrate a new role into a workplace where relationships, roles, scope of practice and work patterns have already been established $(26,31,122)$. Moreover, it is time-consuming to go through a role transition to change one's role from that of RN to NP $(65,66)$. On the occasion of the recruitment of AGNs to participate as informants and during the interviews, several of the AGNs who had been practicing for less than a year stated that they did not see themselves as an AGN and that they did not have an AGN role or a position as an AGN at their workplaces. Such statements by the AGNs indicate that their workplace conditions had not allowed them to go through a role transition. One interpretation of why the AGNs did not see themselves as AGNs may be that they had not had sufficient time to go through a transition process from RN to AGN. A partial role transition from $\mathrm{RN}$ to AGN may also explain why the AGN role is unknown among the colleagues (Sub-studies I and II). The lack of sufficient time to go through a role transition from $\mathrm{RN}$ to AGN may therefore have hindered the AGNs that participated in this 
study from becoming fully integrated into their workplaces at the time the studies were conducted.

To summarise, several external and internal factors affected the AGNs' level of integration (Figure 2). In Paper III, which focuses on the integration of AGNs, I have not included any internal factors as none were identified in any studies during the literature searches that indicated that internal factors also affect NPs' level of integration.

\begin{tabular}{|l|}
\hline \multicolumn{1}{|c|}{ External factors } \\
\hline - Regulation of the AGN's role and scope \\
of practice \\
- The planning process done at the \\
workplace to introduce the AGN \\
- Level of consensus at the workplace on \\
the AGN's role and scope of practice \\
- The collaboration culture at the workplace \\
- Acceptance and support of the new AGN \\
role at the workplace \\
- The organisational structure at the \\
workplace
\end{tabular}

\begin{tabular}{|l|}
\hline \multicolumn{1}{|c|}{ Internal factors } \\
\hline - The number of valuable services the AGN \\
provides \\
- The AGN's ability to show \\
approachability
\end{tabular}

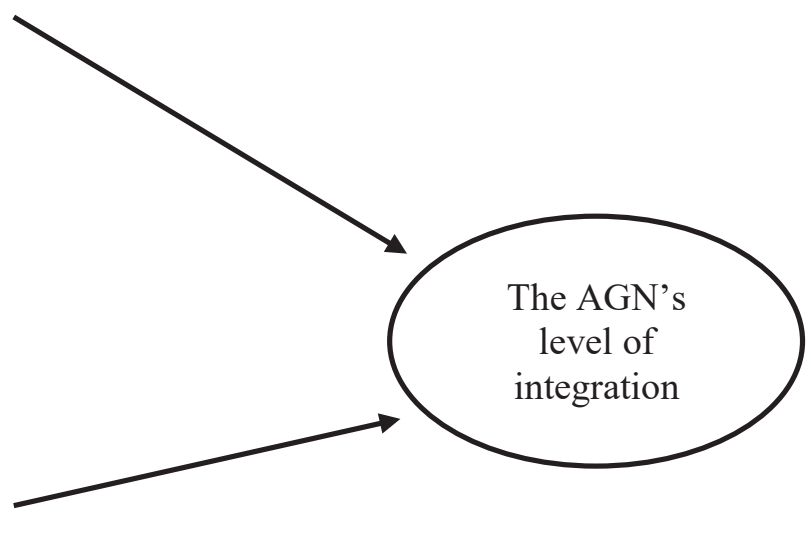

Figure 2 Flowchart of factors that may affect the AGN's level of integration

\subsubsection{The importance of the study for the further development of advanced practice nursing}

This thesis has focused specifically on AGNs, who are NPs with a specialisation in the care of older adults. As a part of their education, AGNs receive advanced teaching in subjects such as pharmacology, pathophysiology, physical assessment and clinical diagnosis adjusted for older adults. In the interviews, the AGNs portrayed the care of older adults as complex and knowledge-intensive; however, the AGNs reported that they were not aware of this before their AGN education, which indicates that detailed knowledge about older adults is important for grasping and meeting the full range of older adults' needs. The AGNs expressed in the interviews that they view the care of older adults as exciting and are motivated to work in the field. The description of the role and scope of practice of the AGNs in Section 6.1.1 explains 
that the education of colleagues is a central part of the AGN's role and that colleagues saw the AGNs as knowledgeable RNs that they want to learn from. The colleagues' desire for AGNs to teach them can be understood as recognition that there is a need to increase the knowledge and skills of healthcare providers who care for older adults. Several Norwegian healthcare reforms $(1-3,16,159)$, an OECD report (5) and a literature review (14) also assert that there is a need for increased knowledge and skills among healthcare providers caring for older adults to ensure that high-quality services are provided. This study shows that AGNs already contribute sufficient knowledge and skills to the care of older adults to healthcare providers and thus contribute to meeting the need indicated by the healthcare reforms and the OECD report.

As described in the background chapter, the master's degree programme in advanced practice nursing at the University of Oslo, which educates AGNs, had its last student admission in the autumn of 2019. Instead, a new master's degree programme is planned focusing on family care, which is in line with the Norwegian Directorate of Health's recommendation for the development of advanced practice nursing in Norway. Research indicates that there is a need for NPs with broad expertise as the practice of RNs working in primary care has become increasingly advanced, and RNs are performing activities that were previously performed only in hospitals (45). In addition, the complexity of patient trajectories is increasing, and the care provided is frequently fragmented, which studies indicate can lead to inadequate followup and care $(45,160,161)$. An analysis of primary care patients' care needs in Norway found that the oldest patients are among the patient groups that often have comprehensive care needs (162), and as shown in the background chapter of this thesis and by the results of this study, the care provided to older adults can be described as unique and complex.

It is debatable whether two years of education is enough for the graduated NPs from the new master's degree programme to acquire sufficient knowledge and skills to cover all possible groups that can be included in the broad age range targeted. It is unknown whether the AGNs would have the same amount of knowledge and skills related to the care of older adults that they have today if they were to focus on all possible groups that can be included in the broad age range targeted during their education. Based on the programme description for the new master's degree programme focusing on family care (116), it is reasonable to assume that the graduated NPs will have less knowledge about the care of older adults than the AGNs. It is therefore debatable whether it is likely that family care NPs will have sufficient knowledge 
about the care of older adults in order to ensure that high-quality services are provided to older adults and thus remain in line with healthcare reforms $(1-3,16,159)$. It is important to have a discussion about whether the programme should maintain a degree of specialisation that is distinct to particularly vulnerable groups. Perhaps it is appropriate to offer a programme that combines a generally raised level of knowledge and skills for RNs with an optional specialisation in which the care of older adults is one of the areas that can be chosen as a specialisation. Such an educational programme may contribute to providing the graduated NPs with sufficiently specialised knowledge and skills for the patient group they care for, and it may improve the quality of the services provided to the specific patient group.

Although the focus of this study is on AGNs, part of the results are relevant to Norwegian NPs with specialisations other than the care of older adults. For example, the NP role is not well established in the Norwegian healthcare service. Therefore, the role-transition process and establishment of an NP role and a formal position that allow for the best possible utilisation of Norwegian NPs' knowledge and skills will probably be challenging for all Norwegian NPs, independent of any field of specialisation. The AGNs' experiences related to the strategies that they described as important to developing their roles were probably not related to the care of older adults but to how to develop a new role at a workplace where the other employees already have established roles and responsibilities. Therefore, the AGNs' descriptions of the strategies employed to develop their role are probably relevant to all Norwegian NPs that are striving to develop an NP role in the workplace.

Also, in all likelihood, the results related to the colleagues' knowledge about the AGNs' role and scope of practice and the collaboration between the AGNs and their colleagues were not related to the AGNs' field of specialisation but to other factors (Sub-study III). It is likely that the planning phase related to the information disseminated about a new AGN's intended role and scope of practice and the collaborative culture at the workplace are more important to their colleagues' knowledge about the AGNs' role and scope of practice than the AGN's field of specialisation. As highlighted by Contandriopoulos et al. (31) and discussed earlier in this chapter, there seems to be a need for workplaces that want to integrate an NP to place a strong focus on the planning process regarding how to develop a new NP role and familiarise the employees at the NP's workplace with it.

As highlighted in Paper I, the municipalities of most of the AGNs who graduated in 2014 have collaborated with the University of Oslo, which educates AGNs on how to develop an 
AGN role. Despite this collaboration, the results indicate that there was not sufficient planning on how to integrate the AGNs, achieve role consensus, establish a collaborative relationship between the AGNs and their colleagues or adjust the organisational structure in the workplace to accommodate an AGN role (Sub-studies I and III). Nevertheless, as Paper I emphasises, the AGNs who graduated in 2014 had a more well-defined AGN role than the AGNs who graduated in either 2015 or 2016 . Based on this finding, educational institutions that prepare NPs should be encouraged to place a strong focus on the establishment of a collaborative relationship with their NP students' workplaces to stimulate those workplaces to plan, achieve role consensus, establish collaboration and adjust the organisational structure. In addition, the educational institutions should be encouraged to familiarise their students with the strategies presented in Sub-study I that can be valuable to NP students in their role transition from RN to NP and to inform the AGN students of the factors that may affect integration (summarised in Figure 2, p. 47). Dissemination of these strategies and factors could contribute to preparing NP students for what they can expect after graduation and what to focus on to establish their new role as AGN at their future workplaces. The University of Oslo has introduced certain strategies and factors as part of their educational programme, but the effect of the implementation has not been examined yet.

Although the AGNs associated the 'gaze' they described in the interviews with the care of older adults, the AGNs' description of this gaze indicates that more knowledge provided via education enables professionals to see the patients, relatives and system in which they work from a new perspective. The interviews with the AGNs reveal that this perspective was related to disease prevention and health promotion. This new, knowledge-based perspective will differ slightly among NPs who are educated in different educational programmes targeting different patient groups as the knowledge they acquire will be related to specific patient groups. Therefore, the NPs who will graduate from the new master's degree programme focusing on family care will most likely have a slightly different gaze than the AGNs. Nevertheless, the interviews indicate that increased knowledge results in the ability to work more effectively in promoting health and preventing disease; therefore, it is likely that the NPs' gaze will also be related to health promotion and disease prevention.

To summarise, the findings of this study indicate that healthcare providers who care for older adults perceive the field as complex, and there seems to be a need for RNs with sufficient knowledge and skills in the care of older adults, such as AGNs, to ensure that high-quality 
services are provided. This section suggests that even though this study has a specific focus on NPs caring for older adults, part of the results can also be relevant to the development of the role of NPs with specialisations other than the care of older adults.

\subsection{Methodological considerations}

This section presents a discussion of relevant methodological considerations regarding mixed methods design, sampling procedures and representativeness as well as the trustworthiness, validity and reliability of the results of this thesis.

\subsubsection{Mixed methods design}

Creswell and Creswell (127) argue that when using an exploratory sequential mixed methods design, it is best that the sample in the qualitative phase not be included in the quantitative phase as this can introduce confounding factors into the study. Because of the low number of AGNs in Norway, I chose to include the AGNs from the qualitative phase in the quantitative phase as well. However, in this study, I consider the inclusion of all the AGNs in both phases to be a strength as the total population of AGNs in Norway has thereby been included, which means that results of the questionnaires are based on the AGNs' opinions as a group instead of only a few AGNs. According to Creswell and Plano Clark (126), a major challenge of the exploratory sequential mixed methods design is that the approach requires considerable time to conduct the qualitative study, develop the questionnaires based on the qualitative results, conduct the quantitative study and interpret the connected results. At the same time, the phases of the design are separated, which in the case of the present study made describing and reporting the three sub-studies manageable compared to other mixed methods designs in which the qualitative and quantitative data are conducted and reported simultaneously.

A strength of the exploratory sequential mixed methods design of this study is that the questionnaires were developed based on the findings of the qualitative data. According to Creswell and Plano Clark (126), questionnaires based on experiences from interviews with a sample of potential respondents are more likely to be seen as relevant by the responders to the questionnaires. The potential responders who tested the questionnaires in this study also seem to have seen the questionnaires as relevant as they had few comments on them, although the questionnaires were changed in line with what comments there were. This method of questionnaire development has resulted in questionnaires that are adapted to the field of the care of older adults and what is unique to the Norwegian context. 


\subsubsection{Sampling procedures and representativeness}

The total population of AGNs in 2016 participated in the qualitative interview study reported in Paper I. Five more AGNs graduated in 2017. The total population of AGNs in 2017 was invited to participate in the quantitative survey study reported in Papers II and III, but three AGNs declined to participate. The AGNs who did not answer the questionnaire are graduates from different years. One of the AGNs explained that a lack of time to answer the questionnaire was the reason for not participating, but I do not know why the other AGNs refused to participate nor if they shared specific characteristics. Response rates also tend to be lower in Internet surveys compared to face-to-face interviews, and people are more likely to participate when asked in person (163), as demonstrated by the AGNs who participated in the qualitative and quantitative data collection.

Colleagues were recruited from 16 units. However, leaders in 19 different units were asked to recruit people to participate in the study. I phoned the three leaders who did not want to participate in the study to discuss whether I or someone else could assist them in recruiting participants. The leaders stated that they lacked the time and resources to participate in the study and that there was nothing I could do to assist them. As with the units of the AGNs who did not want to participate in the quantitative survey study, I do not know whether these units share specific characteristics that are different from the units of the participants in the study, especially since both the participating and non-participating units represent both hospital and primary care. I therefore assume that the units that participated in the quantitative survey study are representative of the units that the AGNs work in.

As discussed in Papers II and III, I am not sure whether the responding colleagues are representative of the population of AGNs' colleagues. The recruiters were asked to keep track of those who did not want to participate in the study, but only some of them did so. The number of available colleagues in each case is therefore unknown. It is also unknown how many colleagues were asked to participate by their leaders but refused and whether these individuals had the same occupation. The lack of information regarding the non-participating colleagues has hampered the ability to check for nonresponse-bias differences between participants and those who declined to participate (163). Another limitation is that it is uncertain whether the leaders followed the inclusion criteria, which were developed to ensure variability when they recruited colleagues. Some AGNs participated in recruiting colleagues, and one hypothesis is that the colleagues recruited by AGNs had better knowledge about the 
AGNs compared to those who were not recruited by one. Another hypothesis is that the AGNs learned about the importance of following inclusion criteria for participating in research during their master's degree programme and therefore followed the criteria more strictly than recruiters without this knowledge. However, the AGNs might also have recruited individuals with whom they had a good relationship and collaborated well.

When discussing sampling procedures and representativeness, the participants' motivation to participate must be considered. Clark (164) has shown that there are several reasons for participating in qualitative research. Some motivations to participate are related to engaging on an individual level, such as the chance to express an opinion on subjects of one's interest, satisfy one's curiosity, the pleasure of participating, individual empowerment, the opportunity to share one's thoughts and experiences with a sympathetic listener, social comparison, the opportunity to compare one's experiences with similar but unconnected others and therapeutic interest (164). Other motivating reasons for participating in qualitative research are related to the collective level, such as the opportunity to represent and give a voice to a group of people, political empowerment and to influence a change in some area of policy or professional practice (164). Even though participation in the study was voluntary, the AGNs may have been motivated to participate by several of these reasons. All the AGNs were willing to be interviewed and expressed gratitude when I met them. They stated that they wanted to contribute to putting advanced geriatric nursing on the agenda and to make it well known and recognised in Norway. By participating, the AGNs could themselves 'decide' how their role and scope of practice were outlined in the research literature, which would probably be of value to them. It is also likely that the colleagues had a subjective interest in participating in the study as the questions in the questionnaire concerned their daily practice. In addition, the survey gave the colleagues the opportunity to express what they see as appropriate activities for AGNs and thus affect what is outlined in existing research as the appropriate scope of practice for AGNs. The results of the three sub-studies correspond well with similar studies, and it therefore seems that the motivations to participate did not affect the representativeness of the participants.

\subsubsection{Trustworthiness, validity and reliability Qualitative approach}

To demonstrate the trustworthiness of the qualitative results, I followed some general principles known to add credibility to the analysis of qualitative data. To ensure transparency, 
Paper I has a thorough description of the data analysis procedure used, which included 'conventional content analysis', as described by Hsieh and Shannon (137), and examples of how NVivo Version 11 (138) was used to structure codes and categories from the transcribed text $(165,166)$. To promote the validity of our interpretations, we sought to include quotes in the results section of Paper I with sufficient context for the reader to assess the different interpretations (165-167). To ensure the reliability of the interpretations of the transcribed text, I and one of my supervisors read and coded the text separately and met to discuss our interpretations. The reliability of the interpretations was further promoted by discussing the evolving analysis and interpretation with the entire research team, which resulted in a consensus on the published results $(165,166)$. The reliability of the interpretations was also increased by including examples of how the transcribed interviews evolved from raw data to codes, subcategories and main categories $(165,166)$. Although I followed Elo and Kyngas's (165) and Green and Thorogood's (166) recommendations on how to ensure the validity and reliability of interpretations, there is a possibility that our previous experiences have affected our interpretation of the data. All the research team members are employed at the department that educates AGNs, and there has been a strong focus in the department on promoting the role of AGNs. The transparency of the data analysis procedure has therefore been emphasised in this study so that the reader can assess the validity of the various interpretations.

\section{Quantitative approach}

In retrospect, I have reflected on whether the questionnaires were suitable to achieve the overall aim and answer the research questions of this thesis. The questionnaires were designed as data collection tools with descriptive questions based on interviews with the AGNs and were informed by earlier research and literature regarding the integration of NPs and their scope of practice. As highlighted in the description of the development of the questionnaires, each question and response option was developed based on the literature and interviews with the AGNs and was critically evaluated by the research team and potential respondents. Despite these efforts to ensure the clarity and relevance of the included items, we see in hindsight that the respondents could have interpreted some questions differently. For example, the AGNs were asked questions about the degree to which they estimated that they used their knowledge and skills related to different functions. The wording of the questions is quite clear, but what is meant by the functions could have been interpreted differently by the AGNs as the functions are not all operationalised on the same level of specificity. Some activities that are related to the functions are very specific, while others are broad patient 
situations that could have generated differences in the AGNs' interpretation. The AGNs followed the same educational programme, which might have led to a common understanding of what is meant by the functions. Nevertheless, I recognise that the AGNs might have had different interpretations of the functions that could have affected their estimations of how they used their knowledge and skills. Another example of questions that could have been interpreted differently by the respondents regards whether different activities were appropriate or not. The respondents could have based their answers to the activity questions on considerations of whether the AGNs are capable of performing the activities based on their perceptions of the AGNs' knowledge and skills. Another possibility is that the respondents could have based their answers on their perceptions of whether there is a need for a healthcare provider to perform the activities at the workplace and whether they consider the AGN to be the appropriate healthcare provider. Thus, the possibility of interpreting some questions in different ways may have affected the validity of the questionnaires. It is important to emphasise that the questionnaires were pilot-tested for content and face validity and that none of the testers expressed confusion about what was meant by the questions. Still, I acknowledge that some questions may have generated different associations.

Another weakness of the questionnaires developed for this study is the operationalisation of the factors that are identified as affecting integration. In order to examine the planning process carried out at the workplace to introduce the AGNs and whether there was consensus at the workplace on the AGNs' role and scope of practice, the colleagues were asked whether they knew who the AGN was at the workplace, whether they felt adequately informed about the AGNs' role and scope of practice and whether the AGNs' scope of practice was clear. The collaborative culture at the workplace was examined by asking the colleagues how often they collaborated with the AGNs and the degree to which they facilitated contact between patients and AGNs. The question about the degree to which colleagues believed that the role and scope of practice of AGNs contributed positively to health service provision was used as an indication of the acceptance and support of the AGNs' role in the workplace. In retrospect, I acknowledge that acceptance and support have, to a lesser degree, been examined through the included question. According to my understanding of integration (see Section 2.3), the degree to which AGNs are included in the daily practice of health services for older adults is essential to their degree of integration. The degree to which AGNs are included in daily practice can be seen as an indication of the degree to which colleagues accept and support the AGNs' role in the workplace. It could therefore also have been relevant to ask about the 
degree to which the AGNs are included in the daily practice of health services for older adults. In order to determine whether the organisational structure at the workplace was adjusted to accommodate a role that ensured the optimal use of the AGNs' knowledge and skills, the AGNs were asked what type of position they had and the degree to which they used their knowledge and skills. The position was chosen as an indication of organisational structure as the AGNs specifically stated in the interviews that it was important that they had a position that gave them the opportunity to prioritise their own agenda. In retrospect, I acknowledge that it could have been relevant to also include a question about whether the AGNs had a position that allowed them to prioritise their own agenda.

Although the questionnaires were developed based on interviews with the AGNs and previous literature and were tested for content and face validity, the discussion of the results in Section 6.1.2 indicates that I have not included all the factors that may have affected the integration of the AGNs. Specifically, I have not included two internal factors: the amount of valuable services the AGN provides and the AGNs' ability to show approachability. If I were to start over again on my $\mathrm{PhD}$, I would change the questionnaire content and include these two internal factors as they might also affect the integration of the AGNs. In addition, I would include the two questions suggested in the previous paragraph, which could contribute to a more complete operationalisation of how the workplace is organised structurally and how the AGN's role is accepted and promoted. In retrospect, I see that other angles in the analysis of the interviews could have led to the inclusion of other questions in the questionnaires.

Despite the methodological considerations in this section, I have assessed the questionnaires as having provided relevant information about the degree to which the AGNs are integrated into their workplaces and whether various activities are appropriate to include in the AGNs' scope of practice. The questionnaires can therefore be deemed suitable for this study as I had data that contributed to achieving the overall aim and answering the research questions. Furthermore, the integration factors from Contandriopoulos et al. (31) upon which the questionnaires are based are independent of NP specialisation; therefore, the questionnaires are probably also appropriate for the new NPs who will be educated in Norway. However, the questionnaires should first be further developed according to the discussion in this section.

To summarise, this discussion of the methodological considerations regarding this study indicates that the choice to use an exploratory sequential mixed methods design has resulted in the development of questionnaires that are adapted to the field of the care of older adults 
and to the Norwegian context. It also seems as if the participating AGNs are representative of the group of AGNs as the total population of AGNs participated in the interviews and almost the total population of AGNs answered the survey. It is unsure whether the participating colleagues are representative of the total population of AGNs' colleagues, but it is likely that the colleagues' motivations to participate do not threaten the study's external validity. This section suggests that the qualitative and quantitative approaches used in this study have contributed to the reliability of the results of the three sub-studies presented above. 


\section{Conclusions}

The three sub-studies of this thesis have investigated the role of newly introduced NPs in Norway known as AGNs, what AGNs and their collaborators see as an appropriate scope of practice for AGNs and the AGNs' integration into the Norwegian healthcare system. The results of the three sub-studies have shown that the AGNs have a multifaceted role and a broad scope of practice that include direct and indirect care, coordination, teaching/supervision and research and development work. Despite this multifaceted role, the AGNs state that their main focus is on direct care. This multifaceted role and scope of practice are desired by the AGNs, their colleagues and their leaders. The results of this study provide grounds for asserting that a master's degree education for RNs in the care of older adults is justified as the sub-studies indicate that AGNs and their colleagues and leaders agree on the need for RNs with advanced knowledge and skills in the care of older adults in Norway.

The concept of integration has been central to the current study. In this context, integration has been seen as an expression of the use of the AGNs' knowledge and skills and their acceptance and inclusion among their colleagues in the workplace. The current study has described how external and internal factors may affect the AGNs' level of integration and thus the use of their knowledge and skills. By combining the results of the first and third substudies, it has become clear that the AGNs do not consider that they use their knowledge and skills to their full potential and that they are not always included in the daily practice at their workplaces. Therefore, there is a need to place greater focus on how to integrate AGNs into the Norwegian healthcare system. The results of this study indicate that there is a need to regulate advanced practice nursing in Norway in a way that promotes the following: the utilisation of the AGNs' knowledge and skills, the clarification of the AGN role and scope of practice, improvement of the collaboration between AGNs and their colleagues and adjustments of organisational conditions that facilitate the full use of AGNs' knowledge and skills and lends support to the AGNs in their role transition from RN to AGN.

\subsection{The significance of the study in today's health debate on advanced practice nursing}

As described in this thesis, the Ministry of Education and Research and the Ministry of Health and Care Services have recently started to regulate advanced practice nursing education in Norway and to give accreditation to family care NPs. During the process of regulating 
advanced practice nursing education in Norway, public debates have been conducted in newspapers and nursing and medical magazines about the role and scope of practice NPs should have in Norway. There is no previous research related to the NP role in Norway; therefore, many of the contributions to the debate are based on personal experience and opinions. Several of the contributions have highlighted that the role and scope of practice that the Norwegian health authorities intend for the new NPs is unclear.

The current study supports the impression that the role and scope of practice of NPs specialised in the care of older adults are unclear among healthcare providers in Norway. The above-mentioned lack of clarity in public debates indicates that there is a need for thoughtful deliberation regarding what role and scope of practice are appropriate for the AGNs to meet the identified and unmet needs. Norwegian healthcare reforms $(1-3,16,159)$ have identified that there is a need for increased knowledge and skills among healthcare providers caring for older adults to ensure that high-quality services are provided to this patient group. Two $(1,16)$ of the reforms specifically mention that NPs have the potential to play an extended role in healthcare services and contribute to a closer follow-up of older adults with complex needs. This study portrays AGNs as enthusiastic, knowledgeable RNs who focus on systematic quality improvement by providing direct care to older adults and by disseminating their knowledge and skills through clinical advising and teaching to students and colleagues. The AGNs thus seem to be important in meeting the need for increased knowledge and skills described in the healthcare reforms $(1-3,16,159)$. As discussed, it is uncertain whether NPs with a specialisation in family care will have sufficient knowledge and skills related to the care of the elderly to meet older adults' complex healthcare needs. The results of the first and third sub-studies suggest that there is a need for an NP education in which the students can choose different fields of specialisation and in which the care of older adults is one of the areas of specialisation.

\subsection{Future research}

The role and scope of practice of AGNs in Norway is continually developing, and, based on the number of AGN students enrolled in the educational programme, it is expected that within two years' time, the number of AGNs will double. At the moment, the Ministry of Health and Care Services is focused on the development of advanced practice nursing in Norway. It could therefore be fruitful to follow up on the integration of AGNs in a few years' time to evaluate whether they have been successfully integrated into the Norwegian healthcare 
services as desired by educational institutions that offer accreditation programmes in advanced practice nursing and by the Ministry of Health and Care Services. The collected data can also be used as the basis for a study that investigates the effect of regulation on integration.

The first and third sub-studies have underlined the need for organisational adjustments at the AGNs' workplaces, although the types of adjustments needed have not been elaborated. There is therefore a need to further investigate the type of organisational adjustments needed in order for AGNs to use their knowledge and skills to their full potential and be included on the appropriate level among other healthcare providers in the daily practice of health services for older adults. Research should also be conducted to investigate the consequences of implementing this new role in the care of older adults as we do not have sufficient knowledge about the contributions AGNs make to patient outcomes. One opportunity could be to explore patients' and relatives' experiences with the AGN role as the individual patient is seen as an expert on her/his body, symptoms and situations, and her/his participation is recognised as vital to the success of treatment and the improvement of the quality of care (168). Another could be to perform effect studies on the contribution of the AGN's role in the Norwegian context. As described in Section 2.2.1, NPs' roles differ from context to context, and the AGNs' contribution might therefore be different from the effect of the NP role depicted in the section. Last but not least, since the AGN education is planned to be changed in line with the new programme description for a programme focusing on family care, research should be conducted to explore whether the new NPs with a specialisation in family care have sufficient knowledge and skills to meet older adults' complex healthcare needs. It could also be interesting to compare the contributions of the AGN role with that of the NP family care role in the care of older adults. 


\section{References}

1. Report to the Storting No. 26 (2014-2015). The primary health and care services of tomorrow - localised and integrated. Oslo: Norwegian Ministry of Health and Care Services. 2. Report to the Storting No. 25 (2005-2006). Mestring, muligheter og mening: Framtidas omsorgsutfordringer [Coping, opportunities and meaning: Future care challenges]. Oslo: Norwegian Ministry of Health and Care Services.

3. Report to the Storting No. 47 (2008-2009). Samhandlingsreformen: Rett behandling på rett sted - til rett tid [The coordination reform - Proper treatment - at the right place and right time]. Oslo: Norwegian Ministry of Health and Care Services.

4. Report to the Storting No. 9 (1974-75). Sykehusutbygging m.v. i et regionalisert helsevesen [Hospital development etc. in a regionalised health care system]. Oslo: Ministry of Social Affairs.

5. OECD. OECD Reviews of Health Care Quality: Norway 2014. Paris: OECD Publishing; 2014.

6. Sheer B, Wong FK. The development of advanced nursing practice globally. J Nurs Scholarsh. 2008;40(3):204-11.

7. Heale R, Rieck Buckley C. An international perspective of advanced practice nursing regulation. Int Nurs Rev. 2015;62(3):421-9.

8. Pulcini J, Jelic M, Gul R, Loke AY. An international survey on advanced practice nursing education, practice, and regulation. J Nurs Scholarsh. 2010;42(1):31-9.

9. Delamaire M-L, Lafortune G. Nurses In Advanced Roles: A Description And Evaluation Of Experiences In 12 Developed Countries. Paris: OECD Publishing. 2010.

10. Fougere B, Morley JE, Decavel F, Nourhashemi F, Abele P, Resnick B, et al. Development and Implementation of the Advanced Practice Nurse Worldwide With an Interest in Geriatric Care. J Am Med Dir Assoc. 2016;17(9):782-8.

11. Boerma WGW. Coordination and integration in European primary care. In: Saltman RB, Rico A, Boerma WGW, editors. Primary Care In The Driver's Seat? Organizational Reform In European Primary Care. Berkshire, UK: Open University Press; 2006. p. 3-21. 12. Kringos DS, Boerma WGW, Hutchinson A, Saltman RB. Building primary care in a changing Europe. Copenhagen, Denmark: European Observatory on Health Systems and Policies. 2015. 172 p.

13. Maier CB, Aiken LH, Busse R. Nurses in advanced roles in primary care: Policy levers for implementation. Paris: OECD Publishing. 2017.

14. Kiljunen O, Valimaki T, Kankkunen P, Partanen P. Competence for older people nursing in care and nursing homes: An integrative review. Int J Older People Nurs. 2017;12(3):e12146.

15. Bing-Jonsson PC, Hofoss D, Kirkevold M, Bjork IT, Foss C. Sufficient competence in community elderly care? Results from a competence measurement of nursing staff. BMC Nurs. 2016;15:5.

16. Report to the Storting No. 15 (2017-2018). A full life - all your life - A Quality Reform for Older Persons. Oslo: Norwegian Ministry of Health and Care Services.

17. Report to the Storting No. 7 (2020-2023). Nasjonal helse- og sykehusplan 2020-2023 (National health and hospital plan 2020-2023). Oslo: Norwegian Ministry of Health and Care Services.

18. Hamric AB. A definition of advanced practice nursing. In: Hamric AB, Hanson CM, Tracy MF, O'Grady ET, editors. Advanced practice nursing: An integrative approach. 5th ed. St. Louis: Elsevier; 2014. p. 67-85. 
19. Tracy MF. Direct Clinical Practice. In: Hamric AB, Hanson CM, Tracy MF, O'Grady ET, editors. Advanced Practice Nursing: An Integrative Approach. 5th ed. St. Louis: Elsevier; 2014. p. 147-82.

20. Wisur-Hokkanen C, Glasberg AL, Makela C, Fagerstrom L. Experiences of working as an advanced practice nurse in Finland - the substance of advanced nursing practice and promoting and inhibiting factors. Scand J Caring Sci. 2015;29(4):793-802.

21. International Council of Nurses. Definition and Characteristics of the Role [Internet]. 2019. Available from: http://international.aanp.org/Practice/APNRoles.

22. Thomas A, Crabtree MK, Delaney K, Dumas MA, Kleinpell R, Marfell J, et al. Nurse practitioner core competencies content 2017. Available from:

http://c.ymcdn.com/sites/www.nonpf.org/resource/resmgr/competencies/2017_NPCoreComps -with_Curric.pdf.

23. Sangster-Gormley E, Martin-Misener R, Downe-Wamboldt B, Dicenso A. Factors affecting nurse practitioner role implementation in Canadian practice settings: an integrative review. J Adv Nurs. 2011;67(6):1178-90.

24. Stolee P, Hillier LM, Esbaugh J, Griffiths N, Borrie MJ. Examining the nurse practitioner role in long-term care: evaluation of a pilot project in Canada. J Gerontol Nurs. 2006;32(10):28-36.

25. de Guzman A, Ciliska D, DiCenso A. Nurse practitioner role implementation in Ontario public health units. Can J Public Health. 2010;101(4):309-13.

26. Jean E, Sevilla Guerra S, Contandriopoulos D, Perroux M, Kilpatrick K, Zabalegui A. Context and implementation of advanced nursing practice in two countries: An exploratory qualitative comparative study. Nurs Outlook. 2019;67(4):365-80.

27. Carter N, Martin-Misener R, Kilpatrick K, Kaasalainen S, Donald F, Bryant-Lukosius $\mathrm{D}$, et al. The role of nursing leadership in integrating clinical nurse specialists and nurse practitioners in healthcare delivery in Canada. Nurs Leadersh (Tor Ont). 2010;23 Spec No 2010:167-85.

28. Poghosyan L, Nannini A, Smaldone A, Clarke S, O'Rourke NC, Rosato BG, et al. Revisiting scope of practice facilitators and barriers for primary care nurse practitioners: a qualitative investigation. Policy Polit Nurs Pract. 2013;14(1):6-15.

29. Sangster-Gormley E, Martin-Misener R, Burge F. A case study of nurse practitioner role implementation in primary care: what happens when new roles are introduced? BMC Nurs. 2013;12:1.

30. Bryant-Lukosius D, Dicenso A, Browne G, Pinelli J. Advanced practice nursing roles: development, implementation and evaluation. J Adv Nurs. 2004;48(5):519-29.

31. Contandriopoulos D, Brousselle A, Dubois CA, Perroux M, Beaulieu MD, Brault I, et al. A process-based framework to guide nurse practitioners integration into primary healthcare teams: results from a logic analysis. BMC Health Serv Res. 2015;15:78.

32. Andregard AC, Jangland E. The tortuous journey of introducing the nurse practitioner as a new member of the healthcare team: a meta-synthesis. Scand J Caring Sci. 2015;29(1):314.

33. Poghosyan L, Nannini A, Stone PW, Smaldone A. Nurse practitioner organizational climate in primary care settings: implications for professional practice. J Prof Nurs. 2013;29(6):338-49.

34. Brown MA, Draye MA. Experiences of Pioneer Nurse Practitioners in Establishing Advanced Practice Roles. J Nurs Scholarsh. 2003;35(4):391-7.

35. Jokiniemi K, Haatainen K, Pietila AM. From challenges to advanced practice registered nursing role development: Qualitative interview study. Int J Nurs Pract. 2014. 
36. Jangland E, Yngman Uhlin P, Arakelian E. Between two roles - Experiences of newly trained nurse practitioners in surgical care in Sweden: A qualitative study using repeated interviews. Nurse Educ Pract. 2016;21:93-9.

37. Hallman E-B, Gillsjö C. Avancerad specialistsjuksköterska; från idé till verklighet. Vard Nord Utveckl Forsk. 2005;25(3):76-8.

38. Fagerstrom L. Developing the scope of practice and education for advanced practice nurses in Finland. Int Nurs Rev. 2009;56(2):269-72.

39. Ringard A, Sagan A, Sperre Saunes I, Lindahl AK. Norway: health system review. Health systems in transition. 2013;15(8):1-162.

40. Statistics Norway. Users of nursing and care services, by age and kind of service (C) 2007-2018 Oslo: Statistics Norway; 2019. Available from:

https://www.ssb.no/en/statbank/table/06969/.

41. Ruiz M, Bottle A, Long S, Aylin P. Multi-Morbidity in Hospitalised Older Patients: Who Are the Complex Elderly? PLoS One. 2015;10(12):e0145372.

42. Naess G, Kirkevold M, Hammer W, Straand J, Wyller TB. Nursing care needs and services utilised by home-dwelling elderly with complex health problems: observational study. BMC Health Serv Res. 2017;17(1):645.

43. Zwijsen SA, Nieuwenhuizen NM, Maarsingh OR, Depla MF, Hertogh CM.

Disentangling the concept of "the complex older patient" in general practice: a qualitative study. BMC Fam Pract. 2016;17(1):64.

44. Inouye SK, Studenski S, Tinetti ME, Kuchel GA. Geriatric Syndromes: Clinical, Research, and Policy Implications of a Core Geriatric Concept. J Am Geriatr Soc. 2007;55(5):780-91.

45. Melby L, Obstfelder A, Helleso R. "We Tie Up the Loose Ends": Homecare Nursing in a Changing Health Care Landscape. Global qualitative nursing research.

2018;5:2333393618816780.

46. Bing-Jonsson PC, Bjork IT, Hofoss D, Kirkevold M, Foss C. Competence in advanced older people nursing: development of 'nursing older people - competence evaluation tool'. Int J Older People Nurs. 2015;10(1):59-72.

47. Bing-Jonsson PC, Hofoss D, Kirkevold M, Bjork IT, Foss C. Nursing Older People Competence Evaluation Tool: Development and Psychometric Evaluation. J Nurs Meas. 2015;23(1):127-53.

48. Hauge S, Hestetun M, Kirkevold M. Avansert geriatrisk sykepleie - hva er det og hvorfor trenger vi slike sykepleiere i Norge? [Advanced geriatric nursing - what is it and why do we need such nurses in Norway?]. Geriatrisk Sykepleie. 2011;3(1):20-3.

49. Jokiniemi K, Pietila AM, Kylma J, Haatainen K. Advanced nursing roles: A systematic review. Nurs Health Sci. 2012;14(3):421-31.

50. Cockerham AC, Keeling AW. A brief history of advanced practice nursing in the United States In: Hamric AB, Tracy MF, Hanson C, O'Grady E, editors. Advanced practice nursing: An integrative approach. 5th ed. St. Louis: Elsevier; 2014. p. 1-26.

51. International Council of Nurses. Frequently Asked Questions of the ICN International NP/APN Network [Internet]. 2019. Available from: http://international.aanp.org/Home/FAQ. 52. Hamric AB, Tracy MF, Hanson C, O'Grady E. Advanced practice nursing: An integrative approach. 5th ed. St. Louis: Elsevier. 2014. 726 p.

53. Schober M, Affara FA. International Council of Nurses: Advanced Nursing Practice. Oxford, UK: Blackwell Publishing Ltd; 2006. Available from:

https://ebookcentral.proquest.com/lib/oslo/detail.action?docID=284104.

54. Schober M. Introduction to Advanced Nursing Practice. Debout C, editor. Cham, Switzerland: Springer International Publishing. 2016. 166 p. 
55. Blair KA. Advanced Practice Nursing Roles: Core Concepts for Professional Development. 6th ed. New York: Springer Publishing Company. 2019. 326 p.

56. DiCenso A, Auffrey L, Bryant-Lukosius D, Donald F, Martin-Misener R, Matthews S, et al. Primary health care nurse practitioners in Canada. Contemp Nurse. 2007;26(1):104-15.

57. Pearson A, Peels S. The nurse practitioner. Int J Nurs Pract. 2002;8(4):5-9.

58. Lindblad E, Hallman EB, Gillsjo C, Lindblad U, Fagerstrom L. Experiences of the new role of advanced practice nurses in Swedish primary health care - A qualitative study. Int J Nurs Pract. 2010;16(1):69-74.

59. Msuya M, Blood-Siegfried J, Chugulu J, Kidayi P, Sumaye J, Machange R, et al. Descriptive study of nursing scope of practice in rural medically underserved areas of Africa, South of the Sahara. International Journal of Africa Nursing Sciences. 2017;6(C):74-82.

60. Lin LC, Lee S, Ueng SW, Tang WR. Reliability and validity of the Nurse Practitioners' Roles and Competencies Scale. J Clin Nurs. 2016;25(1-2):99-108.

61. Ono M, Miyauchi S, Edzuki Y, Saiki K, Fukuda H, Tonai M, et al. Japanese nurse practitioner practice and outcomes in a nursing home. Int Nurs Rev. 2015;62(2):275-9.

62. Yafa H, Dorit R, Shoshana R. Gerontological nurse practitioners (GNPs) for the first time in Israel: Physicians' and nurses' attitudes. J Am Assoc Nurse Pract. 2016;28(8):415-22. 63. Brown MA, Olshansky EF. From Limbo to Legitimacy: A Theoretical Model of The Transition to the Primary Care Nurse Practitioner Role. Nurs Res. 1997;46(1):46-51.

64. Brown MA, Olshansky E. Becoming a primary care nurse practitioner: challenges of the initial year of practice. Nurse Pract. 1998;23(7):46-56.

65. Barnes H. Nurse Practitioner Role Transition: A Concept Analysis. Nurs Forum. 2015;50(3):137-46.

66. MacLellan L, Levett-Jones T, Higgins I. Nurse practitioner role transition: a concept analysis. J Am Assoc Nurse Pract. 2015;27(7):389-97.

67. Faraz A. Novice Nurse Practitioner Workforce Transition Into Primary Care: A Literature Review. West J Nurs Res. 2016;38(11):1531-45.

68. Faraz A. Facilitators and barriers to the novice nurse practitioner workforce transition in primary care. J Am Assoc Nurse Pract. 2019;31(6):364-70.

69. Sullivan-Bentz M, Humbert J, Cragg B, Legault F, Laflamme C, Bailey PH, et al. Supporting primary health care nurse practitioners' transition to practice. Can Fam Physician. 2010;56(11):1176-82.

70. MacLellan L, Levett-Jones T, Higgins I. The enemy within: Power and politics in the transition to nurse practitioner. NursingPlus Open. 2016;2:1-7.

71. Hardy ME, Conway ME. Role Theory: Perspectives for Health Professionals. 2nd ed. Norwalk, Conn: Appleton \& Lange. 1988. 455 p.

72. Carryer J, Gardner G, Dunn S, Gardner A. The core role of the nurse practitioner: practice, professionalism and clinical leadership. J Clin Nurs. 2007;16(10):1818-25.

73. Bakerjian D. Care of nursing home residents by advanced practice nurses. A review of the literature. Res Gerontol Nurs. 2008;1(3):177-85.

74. Hendrix CC, Wojciechowski CW. Chronic care management for the elderly: an opportunity for gerontological nurse practitioners. J Am Acad Nurse Pract. 2005;17(7):263-7. 75. Grant J, Lines L, Darbyshire P, Parry Y. How do nurse practitioners work in primary health care settings? A scoping review. Int J Nurs Stud. 2017;75:51-7.

76. Abdallah LM. EverCare nurse practitioner practice activities: similarities and differences across five sites. J Am Acad Nurse Pract. 2005;17(9):355-62.

77. Gadbois EA, Miller EA, Tyler D, Intrator O. Trends in State Regulation of Nurse Practitioners and Physician Assistants, 2001 to 2010. Med Care Res Rev. 2015;72(2):200-19. 78. Martin-Misener R, Reilly SM, Vollman AR. Defining the role of primary health care nurse practitioners in rural Nova Scotia. Can J Nurs Res. 2010;42(2):30-47. 
79. Kaasalainen S, Ploeg J, McAiney C, Schindel Martin L, Donald F, Martin-Misener R, et al. Role of the nurse practitioner in providing palliative care in long-term care homes. Int $\mathrm{J}$ Palliat Nurs. 2013;19(10):477-85.

80. Ploeg J, Kaasalainen S, McAiney C, Martin-Misener R, Donald F, Wickson-Griffiths $\mathrm{A}$, et al. Resident and family perceptions of the nurse practitioner role in long term care settings: a qualitative descriptive study. BMC Nurs. 2013;12(1):24.

81. Martin-Misener R, Donald F, Wickson-Griffiths A, Akhtar-Danesh N, Ploeg J, Brazil $\mathrm{K}$, et al. A mixed methods study of the work patterns of full-time nurse practitioners in nursing homes. J Clin Nurs. 2015;24(9-10):1327-37.

82. Gardner G, Gardner A, Middleton S, Della P, Kain V, Doubrovsky A. The work of nurse practitioners. J Adv Nurs. 2010;66(10):2160-9.

83. Bentley M, Minstrell M, Bucher H, Sproule L, Robinson A, Stirling C. Aged care nurse practitioners working in general practice. J Clin Nurs. 2015;24(23-24):3745-7.

84. Fagerstrom L, Glasberg AL. The first evaluation of the advanced practice nurse role in Finland - the perspective of nurse leaders. J Nurs Manag. 2011;19(7):925-32.

85. Schofield I, Ford P. The need for specialist nurses to work with older people. Br J Nurs. 2000;9(20):2148-54.

86. American Association of Nurse Practitioners. What's an NP? [Internet]. 2016. Available from: https://www.aanp.org/all-about-nps/what-is-an-np.

87. Dick K, Frazier SC. An exploration of nurse practitioner care to homebound frail elders. J Am Acad Nurse Pract. 2006;18(7):325-34.

88. Stasa H, Cashin A, Buckley T, Donoghue J. Advancing advanced practice - clarifying the conceptual confusion. Nurse Educ Today. 2014;34(3):356-61.

89. Fougere B, Lagourdette C, Abele P, Resnick B, Rantz M, Kam Yuk Lai C, et al. Involvement of Advanced Practice Nurse in the Management of Geriatric Conditions: Examples from Different Countries. J Nutr Health Aging. 2018;22(4):463-70.

90. Laurant M, van der Biezen M, Wijers N, Watananirun K, Kontopantelis E, van Vught AJ. Nurses as substitutes for doctors in primary care. Cochrane Database Syst Rev. 2018;7:CD001271.

91. Tranmer JE, Colley L, Edge DS, Sears K, VanDenKerkhof E, Levesque L. Trends in nurse practitioners' prescribing to older adults in Ontario, 2000-2010: a retrospective cohort study. CMAJ open. 2015;3(3):E299-304.

92. Poot B, Zonneveld R, Nelson K, Weatherall M. Prescribing by nurse practitioners: Insights from a New Zealand study. J Am Assoc Nurse Pract. 2017;29(10):581-90.

93. Poot B, Nelson K, Zonneveld R, Weatherall M. Potentially inappropriate medicine prescribing by nurse practitioners in New Zealand. J Am Assoc Nurse Pract. 2019.

94. O'Rourke T, Kirk J, Duff E, Golonka R. A survey of nurse practitioner controlled drugs and substances prescribing in three Canadian provinces. J Clin Nurs. 2019.

95. Mahoney DF, Ladd E. More than a Prescriber: Gerontological Nurse Practitioners' Perspectives on Prescribing and Pharmaceutical Marketing. Geriatr Nurs. 2010;31(1):17-27. 96. Kennedy-Malone L, Fleming ME, Penny J. Prescribing patterns of gerontological nurse practitioners in the United States. J Am Acad Nurse Pract. 2008;20(1):28-34.

97. Fong J, Buckley T, Cashin A, Pont L. Nurse practitioner prescribing in Australia: A comprehensive literature review. Aust Crit Care. 2017;30(5):252-9.

98. Cashin A, Stasa H, Dunn SV, Pont L, Buckley T. Nurse practitioner prescribing practice in Australia: confidence in aspects of medication management. Int J Nurs Pract. 2014;20(1):1-7.

99. Buckley T, Cashin A, Stuart M, Browne G, Dunn SV. Nurse practitioner prescribing practices: the most frequently prescribed medications. J Clin Nurs. 2013;22(13-14):2053-63. 
100. Altersved E, Zetterlund L, Lindblad U, Fagerstrom L. Advanced practice nurses: A new resource for Swedish primary health-care teams. Int J Nurs Pract. 2011;17(2):174-80. 101. Kennedy-Malone L, Penny J, Fleming ME. Clinical practice characteristics of gerontological nurse practitioners: a national study. J Am Acad Nurse Pract. 2008;20(1):1727.

102. Nieminen AL, Mannevaara B, Fagerstrom L. Advanced practice nurses' scope of practice: a qualitative study of advanced clinical competencies. Scand J Caring Sci. 2011;25(4):661-70.

103. Bergman K, Perhed U, Eriksson I, Lindblad U, Fagerstrom L. Patients' satisfaction with the care offered by advanced practice nurses: a new role in Swedish primary care. Int J Nurs Pract. 2013;19(3):326-33.

104. Chavez KS, Dwyer AA, Ramelet AS. International practice settings, interventions and outcomes of nurse practitioners in geriatric care: A scoping review. Int J Nurs Stud. 2018;78:61-75.

105. Naylor MD, Kurtzman ET. The role of nurse practitioners in reinventing primary care. Health Aff (Millwood). 2010;29(5):893-9.

106. Stanik-Hutt J, Newhouse RP, White KM, Johantgen M, Bass EB, Zangaro G, et al. The Quality and Effectiveness of Care Provided by Nurse Practitioners. Jnp-J Nurse Pract. 2013;9(8):492-500.

107. Donald F, Martin-Misener R, Carter N, Donald EE, Kaasalainen S, Wickson-Griffiths A, et al. A systematic review of the effectiveness of advanced practice nurses in long-term care. J Adv Nurs. 2013;69(10):2148-61.

108. Horrocks S, Anderson E, Salisbury C. Systematic review of whether nurse practitioners working in primary care can provide equivalent care to doctors. BMJ. 2002;324(7341):819-23.

109. van der Biezen M, Schoonhoven L, Wijers N, van der Burgt R, Wensing M, Laurant M. Substitution of general practitioners by nurse practitioners in out-of-hours primary care: a quasi-experimental study. J Adv Nurs. 2016;72(8):1813-24.

110. Eriksson I, Lindblad M, Moller U, Gillsjo C. Holistic health care: Patients' experiences of health care provided by an Advanced Practice Nurse. Int J Nurs Pract. 2018;24(1).

111. Ljungbeck B, Sjogren Forss K. Advanced nurse practitioners in municipal healthcare as a way to meet the growing healthcare needs of the frail elderly: a qualitative interview study with managers, doctors and specialist nurses. BMC Nurs. 2017;16:63.

112. The Norwegian Directorate of Health. Videreutdanning for sykepleiere - Hvordan sikre at behovet for avansert breddekompetanse blir ivaretatt i fremtiden? [Continuing education for nurses - How to ensure that the need for advanced expertise width are taken care of in the future?]. Oslo: The Norwegian Directorate of Health; 2017.

113. The Norwegian Directorate of Health. Lønnstilskudd for masterutdanning i avansert klinisk sykepleie [Wage subsidy for master's degree in advanced practice nursing] Oslo: The Norwegian Directorate of Health; 2019. Available from:

https://www.helsedirektoratet.no/tilskudd/lonnstilskudd-for-masterutdanning-i-avansertklinisk-sykepleie\#m\%C3\%A5lgruppe.

114. Health Personnel Act. Act of 2 July 1999 No. 64 relating to Health Personnel etc. 1999.

115. The Norwegian Directorate of Health. Masterutdanning i avansert klinisk allmennsykepleie [Master's degree in advanced family care]. Oslo: The Norwegian Directorate of Health; 2019.

116. Forskrift om nasjonal retningslinje for masterutdanning i avansert klinisk allmennsykepleie. Forskrift om nasjonal retningslinje for masterutdanning i avansert klinisk 
allmennsykepleie [Regulations on national guidelines for master's programs in advanced clinical general nursing]. 2020.

117. Forskrift om spesialistgodkjenning for sykepleiere. Forskrift om spesialistgodkjenning for sykepleiere [Regulations on accreditation for registered nurses]. 2020.

118. Blau PM. A Theory of Social Integration. American Journal of Sociology. 1960;65(6):545-56.

119. Chouinard V, Contandriopoulos D, Perroux M, Larouche C. Supporting nurse practitioners' practice in primary healthcare settings: a three-level qualitative model. BMC Health Serv Res. 2017;17(1):437.

120. Koren I, Mian O, Rukholm E. Integration of Nurse Practitioners Into Ontario's Primary Health Care System: Variations Across Practice Settings. Can J Nurs Res. 2010;42(2):48-69.

121. Lowe G, Plummer V, Boyd L. Nurse practitioner integration: Qualitative experiences of the change management process. J Nurs Manag. 2018;26(8):992-1001.

122. Brault I, Kilpatrick K, D'Amour D, Contandriopoulos D, Chouinard V, Dubois CA, et al. Role clarification processes for better integration of nurse practitioners into primary healthcare teams: a multiple-case study. Nurs Res Pract. 2014;2014:170514.

123. DiCenso A, Bryant-Lukosius D, Martin-Misener R, Donald F, Abelson J, Bourgeault I, et al. Factors Enabling Advanced Practice Nursing Role Integration in Canada. Nurs Leadersh (Tor Ont). 2010;23 Spec No 2010(sp):211-38.

124. Burgess J, Martin A, Senner W. A framework to assess nurse practitioner role integration in primary health care. Can J Nurs Res. 2011;43(1):22-40.

125. Poghosyan L, Norful AA, Martsolf GR. Organizational structures and outcomes of newly hired and experienced nurse practitioners in New York State. Nurs Outlook.

2017;65(5):607-14.

126. Creswell JW, Plano Clark VL. Designing and Conducting Mixed Methods Research. 3rd ed. Los Angeles: Sage. 2018. 492 p.

127. Creswell JW, Creswell JD. Research Design: Qualitative, Quantitative \& Mixed Methods Approaches. 5th ed. Los Angeles: Sage. 2018. 275 p.

128. Leech NL, Onwuegbuzie AJ. A typology of mixed methods research designs. Quality \& Quantity. 2009;43(2):265-75.

129. Nastasi BK, Hitchcock JH, Brown LM. An Inclusive Framework for Conceptualizing Mixed Methods Design Typologies: Moving Toward Fully Integrated Synergistic Research Models. Thousand Oaks, California: SAGE; 2016.

130. Johnson RB, Onwuegbuzie AJ, Turner LA. Toward a Definition of Mixed Methods

Research. J Mix Method Res. 2007;1(2):112-33.

131. Tashakkori A, Teddlie C. Major Issues and Controversies in the use of Mixed Methods in the Social and Behavioral Sciences. In: Tashakkori A, Teddlie C, editors. Handbook of Mixed Methods in Social \& Behavioral Research. Thousand Oaks, Calif: SAGE; 2003. p. 3-50.

132. Williams L, Rycroft-Malone J, Burton CR. Bringing critical realism to nursing practice: Roy Bhaskar's contribution. Nurs Philos. 2017;18(2).

133. Maxwell JA, Mittapalli K. Realism as a Stance for Mixed Methods Research In: Tashakkori A, Teddlie C, editors. SAGE handbook of mixed methods in social \& behavioral research. 2. ed. Thousand Oaks, California: SAGE; 2016. p. 145-68.

134. Patton MQ. Qualitative research \& evaluation methods. 3rd ed. Thousand Oaks, Calif: Sage Publications. 2002. 598 p.

135. Henni SH, Kirkevold M, Antypas K, Foss C. The role of advanced geriatric nurses in Norway: A descriptive exploratory study. Int J Older People Nurs. 2018;13(3):e12188. 
136. Elliott N, Begley C, Sheaf G, Higgins A. Barriers and enablers to advanced practitioners' ability to enact their leadership role: A scoping review. Int J Nurs Stud. 2016;60:24-45.

137. Hsieh HF, Shannon SE. Three approaches to qualitative content analysis. Qual Health Res. 2005;15(9):1277-88.

138. QSR International Pty Ltd. NVivo 11 Pro for Windows [Internet]. 2015. Available from: http://download.qsrinternational.com/Document/NVivo11/11.3.0/en-US/NVivo11Getting-Started-Guide-Pro-edition.pdf.

139. Henni SH, Kirkevold M, Antypas K, Foss C. The integration of new nurse practitioners into care of older adults: A survey study. J Clin Nurs. 2019;28(15-16):2911-23. 140. Wilson M. Constructing Measures: An Item Response Modeling Approach. New York: Taylor and Francis; 2004. Available from: https://www.taylorfrancis.com/books/9781410611697.

141. R Core Team. R: A language and environment for statistical computing [Internet]. Vienna, Austria: R Foundation for Statistical Computing; 2018. Available from: https://www.r-project.org/.

142. Reay T, Golden-Biddle K, Germann K. Challenges and leadership strategies for managers of nurse practitioners. J Nurs Manag. 2003;11(6):396-403.

143. Rhee JS, Weaver EM, Park SS, Baker SR, Hilger PA, Kriet JD, et al. Clinical consensus statement: Diagnosis and management of nasal valve compromise. Otolaryngol Head Neck Surg. 2010;143(1):48-59.

144. Diamond IR, Grant RC, Feldman BM, Pencharz PB, Ling SC, Moore AM, et al. Defining consensus: a systematic review recommends methodologic criteria for reporting of Delphi studies. J Clin Epidemiol. 2014;67(4):401-9.

145. World Medical Association. WMA Declaration of Helsinki: Ethical Principles for Medical Research Involving Human Subjects. JAMA. 2013;310(20):2191-4.

146. Lau R, Stevenson F, Ong BN, Dziedzic K, Treweek S, Eldridge S, et al. Achieving change in primary care - causes of the evidence to practice gap: systematic reviews of reviews. Implementation science : IS. 2016;11:40.

147. Cote N, Freeman A, Jean E, Denis JL. New understanding of primary health care nurse practitioner role optimisation: The dynamic relationship between the context and work meaning. BMC Health Serv Res. 2019;19(1):882.

148. Gooden JM, Jackson E. Attitudes of registered nurses toward nurse practitioners. J Am Acad Nurse Pract. 2004;16(8):360-4.

149. Donelan K, DesRoches CM, Dittus RS, Buerhaus P. Perspectives of Physicians and Nurse Practitioners on Primary Care Practice. N Engl J Med. 2013;368(20):1898-906.

150. MacLellan L, Higgins I, Levett-Jones T. Medical acceptance of the nurse practitioner role in Australia: a decade on. J Am Assoc Nurse Pract. 2015;27(3):152-9.

151. Carr J, Bethea J, Hancock B. The attitudes of GPs towards the nurse-practitioner role. Br J Community Nurs. 2001;6(9):444-51.

152. Carr J, Armstrong S, Hancock B, Bethea J. GPs' perceptions of the nurse practitioner role in primary care. Br J Community Nurs. 2002;7(8):408-13.

153. Lowe G, Plummer V, Boyd L. Nurse practitioner roles in Australian healthcare settings. Nurs Manag (Harrow). 2013;20(2):28-35.

154. Poghosyan L, Aiken LH. Maximizing nurse practitioners' contributions to primary care through organizational changes. J Ambul Care Manage. 2015;38(2):109-17.

155. Sangster-Gormley E, Griffith J, Schreiber R, Borycki E, Feddema A, Thompson J. Interprofessional Collaboration: Co-workers' Perceptions of Adding Nurse Practitioners to Primary Care Teams. Qual Prim Care. 2015;23(2):122-6. 
156. Donald F, Mohide EA, Dicenso A, Brazil K, Stephenson M, Akhtar-Danesh N. Nurse Practitioner and Physician Collaboration in Long-Term Care Homes: Survey Results.

Canadian journal on aging $=$ La revue canadienne du vieillissement. 2009;28(1):77-87.

157. Maylone MM, Ranieri L, Quinn Griffin MT, McNulty R, Fitzpatrick JJ. Collaboration and autonomy: Perceptions among nurse practitioners. J Am Acad Nurse Pract.

2011;23(1):51-7.

158. McAiney CA, Ploeg J, Wickson-Griffiths A, Kaasalainen S, Martin-Misener R, Akhtar-Danesh N, et al. Perspectives of Nurse Practitioner-Physician Collaboration among Nurse Practitioners in Canadian Long-Term Care Homes: A National Survey. Nurs Leadersh (Tor Ont). 2017;30(4):10-25.

159. Report to the Storting No. 10 (2012-2013). High Quality - Safe Services - Quality and Patient safety in the Health and Care Services. Oslo: Norwegian Ministry of Health and Care Services.

160. Lafortune C, Huson K, Santi S, Stolee P. Community-based primary health care for older adults: a qualitative study of the perceptions of clients, caregivers and health care providers. BMC Geriatr. 2015;15:57.

161. Boman E, Glasberg AL, Levy-Malmberg R, Fagerstrom L. 'Thinking outside the box': advanced geriatric nursing in primary health care in Scandinavia. BMC Nurs. 2019;18:25. 162. Mørk E, Beyrer S, Haugstveit FV, Sundby B, Karlsen HT. Kommunale helse- og omsorgstjenester 2017: Statistikk om tjenester og tjenestemottakere [Municipal health and care services 2017: Statistics on services and service recipients]. Oslo: Statistics Norway. 2018.

163. Polit DF, Beck CT. Nursing Research: Generating and Assessing Evidence for Nursing Practice. 9th ed. Philadelphia, Pa: Wolters Kluwer Health. 2012. 802 p.

164. Clark T. On 'being researched': why do people engage with qualitative research? Qualitative Research. 2010;10(4):399-419.

165. Elo S, Kyngas H. The qualitative content analysis process. J Adv Nurs. 2008;62(1):107-15.

166. Green J, Thorogood N. Qualitative Methods for Health Research. 3rd ed. London: Sage. 2014. 342 p.

167. Sandelowski M. The use of quotes in qualitative research. Res Nurs Health. 1994;17(6):479-82.

168. Kvael LAH, Debesay J, Langaas A, Bye A, Bergland A. A Concept Analysis of Patient Participation in Intermediate Care. Patient Educ Couns. 2018;101(8):1337-50. 



\section{Original Papers}

I. Henni SH, Kirkevold M, Antypas K, Foss C. The role of advanced geriatric nurses in Norway: A descriptive exploratory study. Int J Older People Nurs. 2018;13(3):e12188.

II. Henni SH, Kirkevold M, Antypas K, Foss C. Perceptions of the scope of practice of nurse practitioners caring for older adults: Level of agreement among different healthcare providers. Scand J Caring Sci. 2020; Article accepted on 25 March, 2020.

III. Henni SH, Kirkevold M, Antypas K, Foss C. The integration of new nurse practitioners into care of older adults: A survey study. J Clin Nurs. 2019;28(15-16):2911-23. 

피

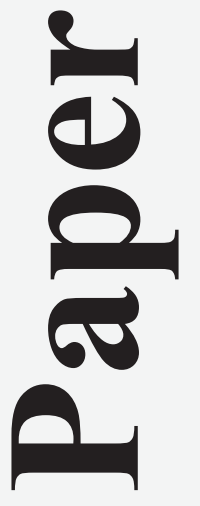





\title{
The role of advanced geriatric nurses in Norway: A descriptive exploratory study
}

\author{
Silje Havrevold Henni RN, MNSc, Doctoral Research Fellow (id ｜ Marit Kirkevold RN, EdD, \\ Professor | Konstantinos Antypas RN, PhD, Postdoctoral Researcher | Christina Foss RN, \\ Dr. Polit, Professor
}

Department of Nursing Science, Institute of Health and Society, Faculty of Medicine, University of Oslo, Oslo, Norway

\section{Correspondence}

Silje Havrevold Henni, Department of Nursing Science, University of Oslo, P.O. Box 1130 Blindern, NO-0318 Oslo, Norway.

Email:s.h.henni@medisin.uio.no

Funding information

The research was funded by The Research Council of Norway, Programme on Health, Care and Welfare Services Research (HELSEVEL), Project number 239766.
Background: Care of older adults in the community is becoming increasingly complex. However, nursing staff often has insufficient knowledge and skills to adequately address the needs of frail older adults. There is therefore a need for nurses with advanced qualifications. To meet this need, advanced geriatric nursing has been introduced in Norway.

Aims and Objectives: This study aimed to describe the experiences of nurses with their new role as advanced geriatric nurses in care of older adults and to determine what strategies the nurses considered important in the development of their new role.

Design: This study applied a descriptive, exploratory design.

Methods: In-depth interviews were conducted with 21 nurses who had undergone an educational programme to become advanced geriatric nurses in Norway in 2016. Content analysis was used to analyse the data.

Findings: The participants described a complex and extensive nursing role, which they related to a new understanding of the patients, relatives and the system in which they worked. This new gaze had developed based on a combination of their new knowledge, their skills, experiences and professional interests. The opportunities to use their role depended on their workplace conditions. They related to contextual challenges at their workplace in different ways to optimise the use of their new gaze.

Conclusions: Common for all participants was a broader and deeper understanding of the patient's health and life situation, which guided participants' actions. The key issue in developing the new role was developing effective strategies to foster role integration.

Implications for Practice: Advanced geriatric nurses should collaborate with their managers to create a role that takes advantage of their knowledge and skills, as well as collaborate with colleagues to enhance understanding of utilisation of their role.

\section{KEYWORDS}

advanced practice nursing, care of older adults, nurse practitioner, nurse roles, primary health care 


\section{1 | INTRODUCTION}

With increased longevity, older patients are becoming frailer and frequently suffer from multimorbidity. This makes care of older adults in the community increasingly complex. The complexity is exacerbated by early discharge from the hospital (Bergman, Beland, \& Perrault, 2002; Bergman et al., 2013). Nurses are essential for the care of older adults in the community but often have insufficient knowledge (Bing-Jonsson, Hofoss, Kirkevold, Bjork, \& Foss, 2016; Kiljunen, Valimaki, Kankkunen, \& Partanen, 2017). Lack of sufficient qualifications may lead to inadequate patient treatment (Kiljunen et al., 2017), rehospitalisation or early nursing home admission, because the nurses do not notice early signs of deterioration (Laging, Ford, Bauer, \& Nay, 2015). To meet the need for nurses with advanced qualifications and to encourage a career in care of older adults, the University of Oslo introduced the first master's degree programme in advanced practice nursing in 2011. Focusing on advanced geriatric nursing, the master's degree programme builds on international research and experiences (Bakerjian, 2008; Newhouse et al., 2011; Stanik-Hutt et al., 2013). "Advanced practice nursing" is a generic term that refers to

a registered nurse who has acquired the expert knowledge base, complex decision-making skills and clinical competencies for expanded practice, the characteristics of which are shaped by the context and/or country in which $s /$ he is credentialed to practice. A master's degree is recommended for entry level (International Council of Nurses, 2015, para. 2).

To explore the new role of advanced geriatric nurses (AGNs) in Norway, this study describes the AGNs' experiences and strategies to introduce and develop the new role from their own perspective. Knowledge about the new role can provide important insights for wider implementation of advanced roles in care of older adults, which is an area of great concern both nationally and internationally.

\section{1 | Background}

Nurses who specialise in care of older adults have expanded knowledge compared to nurses without such specialisation, and it is expected that the role assumed by these specialist nurses will reflect this knowledge expansion (Hardy \& Conway, 1988). A new role to a great extent develops to accommodate the needs of a specific society (Hardy \& Conway, 1988). In this study, we explore the professional role of AGNs. Role in this context is based on role theory, which defines a role as the actions, characteristics, values, rights and obligations of a person or position (Brookes, Davidson, Daly, \& Halcomb, 2007; Hardy \& Conway, 1988).

The role of Norwegian AGNs is inspired by the role of nurse practitioners (American Association of Nurse Practitioners, 2016b). The role of nurse practitioners first appeared in the United States in the 1960s (American Association of Nurse Practitioners, 2016a).

\section{What does this research add to existing knowledge in gerontology?}

- Nurse practitioners specialised in care of older adults have developed a clinical gaze specific to older adults. This study describes this gaze and its use in practice.

- Nurse practitioners specialised in care of older adults need work conditions that enable them to fully utilise their new knowledge and skills. This study describes these work conditions.

\section{What are the implications of this new knowledge for nursing care with older people?}

- Nurse practitioners specialised in care of older adults describe an extended and multifaceted knowledge that they apply in their practice and share with other health personnel at their workplace.

- Work conditions must be adjusted so that nurse practitioners who specialise in care of older adults can perform to the best of their ability.

\section{How could the findings be used to influence policy or practice or research or education?}

- Further research should focus on understanding the perceptions of patients, managers and colleagues regarding the impact nurse practitioners specialised in care of older adults have on care of older adults.

- Educational programmes should prepare nurse practitioner students who specialise in care of older adults for how they can develop their role in their workplace.

- Countries that have nurse practitioners specialised in care of older adults are advised to develop regulations for the enactment of the role and the qualifications required to fill the role.

Nurse practitioners work in ambulatory, acute and long-term care in primary and hospital care settings (American Association of Nurse Practitioners, 2016b). They focus on direct clinical care and management of health needs of individual patients and their relatives. Nurse practitioners have the expertise to perform advanced health assessments and have diagnostic and clinical management skills (including pharmacological management) (Hamric, 2013; International Council of Nurses, 2015; Thomas et al., 2017). The AGNs are primarily intended to practice in primary health care, which the municipalities are responsible for in Norway, although the AGNs can also work in hospitals.

In line with the general qualification requirements of advanced practice nurses (Hamric, 2013; Thomas et al., 2017), AGNs are expected to have expertise in the following areas: direct clinical practice, guidance and coaching of patients and relatives, 
consultation, evidence-base practice, leadership, collaboration and ethical decision-making. Furthermore, they are expected to provide care while considering the complexity and uniqueness of human beings and their situations, rather than solely focusing on the patients' individual diseases or symptoms (Tracy, 2013; WisurHokkanen, Glasberg, Makela, \& Fagerstrom, 2015). However, there is a lack of comprehensive description regarding how these general role characteristics play out when providing care to frail and multimorbid patients. Therefore, exploring the role of AGNs can provide important insights regarding the different expertise domains and the perspective of nurse practitioners specialising in care of older adults. This knowledge may inform leaders and colleagues of the contributions that AGNs may add to the care of complex older adults.

Since the start of the AGN-programme, four other master's degree programmes in advanced practice nursing, focusing on acute-, emergency- and family-care are established in Norway. The role of the AGNs and the other advanced practice nurses in Norway are currently unknown, and there are no formal regulations of these roles (Carney, 2016). The quick expansion of advanced practice education highlights the need for research to explore how these roles are integrated into the existing healthcare system. This study contributes to shed light on this question.

The integration of a new role such as a nurse practitioner into primary health care is a challenging process internationally and across different contexts (Andregard \& Jangland, 2015; Contandriopoulos et al., 2015; Elliott, Begley, Sheaf, \& Higgins, 2016; SangsterGormley, Martin-Misener, Downe-Wamboldt, \& Dicenso, 2011). Little is known of the specific challenges that AGNs may encounter in developing their advanced practice care for older adults, which is a healthcare service area expected to increase in importance in the years to come.

\subsection{Aim}

The aim of the study was to describe the experiences of nurses with their new role as AGNs in care of older adults and to determine what strategies the AGNs consider important in the development of their new role.

\section{2 | METHOD}

\section{1 | Design}

We used a descriptive, exploratory design as we sought to uncover essential experiences in the participants' working life.

\section{2 | Participants}

All the 21 AGNs who graduated from the University of Oslo before summer 2016 were invited by email to participate in the study during spring 2016 and all agreed. They provided names and email addresses to their managers, and a formal enquiry of permission to interview them was obtained. All the AGNs had experience in primary health care except one who had experience in hospital care.

\section{3 | Data collection}

The research team assumed that the role as AGN was related to their formal and informal position at their workplace. We started the interview with an open question, inviting the participants to share their experiences of what they considered important for their role in their own words. To ensure that areas mentioned in the literature regarding role integration for nurse practitioners were also explored, we developed an interview guide with topics and followup questions based on previous literature (Table 1) (Andregard \& Jangland, 2015; Contandriopoulos et al., 2015; Elliott et al., 2016; Sangster-Gormley et al., 2011). We only asked the follow-up questions if the participants did not mention the topics themselves when we invited them to speak freely in the beginning of the inter view. The interview guide was pilot tested by an AGN, and the pilot interview was included in the study because there was no modification after the pilot interview was conducted. The AGNs were interviewed once by the first author at a convenient venue for the participants. The interviews were audio recorded, lasted between 30 and 60 minutes and were conducted between February and August 2016

\subsection{Ethical considerations}

Participation was voluntary and only permitted after written consent. Participants' privacy is protected by presenting demographic data at the group level. Anonymous presentation is important, as there are only a few municipalities/hospitals that have hired AGNs in Norway. The project was approved by the Norwegian Centre for Research Data. We used the consolidated criteria for reporting qualitative research checklist (COREQ) to ensure reporting all important aspects of this study (Tong, Sainsbury, \& Craig, 2007).

\section{5 | Data analysis}

The first author transcribed all interviews verbatim. We used "conventional content analysis" (Hsieh \& Shannon, 2005) to analyse the interviews. The first and last authors started the data analysis by reading the transcripts to familiarise themselves with the data material. We allowed the categories and the names for these categories to flow from the data and applied inductive category development to allow new insights to emerge. All transcribed texts that appeared to describe the role were coded initially by hand. The text was read and coded separately by the first and fourth author. The names of the codes emerged from condensations that described the content of the text. We read through the entire material several times to ensure that all aspects of the role were recognised and coded. Similar codes were then grouped together in subcategories. The evolving 
TABLE 1 Interview guide

\begin{tabular}{|c|c|}
\hline Opening question & Topics and follow-up questions \\
\hline $\begin{array}{l}\text { What experiences have you had as a new AGN that you } \\
\text { consider important for your role? }\end{array}$ & $\begin{array}{l}\text { Planning undertaken before taking up the position } \\
\text { - Describe your role } \\
\text { - What are your expectations and those of others from your workplace (i.e. your } \\
\text { colleagues, managers)? } \\
\text { Role definition } \\
\text { - Is there a job description designed for an AGN role-describe the job description? } \\
\text { - How does your responsibility overlap with those of other professionals? } \\
\text { - How is your current responsibility consistent with the role you trained for? } \\
\text { Description of the practice model } \\
\text { - How is organisation of health care at your workplace? } \\
\text { - How is the allocation of resources and responsibilities suited to the new AGN role? } \\
\text { Support and collaboration } \\
\text { - How can collaboration with other professional groups be described? } \\
\text { - How do you think your colleagues perceive your position? } \\
\text { - Explain in terms of the extent to which- } \\
\text {-You experienced support } \\
\text {-You are being consulted } \\
\text {-You have gained the trust of your colleagues }\end{array}$ \\
\hline
\end{tabular}

\begin{tabular}{|c|c|c|}
\hline Transcribed text & Codes & Subcategories \\
\hline $\begin{array}{l}\text { I'm responsible for all teaching and training of } \\
\text { nurses, auxiliary nurses and assistants (No. 8). }\end{array}$ & Teach colleagues & Different functions \\
\hline $\begin{array}{l}\text { I've been involved in the drug project and the } \\
\text { management and patient safety project (No. 5). }\end{array}$ & Project participant & \\
\hline $\begin{array}{l}\text { They'll [nurses] call me in situations where they } \\
\text { don't quite know what to do (No. 15). }\end{array}$ & Resource person & \\
\hline $\begin{array}{l}\text { I think we can work more systematically in rela- } \\
\text { tion to comprehensive surveys }\end{array}$ & $\begin{array}{l}\text { Comprehensive } \\
\text { survey }\end{array}$ & New expertise \\
\hline $\begin{array}{l}\text { Many patients have often multiple drugs, I } \\
\text { sometimes make suggestions to the physician } \\
\text { "This is contraindicated, may it cause the pa- } \\
\text { tients problem?" } \\
\text { (No. 7). }\end{array}$ & Pharmacology & \\
\hline $\begin{array}{l}\text { I document that I can hear with auscultation ... } \\
\text { and then there is many nurses who don't know } \\
\text { what auscultation is } \\
\text { (No. 11). }\end{array}$ & Auscultation & \\
\hline
\end{tabular}

TABLE 2 Example of how the transcribed text was coded and grouped into subcategories analysis and interpretation were discussed among the entire research group. NVivo Version 11 (QSR International Pty Ltd., 2015) was used to structure codes and categories from the transcribed text. To ensure transparency, data collection and an example of how we coded and categorised the transcribed text are illustrated in Tables 2 and 3 (Elo \& Kyngas, 2008). Characteristics of the AGNs are described in Table 4. We included quotes from the interviews to ensure transparency regarding how the interpretations were placed into categories and thus strengthen the study's trustworthiness (Elo \& Kyngas, 2008). The first author translated the quotes from Norwegian to English and the whole research group approved the translation.

\section{3 | FINDINGS}

Most of the participants had extensive experience as nurses before they became AGNs. A common reaction among the AGNs that permeated their responses to the opening invitation to share their experience was an account of developing what they described as an "AGN-gaze." The participants described this gaze as a multifaceted perspective on their patients' health and life situation as well as on their own broadened role in addressing the patients' needs. Knowledge from several fields guided their new understanding and actions.

The first part of this section describes the dimensions of the AGN-gaze in relation to patients, relatives and the system in which 
TAB LE 3 The subcategories that constitute the main categories

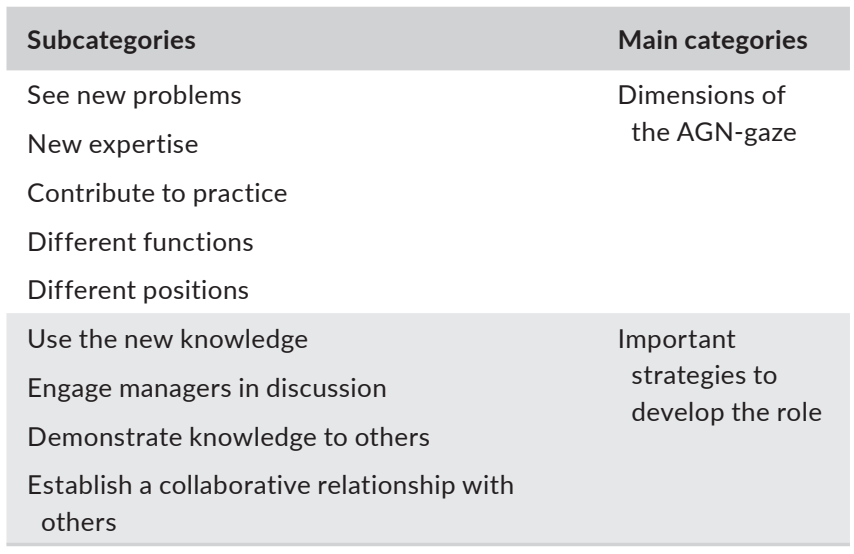

TAB LE 4 Characteristics of the study participants

\begin{tabular}{|c|c|}
\hline & Number \\
\hline \multicolumn{2}{|l|}{ Gender } \\
\hline Female & 20 \\
\hline Male & 1 \\
\hline \multicolumn{2}{|l|}{ Age } \\
\hline $30-50$ years & 13 \\
\hline$>50$ years & 8 \\
\hline \multicolumn{2}{|c|}{ Years practising as a nurse } \\
\hline$<10$ years & 4 \\
\hline $10-19$ years & 9 \\
\hline $20-29$ years & 3 \\
\hline $30-39$ years & 5 \\
\hline \multicolumn{2}{|c|}{ Number of years worked in current position } \\
\hline$<1$ years & 4 \\
\hline $1-5$ years & 12 \\
\hline $6-10$ years & 2 \\
\hline$>10$ years & 3 \\
\hline \multicolumn{2}{|c|}{ Year graduated from master in advanced geriatric nursing } \\
\hline 2014 & 11 \\
\hline 2015 & 9 \\
\hline 2016 & 1 \\
\hline
\end{tabular}

the AGNs worked. The second part of the findings describes how the participants used different strategies to develop their new role, as the opportunity to use the new AGN-gaze depended on the participants' workplace conditions.

\section{1 | Dimensions of the AGN-gaze}

The participants explained that they experienced care of older adults as a more complex and exciting field compared to before their education. The AGNs expressed that the masters' degree programme provided them with knowledge and systematic clinical assessment skills from several different fields (nursing, medicine, pharmacy, physiotherapy, geriatrics etc.). Common to all the AGNs was a description of their ability to combine their new knowledge and systematic clinical assessment skills with their experience and professional interest into an AGN-gaze. The participants described their new role as quite extensive, as they saw patients, relatives and the system in which they worked from a new perspective:

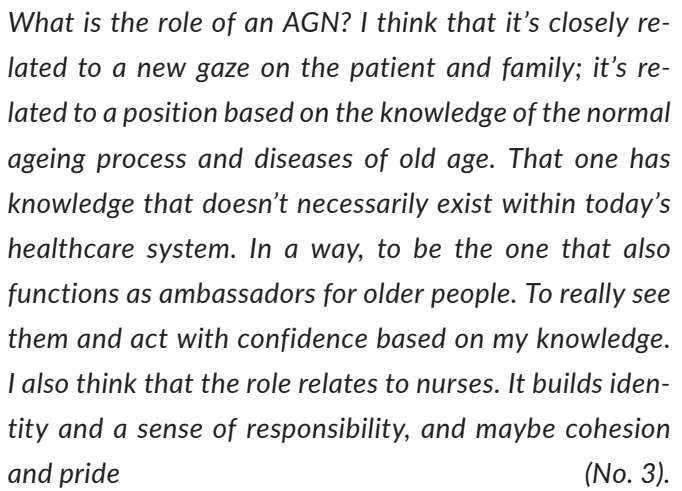

The quote indicates that the AGN-gaze has several dimensions and that it is related to both direct and indirect care. The direct care dimension was described as related to the ability to see a wider spectrum of medical, social and environmental problems in the patient's situation compared to before their education. The participants also explained that they related to issues in a new way because their new gaze provided them with the self-confidence to provide guidance to the patients and their relatives. Through the AGN-gaze, the AGNs expressed that they became more aware of the importance of preventing medical and psychosocial problems. They also expressed that they were able to discover the patient's problems at an earlier stage, and they had the knowledge and skills to address these problems:

You see things that could potentially be unfortunate and you're able to take action. Perhaps others wouldn't discover it in the same systematic way, but [...] more randomly. So, it is about "reading" situations and finding appropriate measures that are useful

(No. 16).

The AGN-gaze also influenced care indirectly through consulting, quality development and tutoring. The participants' ability to see and describe precisely problems in the patients' situations, and their knowledge and skills to act were useful in complex patient situations where other health professionals asked the AGNs for an external opinion. A large proportion of the problems were related to psychosocial conditions and ethical decision-making or to challenges in cooperation with patients/relatives. Examples of such problems could be violence among patients and relatives, social isolation and questions regarding whether the patient was competent to give consent. The AGNs also reported that health professionals from different disciplines asked them for consultation regarding patient care: 
I discuss patients with the unit that allocates services to home care patients: "What services does this person need, is the follow-up enough, do you think he needs something more?" Often, the physiotherapist comes to me to discuss a patient. I also discuss with physicians and professional development leaders in home care. It's very much about consultations with regard to clinical assessments and decisions

Another dimension of the AGN-gaze was the recognition of the importance of quality improvement and knowledge-based practice in care of older adults. The AGNs continually searched for new knowledge because they experienced the field of care of older adults as complex. The participants communicated the importance of recognising this complexity to other employees and students to promote care of older adults as an important and exciting field:

The education gave me a platform to continually seek new knowledge, or apply the knowledge I have at any time when I feel it's needed. It's easier now that I know how to seek information and knowledge, and it makes the job more exciting and I feel like I could be a better mentor for students. [...] I can convey that geriatrics is an exciting field; I can show that it's a field that requires a lot of knowledge, and I can provide motivation to work in geriatrics

(No. 6)

Although AGNs underlined that they saw direct clinical care as their core task, they also described a responsibility for systematic quality improvement within their unit. The participants discussed providing extensive formal and informal teaching and clinical advice to colleagues and students. The AGN-gaze also encompassed an enhanced awareness of the significance of research and development projects to enhance the quality of care:

I'm very a clinically oriented nurse, and I haven't much desire to work too much with projects with all that must be documented and registered. [... but] I understand and believe that research and development work are absolutely a part of the role

(No. 20).

Just under half of the participants had entered new positions explicitly as AGNs; the positions of the rest had not changed significantly. However, the AGNs expressed that they contributed to practice regardless of their position because the AGN-gaze had changed the way they thought about their role regarding patients and the system in which they worked:

I have exactly the same position now as I had before, but I use [my new knowledge and skills], and I spend the time it takes. I have my own nurse bag containing my assessment tools and equipment and if I feel there is a need to do a heart-lung examination, well, then I do it!
The AGNs positions at their workplace were important because their workplace conditions impacted on the possibility to develop their new role, and the respondents gave thorough descriptions of their pursuit of conditions that allowed for the use of AGN knowledge.

\section{2 | Important strategies to develop the role}

The participants not only wanted to use their new knowledge and skills. They also expressed a responsibility to contribute to conditions that would make the use of knowledge and skills possible:

I think everyone needs to accept that nothing comes free with this education; it requires a certain amount of individual effort. You can't believe that the municipalities will come and necessarily request you and your role; you mustn't believe that the university is going to do it for you. To a certain extent, they can support you, but you have to do the job yourself

(No. 14).

The participants expressed that it was difficult to develop the role because there is no regulation, central framework or guidelines for the intended role in Norway. The municipalities of most of the AGNs who graduated in 2014 have collaborated with the educational institution to develop an AGN role. The managers in the collaborating municipalities gave the AGNs the opportunity to prioritise their agenda and work independently through a well-defined AGN role. Few of the other AGNs had this opportunity. However, all of them emphasised the importance of prioritising their own agenda:

[Prioritising my own agenda] is important for me, because then I can spend my time where I think it's most important. [...] I start the day by deciding which patients I should go to, and see where the need is [...] The possibility to make a professional assessment in relation to where you think it's important [is essential]

(No. 9).

Even though the municipalities were favourable to the AGNs, some of the AGNs felt that the managers had not performed enough to customise the AGN position in a way that optimised the use of knowledge and skills:

Clearly, she [manager] has seen the benefits of having a nurse who knows more about pathology and that I can largely complement what she can do. However, I haven't felt that enough has been done to ensure that I can offer this advanced geriatric professional nursing care (No. 15).

All of the AGNs used different strategies to develop a role for themselves that allowed the best possible use of their knowledge and skills. The AGNs who graduated in 2014 expressed more awareness of the use of strategies in their narratives compared to those who graduated in 2015 and 2016. The AGNs who graduated in 2014 expressed 
that they learned from each other's experiences to a greater extent than the AGNs who graduated in 2015 and 2016. The strategies targeted both management and colleagues. One strategy was to discuss with their managers how they could use their new knowledge and skills after graduation. The AGNs emphasised that support from the managers was important, as the managers were in the position to accommodate the AGNs. Still, for most of the AGNs, the discussion with their managers had not been adequate to ensure a role that enabled proper utilisation of their knowledge and skills. Nevertheless, the participants expressed that it was best for AGN students to engage their managers in discussions about their future role before graduating:

Try to get your municipality with you from day one, so that they're almost with you through the education! [...] We didn't manage to engage them, so we have to work on that now

Another often described strategy involved the AGNs demonstrating their knowledge to others so that they would understand how AGNs could contribute to care of older adults:

No one understood what I could do, not the nurse colleagues, not the physicians, so I offered to help in situations that were difficult and complicated. So, then, we worked together on things, and after that, I think that they could see how I could contribute and eventually they begin saying, "AGN, can you look at this?"

(No. 13).

The participants expressed that it was important to collaborate with other health professionals, and they often mentioned physicians in their narratives. The AGNs had support from and collaborated well with most physicians and experienced few conflicts although most physicians were unfamiliar with the AGNs' role to start with. The AGNs spent time presenting themselves, being flexible and showing respect to establish a collaborative relationship with the physicians. The participants stated that potential conflicts with physicians disappeared after they became acquainted with each other and established a collaborative relationship:

They [physicians] were a little more cautious in the beginning, but [collaboration] has evolved over time. I experience more reciprocity in discussions with the physicians now as compared to before I completed the AGN education, regarding patients, their problems, and what we should possibly do next

(No. 10).

Another strategy was to spend time to get other key people in the municipality to understand the AGNs' contribution because they could then communicate the importance of the AGN role to others:

Using the influence of the development centre [for home care services], the Municipal Medical Officer, and individuals who are a little higher up in the hierarchy over my immediate manager has been important. The manager for home care realises the benefits of my role and can influence my closest manager. [...] So, I've got more support, but I've somehow taken a detour to get this support from them

(No.14).

To summarise, the AGNs recognised that their own efforts were essential to get the opportunity to apply their knowledge and skills because they were the only ones who knew the full range of their expertise.

\section{DISCUSSION}

An important finding in this study was the development of a particular AGN-gaze that the participants shared. The AGN-gaze entailed recognition of care of older adults as a complex field and recognition of the patient's health condition and life situation as interwoven. This finding is in line with Tracy (2013) and Wisur-Hokkanen et al. (2015), who describe the perspective of advanced practice nurses as an ability to gain a deeper and more holistic understanding of the patients' medical health in relation to their mental, physical and social situation. Looking at the AGNs' descriptions of their new gaze, we found that the AGNs emphasised the environmental and psychosocial dimensions specific for older adult's life situation and recognised the complex interactions between different disorders and functional decline, frequently coupled with cognitive impairment and social isolation.

Our findings suggest that the AGNs experienced increased knowledge and skills in each of the general domains of advanced practice nursing, including direct clinical care, guidance and coaching of patients and relatives, consultation and ethical decision-making, responsibility for systematic quality improvement and collaboration with other health professionals (Hamric, 2013; Thomas et al., 2017). In line with international findings, the AGNs underlined direct clinical care as the most important dimension (Martin-Misener et al., 2015; Sangster-Gormley, Martin-Misener, \& Burge, 2013). The AGNs also emphasised systematic quality improvement as an important dimension. This focus seemed related to the AGNs' understanding of the complexity and need for quality in care of older adults and the significance of a system that supports and promotes quality care. The AGNs saw direct care and systematic quality improvement as closely related, as systematic quality development was a prerequisite for quality care of the individual patients.

Internationally, the presence of nurse practitioners in long-term care settings has been associated with lower rates of depression, urinary incontinence, pressure ulcers, restraint use and aggressive behaviours (Donald et al., 2013). All the AGNs emphasised prevention as an important dimension of their AGN role. There is a need for nurses who can prevent deterioration of disease in care of older adults both internationally and in Norway (Buchan \& Perfilieva, 2015; Finnbakk, Skovdahl, Blix, \& Fagerstrom, 2012; Murphy et al., 2014). 
Internationally, it has been shown that nurse practitioners can redefine roles and change the system in which they work (Contandriopoulos et al., 2016). Based on the participants' accounts, it seems that nurses with advanced qualifications play a significant role in implementing age-appropriate and research-based knowledge at their workplace to manage complex patient cases.

Knowledge is described as important to help nurse practitioners gain self-confidence to take initiative and perform their role to the fullest capacity (Wisur-Hokkanen et al., 2015). In line with this, most of the AGNs expressed that they had the self-confidence to step up and play a role in spreading knowledge among colleagues through teaching and consultation in complex cases. The AGNs can improve the quality of care given to the individual patient and prevent deterioration of disease among patients at their workplace because they share their expertise with others. The participants' pride and interest in their field seemed to encourage enthusiasm and to challenge pervasive ageism by showing students that geriatric nursing is a complex and exciting field, thus, playing an important role in recruiting and retaining nurses, a possibility also described internationally regarding nurses with advanced qualifications in care of older adults (Campbell-Detrixhe, Grassley, \& Zeigler, 2013).

Our findings indicate that it is challenging to integrate and establish a new nurse role in the primary healthcare system in Norway, as it is in other countries (Andregard \& Jangland, 2015; Contandriopoulos et al., 2015; Elliott et al., 2016; Sangster-Gormley et al., 2011). The AGNs expressed that it was challenging because there are no guidelines or national regulation of the role in Norway. This lends support for the need to develop such guidelines and regulation (Maier, 2015). The possibility for developing the role of AGNs differed among the participants depending on their workplace. Those who did not feel that their role was fully utilised described inadequate role definition and lack of consensus building as key factors. This finding is consistent with the international literature (Bryant-Lukosius, Dicenso, Browne, \& Pinelli, 2004; Contandriopoulos et al., 2015; WisurHokkanen et al., 2015). Earlier research has pointed to a lack of published literature about how to overcome challenges in the development of new nurse practitioner roles (Andregard \& Jangland, 2015; Contandriopoulos et al., 2015). The AGNs gave many examples of comprehensive strategies to develop a functional role without pre-existing guidelines.

The findings show a difference among the AGNs regarding awareness of the use of strategies. The AGNs who graduated in 2014 described more strategies than the others did. There may be several reasons for the difference. The AGNs who graduated in 2014 had had more time to orient themselves in the field and discover what they needed. It could also be because a collaborative relationship had been established between the educational programme, which aimed to develop the AGN role, and most of the leaders of the AGNs who graduated in 2014. Lack of engagement from the managers is described as an issue internationally (Bryant-Lukosius et al., 2004; Contandriopoulos et al., 2015; Lindblad, Hallman, Gillsjo, Lindblad, \& Fagerstrom, 2010; Wisur-Hokkanen et al., 2015), and managers hold a key position in facilitating integration
(Sangster-Gormley et al., 2013). The AGNs described similar experiences regarding their managers. They developed strategies to engage managers in customising the AGN position in a way that optimised the use of AGNs' knowledge and skills. Strategies to engage management may be the most important, as these strategies significantly influence the practice model, role definition, planning, support and collaboration.

Personal knowledge and clarity of the AGN role are important to ensure acceptance of the role from others (Sangster-Gormley et al., 2013). Investing time to get to know the physicians and other colleagues as well as sharing information and knowledge of how they could contribute to improving the quality of care was described as a strategy that led to what was considered a fruitful collaboration. Poor support from physicians has internationally been identified as a main barrier for integration of nurse practitioners in new primary care settings (Fougere et al., 2016). Contrary to this, the AGNs' descriptions indicated that nurses with advanced qualifications and physicians could build a collaborative relationship, but this required a strategic approach on the part of the AGNs. Based on our findings, collaboration with other professionals as well as with the management is vital for the development of a role for nurses with advanced qualifications that allows for realisation of their full potential in the care of older adults.

\section{1 | Limitations}

The first author, who conducted the interviews, had limited experience as an interviewer. The first and fourth author went through the audio recordings of the first interviews to guide and support the development of the first author's interview technique. Only the perspectives of the AGNs themselves have been included in this study.

\section{5 | CONCLUSION}

This study found that newly graduated AGNs had developed a new gaze that significantly changed their understanding of the overall situation of older adults and their ability to work preventively. The AGNs' descriptions suggest that they had the knowledge, enthusiasm, interest and self-esteem to take care of older adults' needs while also sharing their expertise with others. Based on the participants' descriptions, the AGNs seem to meet what is described as the community's mandate (Saltman, Rico, \& Boerma, 2006).

In further research, the concept of "AGN-gaze" should be explored in a dimensional analysis to explain how the gaze is used and the consequences of its use for older adults. To expand the field of care of older adults, there is a need for further research to explore how managers, other healthcare professionals and patients/relatives experience the role of AGNs. It is also important to explore the AGNs' impact on patient outcomes and organisational relationships in the care of older adults. The identified strategies to develop the AGN role are practical and will be communicated to educators, clinicians and administrators in Norway. The strategies will likely be 


\section{Implication for practice}

- Nurse practitioners specialised in care of older adults have a highly relevant function in contemporary elderly care; however, there is a need to increase the formal training capacity.

- Nurse practitioners specialised in care of older adults would benefit from forming an arena to share their experiences and strategies to develop the new nurse practitioner role.

- There is a need to develop organisational and professional guidelines that may secure the full utilisation of the knowledge and skills of nurse practitioners.

beneficial under similar settings internationally. We will use the findings in Norway to help redefine the role of AGNs for those who did not feel that their role was fully utilised and to show the different aspects of the role for future AGN students.

\section{ACKNOWLEDGEMENTS}

The authors want to thank the participants in the study.

\section{CONFLICT OF INTEREST}

The authors declare no conflict of interests.

\section{AUTHOR CONTRIBUTIONS}

Study design: $\mathrm{SHH}, \mathrm{MK}, \mathrm{KA}, \mathrm{CF}$; Data analysis: $\mathrm{SHH}, \mathrm{MK}, \mathrm{KA}, \mathrm{CF}$ and Manuscript preparation: $\mathrm{SHH}, \mathrm{MK}, \mathrm{KA}, \mathrm{CF}$.

\section{ORCID}

Silje Havrevold Henni (iD http://orcid.org/0000-0002-9309-8726

\section{REFERENCES}

American Association of Nurse Practitioners. (2016a). Historical timeline. Retrieved from https://www.aanp.org/all-about-nps/ historical-timeline

American Association of Nurse Practitioners. (2016b). What's an NP? Retrieved from https://www.aanp.org/all-about-nps/what-is-an-np

Andregard, A. C., \& Jangland, E. (2015). The tortuous journey of introducing the nurse practitioner as a new member of the healthcare team: $A$ meta-synthesis. Scandinavian Journal of Caring Sciences, 29(1), 3-14. https://doi.org/10.1111/scs.12120

Bakerjian, D. (2008). Care of nursing home residents by advanced practice nurses. A review of the literature. Research in Gerontological Nursing, 1(3), 177-185. https://doi.org/10.3928/00220124-20091301-01

Bergman, H., Beland, F., \& Perrault, A. (2002). The global challenge of understanding and meeting the needs of the frail older population. Aging Clinical and Experimental Research, 14(4), 223-225. https://doi. org/10.1007/BF03324442
Bergman, H., Karunananthan, S., Robledo, L. M., Brodsky, J., Chan, P., Cheung, M., \& Bovet, P. (2013). Understanding and meeting the needs of the older population: A global challenge. Canadian Geriatrics Journal, 16(2), 61-65. https://doi.org/10.5770/cgj.16.60

Bing-Jonsson, P. C., Hofoss, D., Kirkevold, M., Bjork, I. T., \& Foss, C. (2016). Sufficient competence in community elderly care? Results from a competence measurement of nursing staff. BMC Nursing, 15 5. https://doi.org/10.1186/s12912-016-0124-z

Brookes, K., Davidson, P. M., Daly, J., \& Halcomb, E. J. (2007). Role theory: A framework to investigate the community nurse role in contemporary health care systems. Contemporary Nurse, 25(1-2), 146155. https://doi.org/10.5555/conu.2007.25.1-2.146

Bryant-Lukosius, D., Dicenso, A., Browne, G., \& Pinelli, J. (2004). Advanced practice nursing roles: Development, implementation and evaluation. Journal of Advanced Nursing, 48(5), 519-529. https://doi. org/10.1111/j.1365-2648.2004.03234.x

Buchan, J., \& Perfilieva, G. (2015). Making progress towards health workforce sustainability in the WHO European region. Retrieved from http://www.euro.who.int/__data/assets/pdf_file/0005/287456/ Making-progress-towards-health-workforce-sustainability-in-theWHO-European-Region-rev1.pdf?ua=1

Campbell-Detrixhe, D. D., Grassley, J. S., \& Zeigler, V. L. (2013). Gerontology found me: Gaining understanding of advanced practice nurses in geriatrics. Western Journal of Nursing Research, 35(9), 11531170. https://doi.org/10.1177/0193945913489355

Carney, M. (2016). Regulation of advanced nurse practice: Its existence and regulatory dimensions from an international perspective. Journal of Nursing Management, 24(1), 105-114. https://doi.org/10.1111/jonm.12278

Contandriopoulos, D., Brousselle, A., Breton, M., Sangster-Gormley, E., Kilpatrick, K., Dubois, C. A., ... Perroux, M. (2016). Nurse practitioners, canaries in the mine of primary care reform. Health Policy, 120(6), 682-689. https://doi.org/10.1016/j.healthpol.2016.03.015

Contandriopoulos, D., Brousselle, A., Dubois, C. A., Perroux, M., Beaulieu, M. D., Brault, I., ... Sansgter-Gormley, E. (2015). A process-based framework to guide nurse practitioners integration into primary healthcare teams: Results from a logic analysis. BMC Health Services Research, 15, 78. https://doi.org/10.1186/s12913-015-0731-5

Donald, F., Martin-Misener, R., Carter, N., Donald, E. E., Kaasalainen, S., Wickson-Griffiths, A., ... DiCenso, A. (2013). A systematic review of the effectiveness of advanced practice nurses in long-term care. Journal of Advanced Nursing, 69(10), 2148-2161. https://doi. org/10.1111/jan.12140

Elliott, N., Begley, C., Sheaf, G., \& Higgins, A. (2016). Barriers and enablers to advanced practitioners' ability to enact their leadership role: A scoping review. International Journal of Nursing Studies, 60, 24-45. https://doi.org/10.1016/j.ijnurstu.2016.03.001

Elo, S., \& Kyngas, H. (2008). The qualitative content analysis process. Journal of Advanced Nursing, 62(1), 107-115. https://doi. org/10.1111/j.1365-2648.2007.04569.x

Finnbakk, E., Skovdahl, K., Blix, E. S., \& Fagerstrom, L. (2012). Top-level managers' and politicians' worries about future care for older people with complex and acute illnesses: A Nordic study. International Journal of Older People Nursing, 7(2), 163-172. https://doi. org/10.1111/j.1748-3743.2012.00312.x

Fougere, B., Morley, J. E., Decavel, F., Nourhashemi, F., Abele, P., Resnick, B., ... Vellas, B. (2016). Development and implementation of the ad vanced practice nurse worldwide with an interest in geriatric care. Journal of the American Medical Directors Association, 17(9), 782-788. https://doi.org/10.1016/j.jamda.2016.05.009

Hamric, A. B. (2013). A definition of advanced practice nursing. In A. B. Hamric, C. M. Hanson, M. F. Tracy \& E. T. O'Grady (Eds.), Advanced practice nursing: An integrative approach (5th edn, pp. 67-85). Missouri: Elsevier Health Sciences.

Hardy, M. E., \& Conway, M. E. (1988). Role theory: Perspectives for health professionals (2nd edn). Norwalk: Appleton \& Lange. 
Hsieh, H. F., \& Shannon, S. E. (2005). Three approaches to qualitative content analysis. Qualitative Health Research, 15(9), 1277-1288. https://doi.org/10.1177/1049732305276687

International Council of Nurses. (2015). Definition and characteristics of the role. Retrieved from http://international.aanp.org/Practice/ APNRoles

Kiljunen, O., Valimaki, T., Kankkunen, P., \& Partanen, P. (2017). Competence for older people nursing in care and nursing homes: An integrative review. International Journal of Older People Nursing, 12(3), e12146. https://doi.org/10.1111/opn.12146

Laging, B., Ford, R., Bauer, M., \& Nay, R. (2015). A meta-synthesis of factors influencing nursing home staff decisions to transfer residents to hospital. Journal of Advanced Nursing, 71(10), 2224-2236. https://doi. org/10.1111/jan.12652

Lindblad, E., Hallman, E. B., Gillsjo, C., Lindblad, U., \& Fagerstrom, L. (2010). Experiences of thenewrole ofadvancedpracticenursesinSwedishprimary health care-A qualitative study. International Journal of Nursing Practice, 16(1), 69-74. https://doi.org/10.1111/j.1440-172X.2009.01810.x

Maier, C. B. (2015). The role of governance in implementing task-shifting from physicians to nurses in advanced roles in Europe, U.S., Canada, New Zealand and Australia. Health Policy, 119(12), 1627-1635. https://doi.org/10.1016/j.healthpol.2015.09.002

Martin-Misener, R., Donald, F., Wickson-Griffiths, A., Akhtar-Danesh, N., Ploeg, J., Brazil, K., ... Taniguchi, A. (2015). A mixed methods study of the work patterns of full-time nurse practitioners in nursing homes. Journal of Clinical Nursing, 24(9-10), 1327-1337. https://doi. org/10.1111/jocn.12741

Murphy, M. P., Miller, J. M., Siomos, M. Z., Braun, L., Hinch, B., \& Swartwout, K. (2014). Integrating gerontological content across advanced practice registered nurse programs. Journal of the American Association of Nurse Practitioners, 26(2), 77-84. https://doi. org/10.1002/2327-6924.12074

Newhouse, R. P., Stanik-Hutt, J., White, K. M., Johantgen, M., Bass, E. B., Zangaro, G., ... Weiner, J. P. (2011). Advanced practice nurse outcomes 1990-2008: A systematic review. Nursing Economics, 29(5), 230-250. https://doi.org/10.1016/j.jamda.2016. 05.009

QSR International Pty Ltd. (2015). NVivo 11 Pro for Windows. Retrieved from http://download.qsrinternational.com/Document/ NVivo11/11.3.0/en-US/NVivo11-Getting-Started-GuidePro-edition.pdf
Saltman, R. B., Rico, A., \& Boerma, W. G. W. (2006). Primary care in the driver's seat? Organizational reform in European primary care. Maidenhead, UK: Open University Press.

Sangster-Gormley, E., Martin-Misener, R., \& Burge, F. (2013). A case study of nurse practitioner role implementation in primary care: What happens when new roles are introduced? BMC Nursing, 12, 1. https://doi.org/10.1186/1472-6955-12-1

Sangster-Gormley, E., Martin-Misener, R., Downe-Wamboldt, B., \& Dicenso, A. (2011). Factors affecting nurse practitioner role implementation in Canadian practice settings: An integrative review. Journal of Advanced Nursing, 67(6), 1178-1190. https://doi. org/10.1111/j.1365-2648.2010.05571.x

Stanik-Hutt, J., Newhouse, R. P., White, K. M., Johantgen, M., Bass, E. B., Zangaro, G., ... Weiner, J. P. (2013). The quality and effectiveness of care provided by nurse practitioners. Journal for Nurse Practitioners, 9(8), 492-500. https://doi.org/10.1016/j.nurpra.2013.07.004

Thomas, A., Crabtree, M. K., Delaney, K., Dumas, M. A., Kleinpell, R., Marfell, J., ... Wolf, A. (2017). Nurse practitioner core competencies content. Retrieved from http://c.ymcdn.com/sites/www.nonpf.org/ resource/resmgr/competencies/2017_NPCoreComps_with_Curric.pdf

Tong, A., Sainsbury, P., \& Craig, J. (2007). Consolidated criteria for reporting qualitative research (COREQ): A 32-item checklist for interviews and focus groups. International Journal for Quality in Health Care, 19(6), 349-357. https://doi.org/10.1093/intqhc/mzm042

Tracy, M. F. (2013). Direct clinical practice. In A. B. Hamric, C. M. Hanson, M. F. Tracy \& E. T. O'Grady (Eds.), Advanced practice nursing: An integrative approach (5th edn, pp. 147-182). Missouri: Elsevier Health Sciences.

Wisur-Hokkanen, C., Glasberg, A. L., Makela, C., \& Fagerstrom, L. (2015). Experiences of working as an advanced practice nurse in Finland-the substance of advanced nursing practice and promoting and inhibiting factors. Scandinavian Journal of Caring Sciences, 29(4), 793-802. https://doi.org/10.1111/scs.12211

How to cite this article: Henni SH, Kirkevold M, Antypas K, Foss $C$. The role of advanced geriatric nurses in Norway: $A$ descriptive exploratory study. Int J Older People Nurs. 2018;e12188. https://doi.org/10.1111/opn.12188 


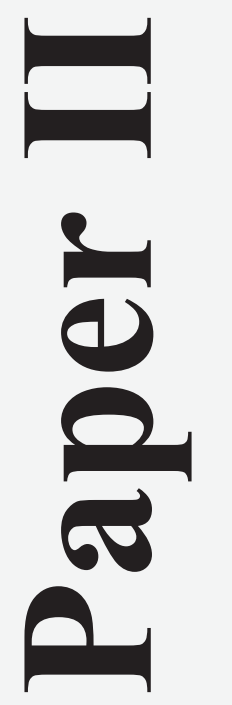





\title{
Perceptions of the scope of practice of nurse practitioners caring for older adults: Level of agreement among different healthcare providers
}

Accepted for publication in Scandinavian Journal of Caring Sciences, 2020.

DOI:10.1111/scs.12861

\begin{abstract}
Background: Globally, new nurse practitioner roles have been introduced into interdisciplinary teams. Research indicates that agreement among the different healthcare providers regarding one another's role and scope of practice is important for establishing interdisciplinary teamwork. Lack of agreement regarding a new nurse practitioner's scope of practice may hinder collaboration.
\end{abstract}

Aim: To investigate the level of agreement among advanced geriatric nurses (AGNs), their colleagues and their leaders regarding which activities related to direct and indirect care, teaching/supervision, coordination and research and development work are perceived as appropriate for AGNs.

Design: A cross-sectional descriptive survey.

Methods: The total population of AGNs in Norway $(n=26)$ and a sample of their colleagues, including leaders $(n=465)$, were invited to answer an online questionnaire. Twenty-three (88.5\%) AGNs and 195 (42\%) colleagues answered the questionnaires. A series of crosstabulations were conducted to identify the respondents' reporting on the appropriateness of different activities.

Results: The respondents identified all of the activities related to coordination, teaching/supervision and research and development work as appropriate for AGNs. Although the respondents considered several of the direct and indirect care activities as appropriate, there were conflicting views on the activities that traditionally fall within the medical field versus those that traditionally fall within the nursing field. The AGNs saw most of the nursing 
and medical activities as appropriate, but their colleagues and leaders saw only some of the nursing activities as appropriate. The results also showed that there was high disagreement among the leaders regarding appropriate activities.

Conclusion: The results indicate that healthcare providers agree on which activities related to teaching/supervision, coordination, and research and development work are appropriate to include in AGNs' scope of practice, but that there are conflicting views regarding activities related to direct and indirect care.

Keywords: advanced nursing practice, advanced practice, nurse practitioners, quantitative approaches, scope of practice, survey designs, teamwork

Word count: 4685 


\section{Introduction}

The increasing complexity of the knowledge and skills needed to provide comprehensive care to frail older adults has resulted in no single healthcare provider being able to fulfil these needs (1). The World Health Organisation (WHO) emphasises how crucial it is for healthcare providers caring for older adults to collaborate in interdisciplinary teams in order to provide the best possible patient care (2) and coordinate care services (3). Interdisciplinary collaboration in teams has proven challenging $(1,4,5)$, and there is often poor communication among healthcare providers about the care being provided to older adults $(6,7)$. One prerequisite for collaboration is that the different healthcare providers in the team have knowledge of and confidence in one another's competence $(4,5,8,9)$. Another prerequisite is an agreement among the healthcare providers regarding their various roles and scopes of practice $(5,8,10)$.

Several countries have introduced new nurse practitioner roles into interdisciplinary teams to improve access to person-centred care and to improve quality of care by allowing for more intensive follow-up and better coordination of the care provided to older adults $(11,12)$. The introduction of a nurse practitioner into a team involves rethinking the collaborators' roles failure to reassess roles can result in overlaps, redundancies, frustrations (8) and collaboration problems due to unclear role definitions (13). There is strong evidence supporting the need to agree on the role and scope of practice of each member of an interdisciplinary team $(8,14$, 15). Disagreement about a new nurse practitioner's scope of practice can lead to tension and uncertainty about who should perform a given activity $(8,14,16)$, causing healthcare providers to perceive one another as competitors instead of collaborators (16). Unclear roles and scopes of practice or disagreement within a team can negatively affect the integration of nurse practitioners (14). Hence, introducing nurse practitioners into a team must be closely monitored to ensure that the level of agreement among the healthcare providers is high. The 
current study follows the introduction of the first nurse practitioners in Norway, here labelled 'advanced geriatric nurses (AGNs)'.

\section{Background}

The goal of interdisciplinary teamwork is to achieve a dynamic process in which all members of a healthcare team - professionals and non-professionals who have complementary educations and fulfil complementary roles - work together to make full use of one another's expertise, knowledge and skills in order to positively impact patient care $(1,10,17)$. In Norway, the teams caring for older adults, which the AGNs are a part of, include a range of practitioners: leaders, physicians, occupational therapists, physical therapists, specialist nurses, registered nurses, auxiliary nurses, assistants and executive officers. The healthcare providers work at different system levels and have different educational backgrounds, which ensures that a variety of skills are available within a team to meet the complex healthcare needs of older adults.

Researchers have highlighted that support from leaders at different hierarchical levels is vital in the establishment of new nurse practitioner roles in interdisciplinary teams (18-20). The leaders are in a position to accommodate nurse practitioner roles in a way that enables the optimal utilisation of the nurses' knowledge and skills $(8,14,21,22)$. Researchers have also shown that leaders play an important role in redesigning activity distribution and establishing new routines when a new nurse practitioner role is introduced into an interdisciplinary team (20).

With many countries undergoing reforms to reduce costs while improving the access to and quality of care, both the role and the scope of practice of nurses working in interdisciplinary teams have been extended $(11,12)$. The nurse practitioner role is internationally the most common advanced role for nurses $(23,24)$. Their responsibilities are primarily associated with 
direct and indirect care, but they also engage in teaching/supervision, coordination and research and development work (25-29). The advancement of nursing roles has been accompanied by nurses assuming new types of activities, which often overlap with activities traditionally performed by physicians, such as (independently or under the supervision of a physician) prescribing medication, diagnosing, ordering diagnostic tests and referring patients within the healthcare system $(11,12,30)$. These activities vary among countries, as every country has its own education, licensing and credential requirements $(11,12,24)$. However, these activities can also vary within a country if the regulations are not nationally recognised (23). AGNs practising in the Norwegian healthcare system do not formally have the authority to perform the medical activities described above, and similar restrictions in performing medical activities can be found in several countries where the nurse practitioner role has been newly introduced (30).

Healthcare providers often have different perceptions of nurse practitioners' education and scope of practice, but the specific differences between these perceptions are rarely discussed in the literature $(8,13,31-33)$. Furthermore, the literature on healthcare providers' perceptions of what is appropriate to include in a nurse practitioner's scope of practice is scarce. Therefore, this study provides insight about the perceptions nurse practitioners, their colleagues and their leaders have about a nurse practitioner's scope of practice.

\footnotetext{
Aim

The aim of this study is to investigate the level of agreement among AGNs, their colleagues and their leaders regarding which activities related to direct and indirect care, teaching/supervision, coordination and research and development work are perceived as appropriate for AGNs. The specific research question is as follows:
} 
- What are the similarities and differences between AGNs, their colleagues and their leaders regarding which activities related to different functions they see as appropriate for AGNs?

\section{Methods}

\section{Design}

This study used a cross-sectional descriptive survey design (34). The STROBE guidelines were used to report the results (see Supplementary File 1).

\section{Recruitment and sample}

In Norway, there are only 26 AGNs, as the master's degree programme in advanced practice nursing is a rather new form of education (see (35)). In the autumn of 2017, an invitation to participate in this study was sent out by email to the entire AGN population in Norway. The AGNs were asked to provide contact information for their workplaces and leaders so that a formal enquiry to recruit a sample of 30 colleagues, including leaders, to answer questionnaires could be sent. One AGN declined to participate in the study before receiving the questionnaire, and another AGN agreed to be sent the questionnaire but did not provide the requested information. Of the 24 AGNs that provided the requested information, 21 were working in clinical positions at 19 different workplaces. The remaining three AGNs were involved in research or teaching in nursing educational programmes; however, these AGNs had worked in clinical settings after graduating with a master's degree in advanced practice nursing. These three AGNs were included in the current study, but former colleagues from their clinical practice were not invited to participate. The leaders of the AGNs who worked in clinical positions were emailed the formal enquiry, which included the following inclusion criteria: 
- Colleagues must be involved in the care of older adults in the municipality/institution where the AGN works.

- The sample should include participants from all system levels and with different job titles.

- A minimum of one to two persons from all healthcare providers involved in the care of older adults at the workplace should be represented.

The inclusion criteria were developed to ensure that the sample included participants from all healthcare provider groups involved in the care of older adults: leaders, physicians, occupational therapists, physical therapists, specialist nurses, registered nurses, auxiliary nurses, assistants and executive officers. Sixteen leaders agreed to collect email addresses from 30 people who were willing to answer our questionnaire (the recruiting leaders were informed that they could also include their own email address on the list). In total, 465 email addresses were collected.

\section{Data collection}

In early January of 2018, the first author emailed the online questionnaires to 25 AGNs and 465 other healthcare providers who were willing to answer a questionnaire. The data collection lasted through March of 2018 and included a total of three follow-up emails. Few participants answered the questionnaire before the third follow-up email was sent out. When the final follow-up email was sent, the recruiting leaders and the AGNs who worked in the same unit as the recruiters were asked to remind the colleagues to respond.

\section{The questionnaires}

A thorough literature search did not yield an existing psychometric questionnaire that could be used to collect data for this study. Therefore, the research team developed two questionnaires: one for the AGNs and one for their colleagues and leaders. The questions in 
the questionnaires were equivalent, but the wording differed depending on the response group.

The questionnaires were divided into three sections. The first section of the questionnaires covered the respondents' gender, age, type of work organisation, job title and years worked in their current position. The AGNs not currently in clinical positions were asked to fill out the questionnaire based on their clinical experience after graduation and the job title they had in that position. The second section of the questionnaires covered the perceived appropriateness of AGNs performing activities related to different functions, along with questions measuring perceptions of the AGNs' use of knowledge and skills related to different functions. The third section covered the integration of AGNs into healthcare settings. The present study has included data from the first and second sections of the questionnaires. The second section asked whether different activities related to different functions were appropriate or inappropriate for AGNs to carry out. The included functions with activities were based upon relevant literature $(12,25-28,36-42)$ as well as previous qualitative interviews with the AGNs (21). Especially, experiences from Scandinavian countries were important in the development of the questionnaires (38-42), as Scandinavian countries have similar healthcare systems with similar nursing scope of practice regulations. The reports from the Scandinavian countries suggested that there is a need for nurses with advanced knowledge and skills to carry out activities related to direct and indirect care, teaching/supervision, coordination and research and development work. After the literature review, a total of 49 activities related to the following five functions were included in the questionnaires:

- Direct care: nursing care for and in the presence of a particular patient, including the guidance/teaching of patients and next of kin (20 activities, Tables 2 and 3).

- Indirect care: nursing care performed away from a patient but for a particular patient, including delegated medical activities (18 activities, Tables 2 and 3). 
- Teaching/supervision: teaching and supervision of colleagues and nursing students (five activities, Table 2).

- Coordination: coordination of collaboration within and outside the organisation of employment (two activities, Table 2).

- Research and development work: activities associated with participation in research and development work (four activities, Table 2).

The questionnaires were reviewed by the research team for content and face validity. In addition, they were tested by two AGNs, one leader, one physician, one registered nurse, one auxiliary nurse and one assistant. The testers provided feedback on whether the included activities related to the different functions were appropriate, relevant and comprehensible. The testers were also asked to provide feedback on whether any relevant activities were missing. The validation process is described in detail elsewhere (35) because the questionnaires were used to collect data for another study. The data were not reused because the current study's data originated from different questions with a different focus.

\section{Ethical considerations}

Participation in the study was voluntary. The respondents did not sign a written consent form, but submission of the questionnaires was considered to be consent. The Norwegian Centre for Research Data assessed and recommended the study (project number: 46618).

\section{Data analysis}

There were no missing data because the respondents had to answer all the questions in order to submit the questionnaires online. All the returned questionnaires were therefore included in the analysis. The first author inspected the data for errors or irregularities before the data were analysed with R version 3.4.4 (43). All the variables were categorical except for two demographic variables - 'age' and 'worked in current position', which were continuous. A 
descriptive data analysis was performed by calculating the mean and the standard deviation $(S D)$ for the continuous variables and the frequency and percentage distribution for the categorical variables.

Consistent with previous research $(14,22)$, the AGNs expressed in a qualitative study that their leaders were in a position to customise the AGNs' positions (21). The leaders were therefore separated from the AGNs' other colleagues in order to distinguish between the two groups' perceptions.

Consensus criteria were established in order to evaluate the level of agreement among the different groups of respondents with regard to whether an activity was considered appropriate for AGNs. Consensus among the AGNs, their colleagues and their leaders was defined as at least $75 \%$ of the AGNs, $75 \%$ of their colleagues and $75 \%$ of their leaders responding that an activity was appropriate. Consensus within one of the specific groups was defined as at least $75 \%$ of the respondents within that group confirming that an activity was appropriate. The consensus criteria was based on what is used in Delphi studies to confirm agreement between members of a group $(44,45)$.

A series of cross-tabulations was conducted to assess which of the activities the AGNs, their colleagues and their leaders agreed were appropriate for the AGNs - and which of the activities they had conflicting views about. This analysis indicated the scope of practice the AGNs, their colleagues and their leaders deemed appropriate.

\section{Results}

The questionnaires were answered by 23 (88.5\%) AGNs and 195 (42\%) colleagues, including leaders. Table 1 presents the demographic details and work characteristics of the respondents. A large proportion of the respondents were female $(n=196,89.9 \%)$ aged 40 years or over $(n=137,62.8 \%)$ and working in primary care $(n=206,94.5 \%)$. 


\section{Activities related to different functions that the AGNs, their colleagues and their leaders}

\section{deemed to be appropriate}

The activities that the AGNs, their colleagues and their leaders saw as appropriate for AGNs are shown in Table 2. The analysis revealed that these activities constituted just over one half of all the activities in the questionnaires. A more detailed analysis showed that all the activities related to teaching/supervision, coordination and research and development work; just under one-half of the direct care activities; and one-third of the indirect care activities were seen as appropriate by all three groups. Of the direct and indirect care activities that were agreed upon, most fell within the traditional scope of nursing. However, the respondents also agreed that some activities not traditionally in the nursing field, such as systematically gathering medical history and referring patients within and across service levels, were appropriate for AGNs.

\section{Activities related to different functions on which the AGNs, their colleagues and their leaders had conflicting views}

The AGNs, their colleagues and their leaders had conflicting views on the appropriateness of several of the activities related to direct and indirect care (Table 3). In addition to the activities that all three groups deemed appropriate, the AGNs reported that over two-thirds of the remaining activities were also appropriate. A more detailed analysis has shown that one half of the activities were related to direct care and the other half to indirect care. A large proportion of the activities that the AGNs saw as appropriate have traditionally belonged to the medical field with the rest pertaining to the nursing field. The activities that the AGNs did not see as appropriate fell mainly in the medical field, the exception being providing nursing care for patients with psychiatric disorders.

The AGNs' colleagues felt that just under one-fourth of the remaining activities were appropriate for the AGNs. All these activities were also seen as appropriate by the AGNs but 
not by the leaders. The leaders only felt that 'prescribe and assess bladder scanning' was appropriate for the AGNs. This activity was also seen as appropriate by the AGNs but not by their colleagues. The activities that both colleagues and leaders felt were appropriate were all typical nursing duties. Overall, the views of the colleague group and the leader group regarding activities that are normally considered to be within the medical field were conflicting.

\section{Discussion}

\section{Activities related to different functions viewed as appropriate for AGNs}

The AGNs, their colleagues and their leaders agreed that several activities related to different functions were appropriate to include in the AGNs' scope of practice. With regards to the teaching/supervision and coordination functions, all three groups deemed the activities to be appropriate. The results indicated that the colleagues and leaders saw AGNs as suitable teachers/supervisors who are capable of supporting knowledge and skill-development in the workplace. This is highly relevant for primary healthcare in Norway, as an earlier Norwegian study (46) reported a lack of knowledge among healthcare workers regarding the care of older adults. The AGNs also felt that teaching/supervision functions were appropriate. Previous research has shown that master's programmes in advanced practice nursing can give the graduates a sense of confidence to do their jobs, as the graduates have increased knowledge and skills (47). One interpretation of why the AGNs saw the teaching/supervision function as appropriate for them could be that their education gave them the confidence to teach and supervise others. The results also indicated that both the colleagues and leaders felt AGNs could lead interdisciplinary teams and coordinate the care provided to older adults. The AGNs also saw themselves as coordinators. Healthcare providers caring for older adults seldom communicate with each other (7), which can lead to misunderstandings, unnecessary repetitions of patient assessments and poor information flow between healthcare providers 
who are caring for the same patient. Recognising that AGNs can be coordinators may be understood as a recognition of the need for a person to coordinate collaboration and follow-up in care of older adults. Internationally, coordinating patient care is a common function for nurse practitioners $(11,26,27)$. Henni et al. (35) argued that AGNs were not satisfactorily integrated in Norway regarding this function.

Previous research has found that nurse practitioners spend only a small portion of their time on research activities $(26,28,29)$. In this study, however, the AGNs, their colleagues and their leaders saw activities related to research and development work as appropriate for AGNs. The results indicated that the AGNs felt confident about engaging in research and development work, and that all three groups considered research and development work to be an important function for AGNs to perform.

\section{Activities related to different functions of AGNs with conflicting views}

Driscoll et al. (48) found that regulations and guidelines can assist nurse practitioners in defining their scope of practice and facilitate the development of practice models at their workplaces. There are no national regulations or guidelines governing the role of nurse practitioners in Norway. A lack of regulations may lead to AGNs being assigned various types of activities (nursing activities, medical activities, etc.) at different workplaces, as found internationally $(12,22)$. In the absence of regulations, it is reasonable to presume that the colleagues' and leaders' views of relevant activities are affected by whether the AGN in their workplace already performs the activity. Therefore, a lack of regulations might explain why the results showed conflicting views between the AGNs, their colleagues and their leaders with regards to some of the activities related to medical and nursing activities.

The medical activities for which the views were conflicting fall within a traditional scope of practice of a physician in Norway. The addition of medical activities to the AGNs' scope of 
practice may therefore be perceived as competing with the physicians' scope of practice. Internationally and in Norway, there have been public discussions about whether nurse practitioners' scope of practice should include medical activities that are traditionally within the field of physicians (49). Inclusion of these activities to AGNs' scope of practice represents a change in the care provided to older adults, and it might take time to be realised in practice (50). The conflicting views on the medical activities of AGNs may therefore also be explained by the potential change that AGNs represent.

Another possible explanation for the conflicting views on what activities are appropriate for AGNs might be the lack of knowledge other healthcare providers' have about what the education of AGNs actually entails. Previous research has shown that colleagues of newly introduced nurse practitioners are in need of more knowledge about nurse practitioners' education (51). New nursing roles can be difficult to define and explain to others (52). The other publication from this dataset (35) found that the majority of colleagues and leaders reported that the information provided at the workplace about AGNs' role and scope of practice was not sufficient and that the AGNs' scope of practise was not completely clear. Therefore, it seems that the responses to the question of what activities are appropriate for AGNs were the result what is inaccurately thought to be appropriate for an AGN and not what can actually be expected based on the AGNs' education. Lack of knowledge about the AGNs' education among the healthcare providers may therefore be a reason for the conflicting views rather than resistance to transfer medical activities to the AGNs.

Some of the activities about which there were conflicting views were those normally performed by registered nurses in Norway after completing basic nursing education. There were also conflicting views regarding some of the direct care activities within broader patient situations where they may need to perform several activities. These direct care activities are related to several fields and can be performed by several types of healthcare providers, which 
may lead to confusion and thus different interpretations. Since some of the activities can be performed by several types of healthcare providers, some healthcare providers will not see these activities as appropriate for AGNs because they see them as appropriate for themselves. The present researchers' interpretation aligns with Lovink et al. (16), who also observed that in primary healthcare for older adults, different healthcare providers perform the same activities.

The leaders were further from reaching an agreement on most activities compared to the colleague group and the AGN group, meaning that there was disagreement within the leader group regarding which activities were appropriate for AGNs. One interpretation may be that there were different views among leaders because leaders in healthcare can have different types of education and positions at different levels in the healthcare organisation. There is no requirement for leaders in the Norwegian healthcare system to have a healthcare-focused education. Leaders' perceptions are important because it is they who are in the position to assign nurse practitioners to a role that enables the nurses' proper utilisation of their knowledge and skills $(8,14,21,22)$. When leaders' perceptions differ from those of the AGNs and their colleagues, they may place AGNs in roles that other healthcare providers do not agree with, which can cause conflict. Therefore, it is reasonable to believe that the challenges associated with the establishment of interdisciplinary collaboration may increase when leaders' perceptions differ from the rest of the team. As can be seen, there is a need to further examine how to establish agreement in interdisciplinary teams where the leaders and other healthcare providers have conflicting views on AGNs' scope of practice.

\section{Methodological considerations}

It is uncertain whether the recruiters followed the inclusion criteria. As reported in Henni et al. (35), there is no way of knowing whether this study's sample represents the total population of AGNs' colleagues and leaders because fewer persons than expected were 
recruited, and less than one-half of the recruited persons answered the questionnaire. Furthermore, the low number of respondents from some of the occupational groups made it impossible to examine whether there were different views between the occupational groups.

Another limitation is that it is possible to interpret the activity questions in the questionnaires in at least two different ways. One interpretation may be that the respondents based their answers on their considerations of whether the AGNs were capable of performing the activities based on their perceptions of the AGNs' knowledge and skills. Another interpretation is that the respondents based their answers on their perceptions of whether there was a need for a person to perform the activities at the workplace and whether they perceived the AGNs to be the suitable person. Furthermore, some of the activity questions regarded specific activities, whereas others were descriptions of patient situations where it may have been appropriate to perform several activities. The patient situations with a broad scope may have led to some colleagues and leaders answering that the patient situations were not appropriate for AGNs because they did not want the AGNs to 'own' these situations and exclude other healthcare providers from participating.

\section{Conclusion}

This study shows that there are identified needs in the healthcare service that require the development of regulations for AGNs' scope of practice. Regulating AGNs' scope of practice could help healthcare providers who care for older adults better understand what activities AGNs are able to perform. Based on previous research $(8,14-16)$, it is important to develop a set of regulations that contribute to a common understanding among all of the members of an interdisciplinary team. This study has shown that healthcare providers agree on which activities related to teaching/supervision, coordination and research and development work are appropriate to include in the AGNs' scope of practice. However, they had conflicting 
views on the activities within the traditional medical field and on some activities within the nursing field related to direct and indirect care. Based on previous research $(5,8,10)$, it is reasonable to presume that these conflicting views adversely affect the interdisciplinary collaboration associated with the direct and indirect care functions.

The Norwegian Directorate of Health is working to develop regulations for nurse practitioners in Norway. Further research should investigate whether these regulations lead to a role and scope of practice that help to meet the needs of older adults and are considered appropriate by all members of an interdisciplinary team.

\section{References}

1. Nancarrow SA, Booth A, Ariss S, Smith T, Enderby P, Roots A. Ten principles of good interdisciplinary team work. Hum Resour Health. 2013;11:19.

2. World Health Organization. World report on ageing and health. Geneva: World Health Organization. 2015.

3. World Health Organization. Primary health care: Now more than ever. Geneva: World Health Organization. 2008.

4. Zijlstra E, Lo Fo Wong S, Teerling A, Hutschemaekers G, Lagro-Janssen A.

Challenges in interprofessional collaboration: experiences of care providers and policymakers in a newly set-up Dutch assault centre. Scand J Caring Sci. 2018;32(1):138-46.

5. Sangaleti C, Schveitzer MC, Peduzzi M, Zoboli E, Soares CB. Experiences and shared meaning of teamwork and interprofessional collaboration among health care professionals in primary health care settings: a systematic review. JBI Database System Rev Implement Rep. 2017;15(11):2723-88.

6. Zwijsen SA, Nieuwenhuizen NM, Maarsingh OR, Depla MF, Hertogh CM. Disentangling the concept of "the complex older patient" in general practice: a qualitative study. BMC Fam Pract. 2016;17(1):64.

7. Lafortune C, Huson K, Santi S, Stolee P. Community-based primary health care for older adults: a qualitative study of the perceptions of clients, caregivers and health care providers. BMC Geriatr. 2015;15:57.

8. Contandriopoulos D, Brousselle A, Dubois CA, Perroux M, Beaulieu MD, Brault I, et al. A process-based framework to guide nurse practitioners integration into primary healthcare teams: results from a logic analysis. BMC Health Serv Res. 2015;15:78.

9. Schadewaldt V, McInnes E, Hiller JE, Gardner A. Views and experiences of nurse practitioners and medical practitioners with collaborative practice in primary health care - an integrative review. BMC Fam Pract. 2013;14:132.

10. O'Reilly P, Lee SH, O'Sullivan M, Cullen W, Kennedy C, MacFarlane A. Assessing the facilitators and barriers of interdisciplinary team working in primary care using normalisation process theory: An integrative review. PLoS One. 2017;12(5):e0177026. 11. Maier CB, Aiken LH, Busse R. Nurses in advanced roles in primary care: Policy levers for implementation. Paris: OECD Publishing. 2017. 
12. Delamaire M-L, Lafortune G. Nurses In Advanced Roles: A Description And Evaluation Of Experiences In 12 Developed Countries. Paris: OECD Publishing. 2010.

13. Andregard AC, Jangland E. The tortuous journey of introducing the nurse practitioner as a new member of the healthcare team: a meta-synthesis. Scand J Caring Sci. 2015;29(1):314.

14. Sangster-Gormley E, Martin-Misener R, Downe-Wamboldt B, Dicenso A. Factors affecting nurse practitioner role implementation in Canadian practice settings: an integrative review. J Adv Nurs. 2011;67(6):1178-90.

15. Findley SE, Matos S, Hicks AL, Campbell A, Moore A, Diaz D. Building a consensus on community health workers' scope of practice: lessons from New York. Am J Public Health. 2012;102(10):1981-7.

16. Lovink MH, van Vught A, Persoon A, Schoonhoven L, Koopmans R, Laurant MGH. Skill mix change between general practitioners, nurse practitioners, physician assistants and nurses in primary healthcare for older people: a qualitative study. BMC Fam Pract. 2018;19(1):51.

17. Xyrichis A, Ream E. Teamwork: a concept analysis. J Adv Nurs. 2008;61(2):232-41.

18. Chouinard V, Contandriopoulos D, Perroux M, Larouche C. Supporting nurse practitioners' practice in primary healthcare settings: a three-level qualitative model. BMC Health Serv Res. 2017;17(1):437.

19. Carter N, Martin-Misener R, Kilpatrick K, Kaasalainen S, Donald F, Bryant-Lukosius $\mathrm{D}$, et al. The role of nursing leadership in integrating clinical nurse specialists and nurse practitioners in healthcare delivery in Canada. Nurs Leadersh (Tor Ont). 2010;23 Spec No 2010:167-85.

20. Reay T, Golden-Biddle K, Germann K. Challenges and leadership strategies for managers of nurse practitioners. J Nurs Manag. 2003;11(6):396-403.

21. Henni SH, Kirkevold M, Antypas K, Foss C. The role of advanced geriatric nurses in Norway: A descriptive exploratory study. Int J Older People Nurs. 2018;13(3):e12188.

22. Bryant-Lukosius D, Dicenso A, Browne G, Pinelli J. Advanced practice nursing roles: development, implementation and evaluation. J Adv Nurs. 2004;48(5):519-29.

23. Pulcini J, Jelic M, Gul R, Loke AY. An international survey on advanced practice nursing education, practice, and regulation. J Nurs Scholarsh. 2010;42(1):31-9.

24. Heale R, Rieck Buckley C. An international perspective of advanced practice nursing regulation. Int Nurs Rev. 2015;62(3):421-9.

25. Martin-Misener R, Donald F, Wickson-Griffiths A, Akhtar-Danesh N, Ploeg J, Brazil $\mathrm{K}$, et al. A mixed methods study of the work patterns of full-time nurse practitioners in nursing homes. J Clin Nurs. 2015;24(9-10):1327-37.

26. Gardner G, Gardner A, Middleton S, Della P, Kain V, Doubrovsky A. The work of nurse practitioners. J Adv Nurs. 2010;66(10):2160-9.

27. Bentley M, Minstrell M, Bucher H, Sproule L, Robinson A, Stirling C. Aged care nurse practitioners working in general practice. J Clin Nurs. 2015;24(23-24):3745-7.

28. Kennedy-Malone L, Penny J, Fleming ME. Clinical practice characteristics of gerontological nurse practitioners: a national study. J Am Acad Nurse Pract. 2008;20(1):1727.

29. Gardner A, Gardner GE, Middleton S, Della PR. The status of Australian nurse practitioners: the first national census. Aust Health Rev. 2009;33(4):679-89.

30. Schober M. Introduction to Advanced Nursing Practice. Debout C, editor. Cham, Switzerland: Springer International Publishing. 2016. 166 p.

31. Bailey P, Jones L, Way D. Family physician/nurse practitioner: stories of collaboration. J Adv Nurs. 2006;53(4):381-91. 
32. Ljungbeck B, Sjogren Forss K. Advanced nurse practitioners in municipal healthcare as a way to meet the growing healthcare needs of the frail elderly: a qualitative interview study with managers, doctors and specialist nurses. BMC Nurs. 2017;16:63.

33. Donelan K, DesRoches CM, Dittus RS, Buerhaus P. Perspectives of Physicians and Nurse Practitioners on Primary Care Practice. N Engl J Med. 2013;368(20):1898-906.

34. Siedlecki SL, Butler RS, Burchill CN. Survey design research: a tool for answering nursing research questions. Clin Nurse Spec. 2015;29(4):E1-8.

35. Henni SH, Kirkevold M, Antypas K, Foss C. The integration of new nurse practitioners into care of older adults: A survey study. J Clin Nurs. 2019;28(15-16):2911-23. 36. American Association of Nurse Practitioners. What's an NP? [Internet]. 2016. Available from: https://www.aanp.org/all-about-nps/what-is-an-np.

37. International Council of Nurses. Definition and Characteristics of the Role [Internet]. 2019. Available from: http://international.aanp.org/Practice/APNRoles.

38. Fagerstrom L. Developing the scope of practice and education for advanced practice nurses in Finland. Int Nurs Rev. 2009;56(2):269-72.

39. Nieminen AL, Mannevaara B, Fagerstrom L. Advanced practice nurses' scope of practice: a qualitative study of advanced clinical competencies. Scand J Caring Sci. 2011;25(4):661-70.

40. Wisur-Hokkanen C, Glasberg AL, Makela C, Fagerstrom L. Experiences of working as an advanced practice nurse in Finland - the substance of advanced nursing practice and promoting and inhibiting factors. Scand J Caring Sci. 2015;29(4):793-802.

41. Bergman K, Perhed U, Eriksson I, Lindblad U, Fagerstrom L. Patients' satisfaction with the care offered by advanced practice nurses: a new role in Swedish primary care. Int J Nurs Pract. 2013;19(3):326-33.

42. Lindblad E, Hallman EB, Gillsjo C, Lindblad U, Fagerstrom L. Experiences of the new role of advanced practice nurses in Swedish primary health care - A qualitative study. Int J Nurs Pract. 2010;16(1):69-74.

43. R Core Team. R: A language and environment for statistical computing [Internet]. Vienna, Austria: R Foundation for Statistical Computing; 2018. Available from: https://www.r-project.org/.

44. Rhee JS, Weaver EM, Park SS, Baker SR, Hilger PA, Kriet JD, et al. Clinical consensus statement: Diagnosis and management of nasal valve compromise. Otolaryngol Head Neck Surg. 2010;143(1):48-59.

45. Diamond IR, Grant RC, Feldman BM, Pencharz PB, Ling SC, Moore AM, et al. Defining consensus: a systematic review recommends methodologic criteria for reporting of Delphi studies. J Clin Epidemiol. 2014;67(4):401-9.

46. Bing-Jonsson PC, Hofoss D, Kirkevold M, Bjork IT, Foss C. Sufficient competence in community elderly care? Results from a competence measurement of nursing staff. BMC Nurs. 2016;15:5.

47. Bench S, Baker E, Dover N, Garry B, Nwosu W, Peacock S, et al. The education and training needs of advanced clinical practitioners: An exploratory, qualitative study. J Nurs Educ Pract. 2018;8(8).

48. Driscoll A, Harvey C, Green A, Weatherby RP, Liew D, Prentice D, et al. National nursing registration in Australia: a way forward for nurse practitioner endorsement. J Am Acad Nurse Pract. 2012;24(3):143-8.

49. Kraus E, DuBois JM. Knowing Your Limits: A Qualitative Study of Physician and Nurse Practitioner Perspectives on NP Independence in Primary Care. J Gen Intern Med. 2017;32(3):284-90. 
50. Lau R, Stevenson F, Ong BN, Dziedzic K, Treweek S, Eldridge S, et al. Achieving change in primary care - causes of the evidence to practice gap: systematic reviews of reviews. Implementation science : IS. 2016;11:40.

51. Lee G, Jennings N, Bailey M. An exploration of staff knowledge on the nurse practitioner's role in the emergency department. Accid Emerg Nurs. 2007;15(2):79-87.

52. Naughton C, Hayes N, Zahran Z, Norton C, Lee G, Fitzpatrick JM, et al. The development of the Older Person's Nurse Fellowship: Education concept to delivery. Nurse Educ Today. 2016;44:1-7. 
Table 1. Respondents' demographic and work characteristics $(n=218)$

\begin{tabular}{llll}
\hline Variables & $\begin{array}{c}\text { AGNs } \\
(n=23)\end{array}$ & $\begin{array}{c}\text { Colleagues } \\
(n=157)\end{array}$ & $\begin{array}{l}\text { Leaders } \\
(n=38)\end{array}$ \\
\hline Gender & $\begin{array}{l}21(91.3) \\
\text { Female }\end{array}$ & $\begin{array}{l}140(89.2) \\
2(8.7)\end{array}$ & $\begin{array}{l}17(10.8) \\
3(91.3)\end{array}$ \\
Male & $45.4[9.4]$ & $43.2[11.8]$ & $48.8[8.9]$ \\
Age [years] & & & \\
Type of work organisation & $21(91.3)$ & $149(94.9)$ & $36(94.7)$ \\
$\quad$ Primary care & $2(8.7)$ & $8(5.1)$ & $2(5.3)$ \\
Hospital care & & & \\
Job title & $1(4.4)$ & & $38(19.5)$ \\
Leader & & $5(2.6)$ & \\
Physician & $9(39.1)$ & & \\
AGN & $8(34.8)$ & $3(1.5)$ & \\
Specialist nurse & $5(21.7)$ & $64(32.8)$ & \\
Registered nurse & & $18(9.2)$ & \\
Occupational therapist & & $10(5.1)$ & \\
Physical therapist & & $30(15.4)$ & \\
Auxiliary nurse & & $10(5.6)$ & \\
Assistant & & $10(5.1)$ & \\
Executive officer & & \\
Other & & & \\
Worked in current position [years] $\dagger$ & $7.8[7.7]$ & $6.5[6.8]$ & $6.3[5.4]$ \\
\hline
\end{tabular}

Values are expressed as mean $[S D]$ or $n(\%)$.

$\dagger$ The AGNs' work experience ranges from 1-27 years, colleagues from 0-37 years and leaders from 1-23 years. The range explains why the $S D$ is larger than the average number of years the colleagues had worked in their current positions. 
Table 2. Activities that the AGNs, their colleagues and their leaders deemed appropriate for AGNs $(n=218)$

\begin{tabular}{|c|c|c|c|}
\hline Activities deemed appropriate for AGNs & $\begin{array}{l}\text { AGNs } \\
(n=23)\end{array}$ & $\begin{array}{l}\text { Colleagues } \\
(n=157)\end{array}$ & $\begin{array}{l}\text { Leaders } \\
(n=38)\end{array}$ \\
\hline \multicolumn{4}{|l|}{ Related to direct care } \\
\hline $\begin{array}{l}\text { Provision of nursing care for patients suffering from } \\
\text { an acute health condition/illness }\end{array}$ & $23(100)$ & $147(93.6)$ & $32(84.2)$ \\
\hline $\begin{array}{l}\text { Provision of nursing care for patients suffering from } \\
\text { a subacute health condition/illness }\end{array}$ & $23(100)$ & $147(93.6)$ & $34(89.5)$ \\
\hline $\begin{array}{l}\text { Provide nursing care for patients with impaired } \\
\text { cognitive impairment }\end{array}$ & $23(100)$ & $134(85.4)$ & $32(84.2)$ \\
\hline Provide nursing care for chronically ill patients & $23(100)$ & $137(87.3)$ & $32(84.2)$ \\
\hline $\begin{array}{l}\text { Survey patients for risk factors and early signs of } \\
\text { disease }\end{array}$ & $23(100)$ & $151(96.2)$ & $37(97.4)$ \\
\hline $\begin{array}{l}\text { Systematic clinical examination (inspection, } \\
\text { palpation, percussion and auscultation) }\end{array}$ & $21(91.3)$ & $135(86)$ & $30(78.9)$ \\
\hline Systematic gathering of medical history & $21(91.3)$ & $145(92.4)$ & $36(94.7)$ \\
\hline Patient guidance/teaching & $23(100)$ & $145(92.4)$ & $32(84.2)$ \\
\hline Next of kin guidance/teaching & $23(100)$ & $138(87.9)$ & $32(84.2)$ \\
\hline \multicolumn{4}{|l|}{ Related to indirect care } \\
\hline $\begin{array}{l}\text { Helping patients use their right to participate in } \\
\text { decisions regarding their own care }\end{array}$ & $21(91.3)$ & $136(86.6)$ & $32(84.2)$ \\
\hline $\begin{array}{l}\text { Referring patients across service levels (e.g., from } \\
\text { primary care to hospitals) }\end{array}$ & $19(82.6)$ & $135(86)$ & $33(86.8)$ \\
\hline $\begin{array}{l}\text { Referring patients within service levels (e.g., from } \\
\text { home care to nursing home) }\end{array}$ & $22(95.7)$ & $126(80.3)$ & $29(76.3)$ \\
\hline Use eHealth and care technology & $21(91.3)$ & $124(79)$ & $32(84.2)$ \\
\hline $\begin{array}{l}\text { Perform drug review in collaboration with the } \\
\text { patient's physician }\end{array}$ & $19(82.6)$ & $136(86.6)$ & 31 (81.6) \\
\hline Evaluation of patient services & $22(95.7)$ & $135(86)$ & $35(92.1)$ \\
\hline \multicolumn{4}{|l|}{ Related to teaching/supervision } \\
\hline Teaching colleagues a fixed subject & $22(95.7)$ & $152(96.8)$ & $38(100)$ \\
\hline Supervise colleagues in specific patient situations & $22(95.7)$ & $151(96.2)$ & $38(100)$ \\
\hline Supervise nursing students & $18(78.3)$ & $131(83.4)$ & $32(84.2)$ \\
\hline $\begin{array}{l}\text { Supervise nurses who are taking a master's degree or } \\
\text { further education in nursing }\end{array}$ & $23(100)$ & $146(93)$ & $33(86.8)$ \\
\hline Other types of teaching/supervision functions & $22(95.7)$ & $145(92.4)$ & $34(89.5)$ \\
\hline \multicolumn{4}{|l|}{ Related to coordination } \\
\hline Coordinate collaboration outside of the organisation & $21(91.3)$ & $135(86)$ & $31(81.6)$ \\
\hline Coordinate collaboration within the organisation & $21(91.3)$ & $140(89.2)$ & $33(86.8)$ \\
\hline \multicolumn{4}{|l|}{ Related to research and development work } \\
\hline Participate in research projects & $23(100)$ & $144(91.7)$ & $32(84.2)$ \\
\hline Work in committees/project groups & $21(91.3)$ & $137(87.3)$ & $29(76.3)$ \\
\hline $\begin{array}{l}\text { Contribute to that routines and procedures are } \\
\text { consistent with laws, rules and guidelines }\end{array}$ & $18(78.3)$ & $137(87.3)$ & $35(92.1)$ \\
\hline $\begin{array}{l}\text { Survey domains/activities where there is a need for } \\
\text { increased competence }\end{array}$ & $20(87.0)$ & $141(89.8)$ & $34(89.5)$ \\
\hline
\end{tabular}

Values are expressed as $n(\%)$. 
The table only presents the frequency count of those who responded, 'The activity is appropriate'; the rest of the respondents replied, 'The activity is inappropriate'. 
Table 3. Activities that the AGNs, their colleagues and their leaders have conflicting views regarding appropriateness $(n=218)$

\begin{tabular}{|c|c|c|c|}
\hline Activities with conflicting views & $\begin{array}{l}\text { AGNs } \\
(n=23)\end{array}$ & $\begin{array}{c}\text { Colleagues } \\
(n=157)\end{array}$ & $\begin{array}{l}\text { Leaders } \\
(n=38)\end{array}$ \\
\hline \multicolumn{4}{|l|}{ Related to direct care } \\
\hline $\begin{array}{l}\text { Provide nursing care for patients with a psychiatric } \\
\text { disorder }\end{array}$ & $17(73.9)$ & $107(68.2)$ & $24(63.2)$ \\
\hline Provide nursing care for rehabilitation patients & $23(100)$ & $122(77.7)$ & $20(52.6)$ \\
\hline Provide nursing care for patients in the palliative phase & $19(82.6)$ & $123(78.3)$ & $23(60.5)$ \\
\hline Provide nursing care for patients who have wounds & $18(78.3)$ & $108(68.8)$ & $18(47.4)$ \\
\hline $\begin{array}{l}\text { Perform life story interviews and incorporate it in } \\
\text { patient treatment }\end{array}$ & $20(87)$ & $107(68.2)$ & $15(39.5)$ \\
\hline Echocardiography & $13(56.5)$ & $92(58.6)$ & $19(50)$ \\
\hline Blood sample collection & $20(87.0)$ & $101(64.3)$ & $20(52.6)$ \\
\hline Blood gas sample collection & $13(56.5)$ & $86(54.8)$ & $14(36.8)$ \\
\hline Insert nutritional probe & $18(78.3)$ & $110(70.1)$ & $27(71.1)$ \\
\hline Insert a permanent catheter & $22(95.7)$ & $108(68.8)$ & $25(65.8)$ \\
\hline Manage intravenous fluid treatment & $20(87)$ & $119(75.8)$ & $26(68.4)$ \\
\hline \multicolumn{4}{|l|}{ Related to indirect care } \\
\hline $\begin{array}{l}\text { Planning and documenting care and follow-up of } \\
\text { patient treatment }\end{array}$ & $16(69.6)$ & $110(70.1)$ & $18(47.4)$ \\
\hline Discharge patients from hospitals & $8(34.8)$ & $68(43.3)$ & $7(18.4)$ \\
\hline Discharge patients from primary care & $16(69.6)$ & $92(58.6)$ & $19(50)$ \\
\hline Prescribe and assess haemoglobin & $23(100)$ & $118(75.2)$ & $27(71.1)$ \\
\hline Prescribe and assess C-reactive protein & $23(100)$ & $119(75.8)$ & $26(68.4)$ \\
\hline Prescribe and assess other blood samples & $22(95.7)$ & $100(63.7)$ & $24(63.2)$ \\
\hline Prescribe and assess bladder scanning & $23(100)$ & $115(73.2)$ & $30(78.9)$ \\
\hline Prescribe fluid treatment & $19(82.6)$ & $100(63.7)$ & $23(60.5)$ \\
\hline Prescribe X-ray & $19(82.6)$ & $78(49.7)$ & $18(47.4)$ \\
\hline Prescribe ultrasound & $15(65.2)$ & $70(44.6)$ & $18(47.4)$ \\
\hline Prescribe and order medical supplies & $21(91.3)$ & $96(61.1)$ & $20(52.6)$ \\
\hline Prescribe a pre-agreed selection of drugs & $19(82.6)$ & $92(58.6)$ & $21(55.3)$ \\
\hline
\end{tabular}

Values are expressed as $n(\%)$.

The table only presents the frequency count of those who responded, 'The activity is appropriate'; the rest of the respondents replied, 'The activity is inappropriate'. 


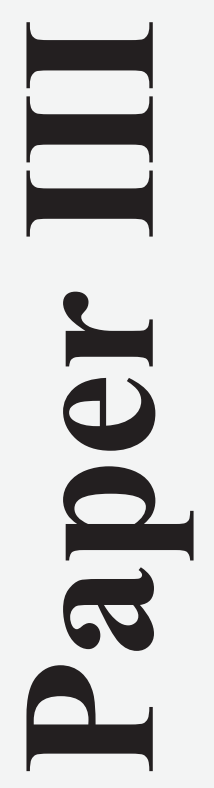





\title{
The integration of new nurse practitioners into care of older adults: A survey study
}

\author{
Silje Havrevold Henni MNSc, RN, Doctoral Research Fellow (iD ｜ Marit Kirkevold EdD, RN, \\ Professor | Konstantinos Antypas PhD, RN, Postdoctoral researcher | Christina Foss Dr. \\ Polit, RN, Professor
}

Department of Nursing Science, Institute of Health and Society, Faculty of Medicine, University of Oslo, Oslo, Norway

Correspondence

Silje Havrevold Henni, Department of Nursing Science, University of Oslo, P.O. Box 1130 Blindern, NO-0318 Oslo, Norway.

Email:s.h.henni@medisin.uio.no

Funding information

The research was funded by The Research Council of Norway, Programme on Health, Care and Welfare Services Research (HELSEVEL), Project number 239766.

\begin{abstract}
Aims and objectives: To assess Norwegian advanced geriatric nurses' (AGNs) use of their knowledge and skills, and factors that may influence AGNs' opportunities to use their knowledge and skills to reach their full potential.

Background: Despite the need for nurses with advanced knowledge and skill in the care of older adults, the introduction of new advanced nursing roles has been challenging. Countries in the process of establishing advanced roles need to monitor and identify possible implementation issues.

Design: A cross-sectional descriptive survey.

Methods: We invited the total population of AGNs in Norway $(n=26)$ and some of their colleagues $(n=465)$ to answer an online questionnaire. Twenty-three (88.5\%) of the AGNs and 195 (42.0\%) of the invited colleagues completed and submitted the questionnaires. The data were analysed with descriptive statistics. STROBE guidelines were used in reporting this study.

Results: Of the AGNs, 16 (69.6\%) used their knowledge and skills to their full potential when providing direct care. However, a minority used their knowledge and skills to their full potential when proving indirect care ( $n=11,47.8 \%)$, teaching/supervision ( $n=11,47.8 \%$ ) and coordination ( $n=5,21.8 \%)$. A total of $47(24.1 \%)$ colleagues experienced the AGNs' scope of practice as completely clear, and 52 (26.6\%) collaborated with the AGNs several times a week. Of the colleagues, 131 (67.2\%) considered the AGNs' role and scope of practice contributed positively to a high degree to health service for older adults.

Conclusion: The results indicate the need for greater focus on organisational adjustment for the AGNs to utilise their knowledge and skills to their full potential.

Relevance to clinical practice: There is a need for greater focus on organisational adjustment to integrate $A G N s$ at the workplace, as complete integration may improve the AGNs' use of their knowledge and skills.

KEYWORDS

advanced nursing, integration, knowledge, nurse practitioners, nurse roles, survey
\end{abstract}


2912 WI LEY-Clinical Nursing

\section{1 | INTRODUCTION}

Globally, there is a trend towards strengthening primary care by introducing highly qualified nurses who are able to provide specialised health care to older adults (Maier, Aiken, \& Busse, 2017) and decreasing the length of stay in hospitals (OECD, 2013). Older adults often have multifaceted care requirements due to complex and interrelated health problems (Ruiz, Bottle, Long, \& Aylin, 2015). Shorter hospital stays result in patients being discharged "quicker and sicker" than before and are thus at an earlier stage of the rehabilitation process (LeClerc, Wells, Craig, \& Wilson, 2002; Qian, Russell, Valiyeva, $\&$ Miller, 2011). The multimorbidity and early discharge from hospitals have led to increased demands on a primary care system that is often fragmented and staffed with employees with varying degrees of education (Maier et al., 2017). To meet these demands and the need for coordination of services within the primary care system, nurses' roles and clinical practice have been expanded by advancing nurses' skills and knowledge through the development of advanced practice nurse roles (Laurant et al., 2018; Maier et al., 2017). This study explores the introduction of nurse practitioners into care of older adults in Norway.

\section{1 | Background}

There is no common understanding of the role of advanced practice nurses, and there is variation in the education, regulation, licensing and credentialing requirements (Heale \& Rieck Buckley, 2015). Still, the International Council of Nurses (2015) has offered the following definition of advanced practice nursing independent of field of practice:

\begin{abstract}
A Nurse Practitioner/Advanced Practice Nurse is a registered nurse who has acquired the expert knowledge base, complex decision-making skills and clinical competencies for expanded practice, the characteristics of which are shaped by the context and/ or country in which $s /$ he is credentialed to practice. A master's degree is recommended for entry level. (International Council of Nurses, 2015, para. 2)
\end{abstract}

To meet the need for qualified nurses in the care of older adults with complex healthcare needs, the University of Oslo, Norway, started a master's degree programme in advanced practice nursing in 2011. The graduates, entitled Advanced Geriatric Nurses (AGNs), comply with the definition from the International Council of Nurses (2015) and have a specific focus on the complex care for older adults.

Nurse practitioners caring for older adults need advanced knowledge and skills to be prepared for managing complex patient situations and for extended roles and functions. In line with advanced practice nursing internationally, the AGNs are prepared for extended roles both with regard to direct and indirect care, teaching/supervision and coordination functions (Bentley et al., 2015; Delamaire \& Lafortune, 2010; Gardner et al., 2010; Henni, Kirkevold,

\section{What does this paper contribute to the wider global clinical community?}

- Nurse practitioners who specialise in the care of older adults use their knowledge and skills to their full potential related to direct care. However, they do not use their knowledge and skills to their full potential related to indirect care, teaching/supervision and coordination.

- Nurse practitioners who specialise in the care of older adults believe that there is a need for organisational adjustments for them to use their knowledge and skills to their full potential.

- Nurse practitioners who specialise in the care of older adults are not fully integrated into their field of practice.

Antypas, \& Foss, 2018; Kennedy-Malone, Penny, \& Fleming, 2008; Martin-Misener et al., 2015). During their education, the AGNs gain advanced theoretical and practical knowledge and skills related to these different functions focusing on the specific health challenges associated with older adults. They attend courses on the normal ageing process, pathophysiology and medical treatment, physical assessment skills and pharmacology. Furthermore, they are prepared to provide advanced direct and indirect acute and subacute care, disease prevention and health promotion related to public and individual health, and rehabilitation and palliative care. They also attend courses addressing laws, reforms and regulations related to care of older adults as well as research and development work. The AGNs are taught comprehensive nursing care to older adults with different health challenges as well as medical care by independently examining, assessing and treating the care needs of older adults. The AGNs also learn to supervise colleagues and students in challenging patient cases, teach colleagues and students fixed subjects, guide/ teach patients and next of kin and coordinate care between health professions both within and outside the organisation of employment by setting up a multidisciplinary treatment plan and to manage patient cases.

Despite the need for nurses with a wide range of knowledge and skills to meet the needs of older adults (Bing-Jonsson, Bjork, Hofoss, Kirkevold, \& Foss, 2015; Kiljunen, Valimaki, Kankkunen, \& Partanen, 2017), research has found that nurse practitioners in these new roles express that they are not able to practice to their full potential (Henni et al., 2018; Poghosyan et al., 2013). One possible explanation for the inability to practice is related to a lack of integration into their work situation.

Andregard and Jangland (2015) show that it is a complex process to integrate the new nurse practitioners' role into an existing workplace. A nurse practitioner is integrated at the workplace when they are included in the routine care provided (Maier et al., 2017). In this study, we assume that integration is related to the degree to which colleagues of the AGNs have knowledge about the AGNs' role and scope of practice, draw on the AGNs' expertise through 
collaboration and see AGNs as partners who contribute to health services (Contandriopoulos et al., 2015; Maier et al., 2017).

International literature has identified multiple factors that influence integration of nurse practitioners into practice settings (Contandriopoulos et al., 2015; Maier et al., 2017; Sangster-Gormley, Martin-Misener, Downe-Wamboldt, \& Dicenso, 2011). A factor that may affect integration is workplace preparation for the introduction of the new nurse practitioner (Bryant-Lukosius, Dicenso, Browne, \& Pinelli, 2004; Contandriopoulos et al., 2015; Sangster-Gormley et al., 2011). Involvement of staff members in the planning process of a nurse practitioner's arrival can lead to a common understanding of the role and scope of practice (Contandriopoulos et al., 2015; Sangster-Gormley et al., 2011). Hence, team consensus on role definition is a factor. Sangster-Gormley et al. (2011) have shown that managers can promote integration of the new nurse practitioner by introducing the person to staff members and providing information about how the new role fits into the practice setting. Another factor that may affect integration is the collaborative culture at the workplace, as collaboration between the nurse practitioner and staff members can lead to a joint practice where workers understand each other's roles and contributions (Contandriopoulos et al., 2015; Sangster-Gormley et al., 2011). Research has further shown that acceptance and support of the new role from managers and staff members is also a factor, as it may influence the nurse practitioners' opportunities to practice all dimensions of the role (Contandriopoulos et al., 2015; Maier et al., 2017; Sangster-Gormley et al., 2011). The final factor found to affect integration is whether the workplace is organised in a way that makes it possible for the nurse practitioner to meet the care needs of older adults, such as access to recourses, collaborative relationship with a physician and internal communication (Contandriopoulos et al., 2015; Maier et al., 2017; Poghosyan et al., 2013)

Nurse practitioners have had a specific role for more than 40 years in Canada and the USA (American Association of Nurse Practitioners, 2016a; Canadian Nurses Association, 2017). Advanced practice nursing is also expanding in Europe. For instance in the UK, the Netherlands and Ireland specific nurse practitioner roles are well established (Maier et al., 2017; Schober, 2016; Sheer \& Wong, 2008). However, nurse practitioner roles are established to a lesser extent in France, Germany and Nordic countries (Maier et al., 2017; Schober, 2016; Sheer \& Wong, 2008). The lack of formal regulation of the nurse practitioner role is common in many European countries (Carney, 2016) and is found to be likely to hamper integration (Maier et al., 2017). The AGNs have expressed in qualitative interviews that the type of position they had affected their possibilities to develop their role, and many of them stated that their managers had not done enough to customise an AGN position that optimised the use of knowledge and skills (Henni et al., 2018).

As it is a political goal to strengthen the care of older adults through nurse practitioners (Boerma, 2006; Boerma et al., 2015; Kringos et al., 2015; Report to the Storting No. 26., 2015), there is a need for knowledge about how nurse practitioners who specialise in the care of older adults can use their knowledge and skills to their full potential. The degree to which nurse practitioners use their knowledge and skills may have different reasons. This study focuses on the degree to which the AGNs are integrated into healthcare settings. According to Maier et al. (2017), there is a need to pursue more information about the uptake of nurses in advanced roles and their knowledge and skills in different countries, as the information about nurse practitioners in countries without regulation is scarce. Sharing information on the uptake of nurse practitioners may foster successful uptake of nurse practitioners in countries that are in the infancy of introducing nurse practitioner roles.

\subsection{Aim}

To investigate the level of integration of AGN's in their fields of practice, we assess AGNs' use of their knowledge and skills, and factors that may influence AGNs' opportunities to use their knowledge and skills to reach their full potential. The specific research questions in this study were as follows:

- To what degree do AGNs estimate that they use their knowledge and skills related to the following functions: direct and indirect care, teaching/supervision and coordination?

- What factors do the AGNs believe influence their opportunities to use their knowledge and skills to their full potential?

- What relationship are there between the AGNs' position and their reported use of their knowledge and skills related to the following functions: direct and indirect care, teaching/supervision and coordination?

- To what degree are AGNs integrated at their workplaces, measured through their colleagues' knowledge about the AGN role and scope of practice, collaboration between colleagues and AGNs, and colleagues' opinions of whether the AGNs contribute positively to health services?

\section{2 | METHODS}

\section{1 | Design}

This study had a cross-sectional descriptive survey design (Siedlecki, Butler, \& Burchill, 2015). We used STROBE guidelines for cross-sectional studies in reporting this study (see File S1).

\section{2 | Sample}

The master's degree programme in advanced practice nursing at the University of Oslo is a new education in Norway, and the total population of AGNs is just 26. The total population of AGNs were invited by email to participate in the study during autumn 2017. They were asked to provide their workplace and their manager's contact information, so a sample of the AGNs' colleagues could be invited to participate in the study. Twenty-four AGNs provided information. One of the AGNs did not want to participate in the study, while 
another AGN wanted to participate in the study but did not want the colleagues to participate. Three of the AGNs that provided information did not work clinically at the time of data collection, but were instructors at nursing education programmes or involved in research. However, they had worked clinically after they graduated as an AGN and were therefore also included in the study. Twentyone AGNs that provided information worked in clinical positions at 19 different workplaces. To optimise the strategy for the recruitment of colleagues, possibilities were discussed with some of the managers and the AGNs who worked in clinical positions. There was consensus that most colleagues would answer the questionnaire if they were recruited by their manager. Furthermore, the managers judged they had the capacity to recruit a maximum of 30 persons. We emailed the managers a formal enquiry, asking them to recruit 30 colleagues from the AGNs' workplaces that were willing to answer a questionnaire. We do not know the number of the total population of colleagues. The managers were asked to register those who did not want to participate in the study, but only a few of the managers did report it. For variation in the sample and to recruit colleagues involved in the care of older adults, we provided managers with the following inclusion criteria for the selection of colleagues:

- Persons must be involved in the care of older adults in the municipality/institution where the AGN works.

- The sample should include participants from all system levels and with different job titles.

- There should be a minimum of one to two persons from all health professions involved in the care of older adults at the workplace.

Sixteen of the managers participated in recruiting colleagues either personally or by delegating the task. Four of the managers did not manage to recruit 30 persons due to scarce capacity and lack of persons to recruit. At five workplaces, more than 30 colleagues were recruited. In total, 465 colleagues were recruited to the study.

\section{3 | Data collection}

At the beginning of January 2018, 25 AGNs and 465 colleagues were emailed a hyperlink forwarding them to a questionnaire. Follow-up reminders were sent by email 2, 4 and 6 weeks after the initial email, and data collection was finished 12 weeks after the first email. In the last reminder, managers and AGNs were asked to encourage people to respond. AGNs who did not currently work in a clinical position were asked to answer the questions based on their previous clinical experiences as an AGN.

\section{4 | The questionnaires}

The research team conducted a literature search to identify existing psychometrically tested questionnaires within the research area, but did not identify any such questionnaire. The research team therefore developed one questionnaire for the AGNs and another questionnaire for their colleagues. The questionnaires consisted of three sections. The two questionnaires were designed to match within the sections, but the wording of the questions was adjusted to match each target group. This study has used data from Section 1 from both questionnaires, Section 2 from the AGN questionnaire and Section 3 from the colleague questionnaire.

The questions from the first section describe the respondents' gender, age, job title/position, years worked in current position and work hours. In Section 2, the AGNs were asked to estimate the degree they used their knowledge and skills related to different functions. In line with international policies for advanced nursing practice, the educational programme stressed that AGNs should have their own patient load. Therefore, we explored how the AGNs used their new knowledge and skills related to both direct and indirect care. Furthermore, we explored how they used their knowledge and skills related to teaching/supervision and coordination (one question per function). The response options were "To a high degree," "To some degree," "To a low degree" and "Absolutely not". The different functions were operationalised into more specific questions of the AGNs' activities as shown in Table 1. However, the context-specific nature of nursing combined with the need to avoid that the questionnaires became too long, made it impossible to operationalise all the activities at the same level of specification. Some of the activities are therefore described as broad patient situations reflecting the educational orientation of the AGN programme. We also included specific tasks related to extended roles and functions. All the included activities are based upon literature describing common tasks for nurse practitioners internationally (American Association of Nurse Practitioners, 2016b; Bentley et al., 2015; Delamaire \& Lafortune, 2010; Gardner et al., 2010; International Council of Nurses, 2015; Kennedy-Malone et al., 2008; Martin-Misener et al., 2015). We judged this to be appropriate as the aim of the questionnaires was to explore the use of knowledge and skills acquired during their education, not to describe the AGN-specific work performance.

In Section 2 in the questionnaire, the AGNs were also asked about reasons for not using their knowledge and skills to a high degree. The question had seven different reasons as response options (with a possibility to select more than one option), in addition to a free text field where the AGNs could write down their answer in their own words (the response options are presented in Table 4). The third section covered integration of AGNs in healthcare settings, measured through colleagues' knowledge about the AGN role and scope of practice, collaboration between colleagues and AGNs, and colleagues' opinions of whether the AGNs contribute positively to health services. The specific questions with response options are presented in Table 6. The data that are not used in this study will be used in another study exploring the AGNs' scope of practice.

The entire research team reviewed the questionnaires for content and face validity. Only questions and response categories that reached $100 \%$ consensual validation by the research team were retained. In the next step, two AGNs tested the AGN questionnaire and one manager, one physician, one registered nurse, one auxiliary nurse and one 
TAB LE 1 Description of different functions and activities that can be related to the functions

\section{Functions}

Direct care

Nursing care for and in the presence of a particular patient, including guidance/teaching given to patients and next of kin (20 activities)

\section{Indirect care}

Nursing care performed away from a patient but for a particular patient, including delegated medical activities (18 activities)

\section{Teaching/supervision}

Teaching and supervision of colleagues and nursing students (5 activities)
Coordination

Coordination of collaboration outside of and within the organisation of employment (2 activities)

\section{Activities that can be related to the functions}

Provision of nursing care for patients suffering from an acute health condition/illness Provision of nursing care for patients suffering from a subacute health condition/illness Provision of nursing care for patients with impaired cognitive impairment Provision of nursing care for patients with a psychiatric disorder Provision of nursing care for chronically ill patients

Provision of nursing care for rehabilitation patients

Provision of nursing care for patients in the palliative phase

Provision of nursing care for patients with wounds

Assessment of patients for risk factors and early signs of disease

Systematic clinical examination (inspection, palpation, percussion and auscultation)

Systematic gathering of medical history

Perform life story interviews and incorporate into patient treatment

Patient guidance/teaching

Next of kin guidance/teaching

Echocardiography

Blood sample collection

Blood gas sample collection

Insertion of nutritional probe

Insertion of permanent catheter

Management of intravenous fluid treatment

Planning and documenting care and follow-up of patient treatment

Helping patients use their right to participate in decisions regarding their own care

Referring patients across service levels (e.g., from primary care to hospitals)

Referring patients within service levels (e.g., from home care to nursing home)

Discharging patients from hospitals

Discharging patients from primary care

Use of eHealth and care technology

Perform drug review in collaboration with the patient's physician

Evaluation of patient services

Prescription and assessment of haemoglobin

Prescription and assessment of C-reactive protein

Prescription and assessment of other blood samples

Prescription and assessment of bladder scanning

Prescription and assessment of fluid treatment

Prescription of X-ray

Prescription of ultrasound

Prescription and ordering of medical supplies

Prescription of a preagreed selection of drugs

Teaching colleagues a fixed subject

Supervision of colleagues in specific patient situations

Supervision of nursing students

Supervision of nurses who are taking a master's degree or further education in nursing

Other types of teaching/supervision functions

Coordination of collaboration outside of the organisation

Coordination of collaboration within the organisation 
TAB LE 2 Demographic characteristics of respondents to the two questionnaires $(n=218)$

\begin{tabular}{|c|c|c|}
\hline Variables & AGNs $(n=23)$ & $\begin{array}{l}\text { Colleagues } \\
(n=195)\end{array}$ \\
\hline \multicolumn{3}{|l|}{ Gender } \\
\hline Female & $21(91.3)$ & $175(89.7)$ \\
\hline Male & $2(8.7)$ & $20(10.3)$ \\
\hline Age [years] & $45.4[9.4]$ & $44.3[11.5]$ \\
\hline \multicolumn{3}{|l|}{ Job title } \\
\hline Manager & & $9(4.6)$ \\
\hline Leader & $1(4.4)$ & 29 (14.9) \\
\hline Physician & & $5(2.6)$ \\
\hline AGN & 9 (39.1) & \\
\hline Specialist nurse & $8(34.8)$ & $3(1.5)$ \\
\hline Registered nurse & $5(21.7)$ & 64 (32.8) \\
\hline Occupational therapist & & $18(9.2)$ \\
\hline Physical therapist & & $10(5.1)$ \\
\hline Auxiliary nurse & & 30 (15.4) \\
\hline Assistant & & $7(3.6)$ \\
\hline Executive officer & & $10(5.1)$ \\
\hline Other & & $10(5.1)$ \\
\hline $\begin{array}{l}\text { Worked in current posi- } \\
\text { tion [years] }{ }^{a}\end{array}$ & $7.8[7.7]$ & $6.4[6.6]$ \\
\hline \multicolumn{3}{|l|}{ Work hours } \\
\hline Day, evening and night & & $10(5.1)$ \\
\hline Day and evening & $9(39.1)$ & $73(37.4)$ \\
\hline Day & $14(60.9)$ & $112(57.5)$ \\
\hline
\end{tabular}

Note: Values are expressed as mean [SD] or $n(\%)$.

${ }^{a}$ The AGNs range from 1-27 years and colleagues from 0-37 years. The range explains why the SD is larger than the average years the colleagues had worked in their current position.

assistant tested the colleague questionnaire for face and content validity. The testers were instructed to give feedback on whether the questions and response categories were comprehensible, relevant and appropriate, whether the questionnaires were easy to fill out and if they contained ambiguous questions and or response categories. The testers were also asked to give feedback on the wording of the questionnaire and whether additional relevant questions and or response categories were missing. A few questions in the questionnaires were slightly changed as a consequence of the testers' responses. Once again, only question and response categories that reached $100 \%$ consensual validation by the whole research team were retained.

\subsection{Ethical considerations}

Participation in the study was voluntary. Submission of the questionnaires was considered consent for participation. The study received ethical approval from the Norwegian Centre for Research Data (project number: 46618).

\section{6 | Data analysis}

The respondents had to answer all the questions to submit the questionnaire online. Missing data were therefore not a problem, and all submitted questionnaires were included in the analysis. The first author prepared the data for analysis by inspecting the data for errors and irregularities. The majority of the answers in the free text field of the question regarding reasons for lack of use of knowledge and skills seemed to correspond well to already existing response options. Therefore, they were coded to the corresponding existing option for the data analysis.

The data were analysed using $\mathrm{R}$ version 3.4.4 ( $\mathrm{R}$ Core Team, 2018). A descriptive data analysis of all variables was conducted by calculating the mean and SD of the continuous variables and the frequency and percentage distribution of the categorical variables. A series of cross-tabulations, Fisher's exact test and Kruskal-Wallis test were conducted to identify whether it was possible to identify a pattern between the AGNs' position and the AGNs' reported use of their knowledge and skills. We divided the colleagues into three groups by their job title to see whether there were differences in what they reported regarding different variables. One group consisted of managers and leaders and another group of registered nurses and specialist nurses. The last group are named "other colleagues" and consists of physicians, occupational therapists, physical therapists, auxiliary nurses, assistants, executive officers and colleagues who had job titles other than those included in the three groups. Thereafter, a series of cross-tabulations, Pearson's chi-squared test/Fisher's exact test and Kruskal-Wallis test was conducted on colleagues' knowledge about the AGNs' variables, collaboration variables and the variable regarding the AGNs' contributions to examine whether there were any differences among the three groups of colleagues. We have conducted both Pearson's chi-squared test/Fisher's exact test and KruskalWallis test because the Pearson's chi-squared test/Fisher's exact test tests associations between the variables, while the Kruskal-Wallis test tests differences between the groups. Analyses with a $p$-value lover than 0.05 were considered statistically significant.

\section{3 | RESULTS}

Twenty-three (88.5\%) of the AGNs and 195 (42.0\%) of the invited colleagues completed and submitted questionnaires. Table 2 shows the respondents' demographic characteristics. Nine (39.1\%) of the AGNs had a designated AGN position, and the rest had positions as leaders, specialist nurses or registered nurses.

\section{1 | AGNs' use of their knowledge and skills related to different functions}

The degree to which the AGNs use their knowledge and skills related to different functions was examined (Table 3). The analysis showed that more than two-thirds of the AGNs expressed that they used their knowledge and skills to their full potential when 
TAB LE 3 The degree AGNs report they use their knowledge and skills related to different functions $(n=23)$

\begin{tabular}{|c|c|c|c|c|}
\hline Functions & Absolutely not & To a low degree & To some degree & To a high degree \\
\hline Direct care & $1(4.3)$ & $1(4.3)$ & $5(21.8)$ & $16(69.6)$ \\
\hline Indirect care & & $5(21.8)$ & $7(30.4)$ & $11(47.8)$ \\
\hline Teaching/supervision & & $4(17.4)$ & $8(34.8)$ & $11(47.8)$ \\
\hline Coordination & $2(8.6)$ & $4(17.4)$ & $12(52.2)$ & $5(21.8)$ \\
\hline
\end{tabular}

Note: Values are expressed as $n(\%)$

providing direct care. Almost half of the AGNs claimed to use their knowledge and skills to their full potential when providing indirect care and teaching/supervision. Looking at the coordination function, under a quarter of the AGNs stated that they used their knowledge and skills to their full potential. Only a few of the AGNs reported that they did not use their knowledge and skills related to different functions at all. Almost all of the AGNs stated that they used their knowledge and skills to some degree or higher when providing direct and indirect care, teaching/supervision and coordination.

\section{2 | Factor AGNs believe influence opportunities to use their knowledge and skills}

Over half of the AGNs stated that the way the workplace was organised influenced their opportunities to use their knowledge and skills, while other factors were identified by only a few respondents (Table 4). Looking at the cross-tabulation of results, we did not observe a relationship between having a designated AGN position and the AGNs' use of knowledge and skills in relation to direct care and coordination (Table 5). The results do, however, show a significant relationship between position and the use of knowledge and skills related to indirect care (Fisher's exact test: $p=0.046$, Kruskal-Wallis test: $H(1)=6.024, p=0.014)$. There also seems to be a relationship between position and the use of knowledge and skills related to teaching/supervision, as Fisher's exact test shows a nearly significant relationship $(p=0.052)$ and the Kruskal-Wallis test shows a significant relationship $(H(1)=5.754, p=0.016)$. The degree to which the AGNs used their skills and knowledge in these areas was higher among responders with a designated AGN position than those in other positions.

\section{3 | Integration of AGNS in the workplace}

The cross-tabulation of results showed no significant differences between job title when it came to colleagues' answers regarding their knowledge about the AGN role and scope of practice, collaboration with AGNs and opinion of whether the AGNs contribute positively to the health service of older adults (Table 6). To study colleagues' knowledge about the AGNs, we examined whether they knew which nurse was the AGN at their workplace, and found that almost all knew (Table 6). We also examined whether colleagues felt adequately informed about the role and scope of practice of the AGNs. Over half of the colleagues reported that they either had not been informed at all about the role and scope of practice of the AGNs or that the information provided was not sufficient ( $n=109,55.9 \%$ ). The rest of the colleagues reported that the information provided was sufficient. Just under a quarter of the colleagues experienced the AGNs' scope of practice as completely clear (Table 6). To study collaboration between AGNs and their colleagues, we examined the frequency of collaboration and found that slightly under three quarters of the colleagues collaborated with the AGNs once a week or less (Table 6). We also found that a quarter of the colleagues provided contact between patients and the AGNs to a high degree (Table 6). Finally, over half of the colleagues reported that the role and scope of practice of the AGN contributed positively to the health services for older adults to a high degree (Table 6).

\section{4 | DISCUSSION}

The results indicate that AGNs have positions that facilitate the delivery of direct care, as most use their knowledge and skills to their
TAB LE 4 Reasons why AGNs do not use their knowledge and skills to a high degree $(n=23)$

\begin{tabular}{lc}
\hline Reasons for not using knowledge and skills to a high degree & AGNs \\
\hline The way the workplace is organised & $12(52.2)$ \\
\hline Lack of request from managers/leaders and or other colleagues & $6(26.1)$ \\
\hline The role and scope of practice of the AGN is too wide & $3(13.0)$ \\
\hline Lack of support from managers/leaders & $3(13.0)$ \\
\hline The role and scope of practice of the AGN is too narrow & $2(8.7)$ \\
\hline Lack of support from colleagues & $2(8.7)$ \\
\hline Lack of confidence to assume the role & $1(4.3)$ \\
\hline
\end{tabular}

Note: Values are expressed as $n$ (\%).

${ }^{a}$ The respondents could tick off one or several response categories. 
TAB LE 5 The degree AGNs report they use their knowledge and skills related to different functions by position ( $n=23$ )

\begin{tabular}{|c|c|c|c|c|c|}
\hline Functions & $\begin{array}{l}\text { Designated AGN posi- } \\
\text { tion }(n=9)\end{array}$ & Other position $(n=14)$ & Total sample $(n=23)$ & $\begin{array}{l}\text { Fisher's exact } \\
\text { test }\end{array}$ & $\begin{array}{l}\text { Kruskal- } \\
\text { Wallis test }\end{array}$ \\
\hline \multicolumn{6}{|l|}{ Direct care } \\
\hline To a high degree & $8(88.9)$ & $8(57.2)$ & $16(69.6)$ & \multirow[t]{4}{*}{$p=0.566$} & \multirow{4}{*}{$\begin{array}{c}H(1)=2.675 \\
p=0.102\end{array}$} \\
\hline To some degree & \multirow[t]{3}{*}{1 (11.1) } & $4(28.6)$ & $5(21.8)$ & & \\
\hline To a low degree & & $1(7.1)$ & $1(4.3)$ & & \\
\hline Absolutely not & & $1(7.1)$ & $1(4.3)$ & & \\
\hline \multicolumn{6}{|l|}{ Indirect care } \\
\hline To a high degree & $7(77.8)$ & $4(28.6)$ & $11(47.8)$ & \multirow[t]{3}{*}{$p=0.046^{a}$} & \multirow{3}{*}{$\begin{array}{c}H(1)=6.024 \\
p=0.014^{\mathrm{a}}\end{array}$} \\
\hline To some degree & \multirow[t]{2}{*}{$2(22.2)$} & 5 (35.7) & $7(30.4)$ & & \\
\hline To a low degree & & $5(35.7)$ & $5(21.8)$ & & \\
\hline \multicolumn{6}{|c|}{ Teaching/supervision } \\
\hline To a high degree & $7(77.8)$ & $4(28.6)$ & $11(47.8)$ & \multirow[t]{3}{*}{$p=0.052$} & \multirow{3}{*}{$\begin{array}{c}H(1)=5.754 \\
p=0.016^{\mathrm{a}}\end{array}$} \\
\hline To some degree & $2(22.2)$ & $6(42.9)$ & $8(34.8)$ & & \\
\hline To a low degree & & $4(28.6)$ & $4(17.4)$ & & \\
\hline \multicolumn{6}{|l|}{ Coordination } \\
\hline To a high degree & $2(22.2)$ & $3(21.4)$ & $5(21.7)$ & \multirow[t]{4}{*}{$p=0.685$} & \multirow{4}{*}{$\begin{array}{c}H(1)=0.858 \\
p=0.354\end{array}$} \\
\hline To some degree & $6(66.7)$ & $6(42.9)$ & $12(52.2)$ & & \\
\hline To a low degree & 1 (11.1) & $3(21.4)$ & $4(17.4)$ & & \\
\hline Absolutely not & & $2(14.3)$ & $2(8.7)$ & & \\
\hline
\end{tabular}

Note: Values are expressed as $n(\%)$.

${ }^{*} P$-value lover than 0.05 .

full potential within direct care. This result is in line with the strong emphasis in the educational programme of the importance of making the advanced knowledge and skills of AGNs accessible to older patients in need. It is also consistent with previous national (Henni et al., 2018) and international studies (Martin-Misener et al., 2015; Sangster-Gormley, Martin-Misener, \& Burge, 2013; Ter MatenSpeksnijder, Dwarswaard, Meurs, \& van Staa, 2016). Contemporary health policy promotes advanced care for frail older adults in the community (World Health Organization, 2015). The AGNs therefore seem to use their knowledge and skills in direct care in line with society's needs.

The majority of AGNs expressed that they used their knowledge and skills in indirect care to some degree or higher, though under half of them to a high degree. Nurse practitioners have stated that lack of authority to order tests, write prescriptions and lack of legislative support hinder them in practicing to their full potential (Gardner, Gardner, Middleton, \& Della, 2009). Our results suggest that there is room for improvement to fully capitalise on the AGNs' knowledge and skills in this area.

Looking at the AGNs' function related to teaching/supervision, the majority of AGNs express that they use their knowledge and skills related to teaching/supervision to some degree or higher, though under half of them to a high degree. Educational activities for staff members in primary care are important, as nurses caring for older adults often need more knowledge (Bing-Jonsson, Hofoss, Kirkevold, Bjork, \& Foss, 2016; Kiljunen et al., 2017). Also, many staff members caring for older adults have little or no formal training within health care in general and within care of older adults in particular (World Health Organization, 2015). Caring for older adults is complex (Ruiz et al., 2015), and research has found that nurse practitioners are well suited to teach health personnel advanced knowledge and skills within the field of care of older adults (Perfetto, Holden, \& McNabney, 2018; Walsh, Moore, Barber, \& Opsteen, 2014). Nurse practitioners caring for older adults have a cross-disciplinary perspective and can, for example, teach health personnel when and how to seek information from others and what are relevant questions to ask (Perfetto et al., 2018). The AGNs have expressed in qualitative interviews that health professionals from other disciplines ask them for consultations regarding the care of older adults (Henni et al., 2018), which indicates that health personnel from different disciplines recognise the AGNs' knowledge and skills and want to learn from them. This may contribute to explain the result that over half of the colleagues considered that the AGNs contributed positively to the health services of older adults.

The majority of AGNs stated that they used their knowledge and skills related to coordination to some degree or higher, but only a few to a high degree. A care and treatment plan for older adults, as well as coordination of multiple care providers, professions, institutions and levels of care, are described as particularly important in improving quality of care for older adults (Donald et al., 2013; Morilla-Herrera et al., 2016). Research has documented that the care of older adults is frequently fragmented, leading to 
TAB LE 6 Integration of AGNs at their workplaces measured through colleagues' knowledge about the AGN role and scope of practice, collaboration between colleagues and AGNs, and colleagues' opinion of whether AGNs contribute positively to health services by colleague job title $(n=195)$

\begin{tabular}{|c|c|c|c|c|c|c|}
\hline & $\begin{array}{l}\text { Managers } \\
\text { and leaders } \\
(n=38)\end{array}$ & $\begin{array}{l}\text { Registered nurses } \\
\text { and specialist } \\
\text { nurses ( } n=67)\end{array}$ & $\begin{array}{l}\text { Other col- } \\
\text { leagues } \\
(n=90)\end{array}$ & $\begin{array}{l}\text { Total sam- } \\
\text { ple }(n=195)\end{array}$ & $\begin{array}{l}\text { Pearson's chi-squared test } \\
\text { or Fisher's exact test }\end{array}$ & $\begin{array}{l}\text { Kruskal- } \\
\text { Wallis test }\end{array}$ \\
\hline Yes & $35(92.1)$ & $55(82.1)$ & 70 (77.8) & $160(82.1)$ & $p=0.155^{\mathrm{a}}$ & $-{ }^{b}$ \\
\hline No & $3(7.9)$ & 12 (17.9) & $20(22.2)$ & 35 (17.9) & & \\
\hline To a high degree & $11(28.9)$ & $15(22.4)$ & $21(23.3)$ & $47(24.1)$ & $p=0.914^{a}$ & $\begin{array}{c}H(2)=0.696 \\
p=0.706\end{array}$ \\
\hline To some degree & $13(34.2)$ & $24(35.8)$ & $29(32.2)$ & $66(33.8)$ & & \\
\hline To a low degree & $8(21.1)$ & $14(20.9)$ & $25(27.8)$ & $47(24.1)$ & & \\
\hline Absolutely not & $6(15.8)$ & $14(20.9)$ & $15(16.7)$ & 35 (18.0) & & \\
\hline $\begin{array}{l}\text { Several times } \\
\text { a day }\end{array}$ & $5(13.2)$ & $2(3.0)$ & $2(2.2)$ & $9(4.6)$ & $-{ }^{d}$ & $\begin{array}{c}H(2)=5.805 \\
p=0.055\end{array}$ \\
\hline Once a day & & $1(1.5)$ & $2(2.2)$ & $3(1.5)$ & & \\
\hline $\begin{array}{l}\text { Several times a } \\
\text { week }\end{array}$ & $7(18.4)$ & $16(23.9)$ & $17(18.9)$ & $40(20.5)$ & & \\
\hline Once a week & $4(10.5)$ & $11(16.4)$ & $5(5.6)$ & $20(10.3)$ & & \\
\hline $\begin{array}{l}\text { About every } \\
\text { 14th day }\end{array}$ & $3(7.9)$ & $4(6.0)$ & $12(13.3)$ & $19(9.8)$ & & \\
\hline Rarely & $14(36.8)$ & $18(26.8)$ & $18(20.0)$ & $50(25.6)$ & & \\
\hline Never & $5(13.2)$ & $15(22.4)$ & 34 (37.8) & $54(27.7)$ & & \\
\hline \multicolumn{7}{|c|}{ Provide contact between patients and the AGN } \\
\hline To a high degree & $12(31.6)$ & $17(25.4)$ & $20(22.2)$ & $49(25.1)$ & $p=0.078^{a}$ & $\begin{array}{c}H(2)=3.408 \\
p=0.182\end{array}$ \\
\hline Absolutely not & $13(34.2)$ & $13(19.4)$ & $34(37.8)$ & $60(30.8)$ & & \\
\hline \multicolumn{7}{|c|}{ The degree the role and scope of practice of the AGN contributes positively to health service } \\
\hline To a high degree & $29(76.3)$ & $46(68.6)$ & $56(62.3)$ & $131(67.2)$ & $p=0.062^{\mathrm{e}}$ & $\begin{array}{c}H(2)=4.031 \\
p=0.133\end{array}$ \\
\hline To some degree & $6(15.8)$ & $14(20.9)$ & $12(13.3)$ & $32(16.4)$ & & \\
\hline To a low degree & & $2(3.0)$ & $2(2.2)$ & $4(2.1)$ & & \\
\hline Absolutely not & & $1(1.5)$ & & $1(0.5)$ & & \\
\hline $\begin{array}{l}\text { The role and } \\
\text { scope of prac- } \\
\text { tice is unknown }\end{array}$ & $3(7.9)$ & $4(6.0)$ & $20(22.2)$ & $27(13.8)$ & & \\
\hline
\end{tabular}

Note: Values are expressed as $n(\%)$.

${ }^{a}$ Pearson's chi-squared test.

${ }^{b}$ Not possible to perform Kruskal-Wallis test as the dependent variable is not ordinal.

${ }^{\mathrm{c}}$ Only asked if the colleague had stated on another question that they had collaborated with the AGN, those who had not collaborated are coded "never."

${ }^{\mathrm{d}}$ Not possible to estimate the $p$-value with Pearson's chi-squared test/Fisher's exact test due to the large number of response options.

${ }^{\mathrm{e}}$ Fisher's exact test.

inadequate follow-up and care (Lafortune, Huson, Santi, \& Stolee, 2015; Melby, Obstfelder, \& Helleso, 2018). Adequate use of the knowledge and skills of AGNs might help address the complexity related to geriatric syndromes of multiple and complex chronic conditions, polypharmacy and the social and cognitive frailty of older adults. AGNs may use what they have described as an increased understanding of the organisation of services at their workplace and knowledge and skills within the field of care of older adults, collaboration and coordination to work as case managers and to lead healthcare teams (Delamaire \& Lafortune, 2010; 
Henni et al., 2018; Maier et al., 2017). Our results indicate that the AGNs are not adequately integrated with regard to this function.

When AGNs look at the factors that influence opportunities to use their knowledge and skills to their full potential, the way the workplace is organised is stated as a main barrier. The AGNs have expressed earlier in qualitative interviews that it was important that their workplace was organised in a way that provided them with the opportunity to work independently through a well-defined AGN role and to prioritise which patients were in greatest need of consultation by an AGN (Henni et al., 2018). The importance of organisational facilitation to integrate a new nurse practitioner role was also pointed out by a recent OECD working group (Maier et al., 2017). Furthermore, qualitative interviews with AGNs also indicate that it is important that the workplace is organised in a way that fosters collaboration between AGNs and their colleagues, especially with physicians, and that the AGNs have the opportunity to demonstrate their knowledge to their colleagues so that the colleagues would understand how AGNs could contribute to the care of older adults (Henni et al., 2018). In Norway, the manager at each workplace can decide themselves how the AGN's position should be to fulfil the needs at the workplace, which is consistent with practice in the UK (Maier et al., 2017). Maier et al. (2017) have shown that lack of regulation of positions often leads to confusion or lack of knowledge about the nurse practitioners' scope of practice, and this lack of role clarity can result in poor utilisation of the nurse practitioners' knowledge and skills. Our results indicate that it may be favourable to have a designated AGN position in order to use the AGN's knowledge and skills related to indirect care and teaching/supervision in an effective way. The results indicate, however, that a designated AGN position is not equally necessary in order to use their knowledge and skills related to direct care. This is consistent with results from qualitative interviews with the AGNs (Henni et al., 2018).

The last research question concerned the integration of AGNs, as measured through the colleagues' knowledge about the AGN role and scope of practice, collaboration between colleagues and AGNs, and colleagues' opinions of whether the AGNs contribute positively to health services. Our results indicate that the scope of practice of the AGNs is not clear to a majority of their colleagues, which is not an uncommon finding in the literature (Contandriopoulos et al., 2015; Henni et al., 2018; Maier et al., 2017; Sangster-Gormley et al., 2011). Clarity of the new role and the relationship with physicians and managers are among the factors found to be of vital importance for the uptake of a new professional role (Maier et al., 2017). Only a small proportion of colleagues reported they collaborated weekly with the AGNs and routinely provided contact between the older adults and the AGN. One way of interpreting the low rate of collaboration is that colleagues were not used to having an AGN in their workplace, and changing practices is known to take time (Lau et al., 2016). Improving the information to colleagues about the AGN role could speed up this process.

Even though a majority of the colleagues of the AGNs claim to not have adequate knowledge about the $A G N$ role and do not collaborate with AGNs often, they report that the role and scope of practice of the AGN contributes positively to health services for older adults. This positivity can be interpreted as an acknowledgement of the need for a person that has expanded knowledge and skills within the field of care of older adults. Furthermore, just above $44 \%$ reported having received sufficient information about the AGN role and scope of practice and almost all of the colleagues knew who the AGN in their workplace was. Most of the colleagues who had reported that they had received sufficient information also reported that the role and scope of practice of the AGN contributed positively to health services for older adults to a high degree. This indicates some degree of familiarity with the AGN role and how it contributes to health services for older adults among the colleagues, for example, through more timely and precise communication with physicians and other healthcare professionals and better follow-up of the health condition and treatment in home care and nursing homes. Another possible interpretation may be that the colleagues experienced that introduction of an AGN at their workplace did not generate redundancies and conflicts among the colleagues, contrary to previous research that has found that introduction of new nurse practitioner roles often leads to tension between healthcare professionals (Contandriopoulos et al., 2015; Sangster-Gormley et al., 2011).

The overall result of this study indicates that the uptake of the AGNs' role in their workplace is not yet complete and the AGNs are not fully integrated. Maier et al. (2017) suggest that process evaluation research is needed for the integration of new nurse practitioner roles to understand the characteristics important to an organisation for successful integration. The process evaluation might benefit from international cooperative research, as many countries struggle with the same barriers.

\section{1 | Methodological considerations}

The study has some methodological limitations that may affect the results. Our goal was that inclusion of the total population of AGNs in Norway and criteria for selection of the colleagues should result in a sample that was representative of the total population of AGNs and their colleagues. However, the recruiters managed to recruit fewer colleagues than anticipated and under half responded to the questionnaire. We do not have information about the characteristics of those who refused to participate in the study, and therefore, we cannot be sure that the sample of colleagues are representative of the total population. Furthermore, the recruiters were asked to include colleagues regardless of whether they knew the AGNs or not in order to provide a realistic picture of the integration of AGNs in their work setting. However, we have no data to tell us if health professionals that do not know of AGNs have been included in the recruitment of colleagues. According to email and phone correspondence between the recruiters and the first author, it seems that most followed the criteria strictly. However, we observed deviations as some seem to have recruited random persons who were present at the workplace at the time they decided to recruit participants to the study, or recruited persons they knew had collaborated with the 
AGN. If all the recruiters followed the inclusion criteria strictly, there might have been more colleagues that reported they did not have knowledge of the AGNs' role and scope of practice, more colleagues that had not collaborated with the AGNs and more colleagues that did not consider the AGNs a positive contribution to health services.

The question regarding the degree to which AGNs use their knowledge and skills related to different functions must be interpreted with caution. In any health profession, there would always be functions that are more prominent than others depending, among other things, on the specific healthcare context and the uptake of the role. We have therefore discussed the AGNs' estimation of their use of knowledge and skills related to different functions and compared this with what research has shown to be important functions in the care of older adults and health policy promotion. As pointed out in the description of the questionnaires, the different functions are not all operationalised at the same level of specificity. The vagueness of some of the activities may have affected the validity of the questionnaires. The broad patient situations may have generated differences in the AGNs' interpretation, which in turn can affect the AGNs' estimation of the use of knowledge and skills related to the different functions. However, the questionnaires were pilot tested and reviewed for content and face validity and none of the testers expressed confusion about what was meant by the functions. Still, we acknowledge that the broad and partial operationalisation of the functions may generate different associations. The main focus of the study is integration measured through the AGNs' use of knowledge and skills estimated by the AGNs themselves and their colleagues' knowledge about the AGN role and scope of practice, collaboration between colleagues and AGNs, and colleagues' opinions of AGNs contribution to health services. We therefore argue that our results are relevant as they provide knowledge of the level of coherence between use of nurse practitioners' knowledge and skills and factors that influence integration of nurse practitioners.

\section{5 | CONCLUSION}

A range of challenges, including those related to the complex care needs of older adults, have led countries to introduce nurse practitioners into the healthcare system, especially in primary care (Maier et al., 2017). Nursing practice has been acknowledged by policymakers to be important in increasing quality of care (Laurant et al., 2018; Maier et al., 2017). This study confirms that not only policymakers, but also health professionals believe that nurse practitioners specialised in the care of older adults make a positive contribution in enhancing the quality of care for this vulnerable group.

As demonstrated with nurse practitioners and other advanced practice nurse roles (Maier et al., 2017), the results of this study indicate that optimal integration of AGNs relies on a clear and regulated definition of the scope of practice of AGNs that is in line with the advanced level of their knowledge and skills. Countries regulating the level and content of education and the scope of practice at a national or a central level are achieving greater role clarity, integration and use than countries with decentralised regulations (Maier et al., 2017). The results of this study provide reasons to believe this principle is highly relevant for AGNs. Different socio-political and professional forces have shaped and will continue to shape further development of the AGN role. The results in this study indicate that in order to utilise the full potential of advanced nursing roles for older adults, there is a need to establish regulations at a central level and focus on organisational adjustments that will enhance the integration of these roles.

\section{6 | RELEVANCE TO CLINICAL PRACTICE}

The AGNs use, to a varying degree, their knowledge and skills. Still, there is room for enhanced use of their knowledge and skills through improved integration of AGNs in health services for older adults. In order for AGNs to use their knowledge and skills to their full potential, organisational adjustments for the new role must be implemented at the workplace. Establishment of designated and well-regulated AGN positions with clear descriptions of role and scope of practice could enable the AGN's enhanced use of their specific knowledge and skills, and could also provide a clearer understanding of the new AGN role and a better integration in local settings.

\section{ACKNOWLEDGEMENTS}

The authors want to thank the participants in the study, Anne Schad Bergsaker for statistical advisement and The Research Council of Norway, Programme on Health, Care and Welfare Services Research (HELSEVEL) for funding.

\section{CONFLICT OF INTEREST}

The authors declare no conflict of interests.

\section{AUTHOR CONTRIBUTIONS}

Study design: $\mathrm{SHH}, \mathrm{MK}, \mathrm{KA}, \mathrm{CF}$; data analysis and interpretation of data: $\mathrm{SHH}, \mathrm{MK}, \mathrm{KA}, \mathrm{CF}$ and manuscript preparation: $\mathrm{SHH}, \mathrm{MK}, \mathrm{KA}$, CF.

\section{ORCID}

Silje Havrevold Henni iD https://orcid.org/0000-0002-9309-8726

\section{REFERENCES}

American Association of Nurse Practitioners (2016a). Historical timeline. Retrieved from https://www.aanp.org/all-about-nps/historical-timeline American Association of Nurse Practitioners (2016b). What's an NP? Retrieved from https://www.aanp.org/all-about-nps/what-is-an-np

Andregard, A. C., \& Jangland, E. (2015). The tortuous journey of introducing the nurse practitioner as a new member of the healthcare team: $A$ 
meta-synthesis. Scandinavian Journal of Caring Sciences, 29(1), 3-14. https://doi.org/10.1111/scs.12120

Bentley, M., Minstrell, M., Bucher, H., Sproule, L., Robinson, A., \& Stirling, C. (2015). Aged care nurse practitioners working in general practice. Journal of Clinical Nursing, 24(23-24), 3745-3747. https://doi. org/10.1111/jocn.13066

Bing-Jonsson, P. C., Bjork, I. T., Hofoss, D., Kirkevold, M., \& Foss, C. (2015). Competence in advanced older people nursing: Development of 'nursing older people - Competence evaluation tool'. International Journal of Older People Nursing, 10(1), 59-72. https://doi.org/10.1111/ opn.12057

Bing-Jonsson, P. C., Hofoss, D., Kirkevold, M., Bjork, I. T., \& Foss, C. (2016). Sufficient competence in community elderly care? Results from a competence measurement of nursing staff. BMC Nursing, 15, 5. https://doi.org/10.1186/s12912-016-0124-z

Boerma, W. G. W. (2006). Coordination and integration in European primary care. In R. B. Saltman, A. Rico \& W. G. W. Boerma (Eds.), Primary care in the driver's seat? Organizational reform in European primary care (pp. 3-21). Berkshire, UK: Open University Press.

Boerma, W. G. W., Bourgueil, Y., Cartier, T., Hasvold, T., Hutchinson, A., Kringos, D. S., \& Kroneman, M. (2015). Overview and future challenges for primary care. In D. S. Kringos, W. G. W. Boerma, A. Hutchinson \& R. B. Saltman (Eds.), Building primary care in a changing Europe (pp. 119-134). Copenhagen, Denmark: European Observatory on Health Systems and Policies.

Bryant-Lukosius, D., Dicenso, A., Browne, G., \& Pinelli, J. (2004). Advanced practice nursing roles: Development, implementation and evaluation. Journal of Advanced Nursing, 48(5), 519-529. https://doi. org/10.1111/j.1365-2648.2004.03234.x

Canadian Nurses Association (2017). Nurse practitioners - Untapped resource. Retrieved from https://cna-aiic.ca/-/media/cna/pagecontent/pdf-en/nurse-practitioners_untapped-resource.pd$\mathrm{f} ? \mathrm{la}=\mathrm{en} \& \mathrm{hash} 28 \mathrm{E} 6 \mathrm{BD} 0019 \mathrm{~F} 663 \mathrm{E0}$ DDE8567640D41D9EF2A1 DA82

Carney, M. (2016). Regulation of advanced nurse practice: Its existence and regulatory dimensions from an international perspective. Journal of Nursing Management, 24(1), 105-114. https://doi.org/10.1111/ jonm.12278

Contandriopoulos, D., Brousselle, A., Dubois, C. A., Perroux, M., Beaulieu, M. D., Brault, I., ... Sansgter-Gormley, E. (2015). A process-based framework to guide nurse practitioners integration into primary healthcare teams: Results from a logic analysis. BMC Health Services Research, 15, 78. https://doi.org/10.1186/s12913-015-0731-5

Delamaire, M.-L., \& Lafortune, G. (2010). Nurses in advanced roles: A description and evaluation of experiences in 12 developed countries. Paris, France: OECD Publishing.

Donald, F., Martin-Misener, R., Carter, N., Donald, E. E., Kaasalainen, S., Wickson-Griffiths, A., ... DiCenso, A. (2013). A systematic review of the effectiveness of advanced practice nurses in long-term care. Journal of Advanced Nursing, 69(10), 2148-2161. https://doi. org/10.1111/jan.12140

Gardner, A., Gardner, G. E., Middleton, S., \& Della, P. R. (2009). The status of Australian nurse practitioners: The first national census. Australian Health Review, 33(4), 679-689.

Gardner, G., Gardner, A., Middleton, S., Della, P., Kain, V., \& Doubrovsky, A. (2010). The work of nurse practitioners. Journal of Advanced Nursing, 66(10), 2160-2169. https://doi. org/10.1111/j.1365-2648.2010.05379.x

Heale, R., \& Rieck Buckley, C. (2015). An international perspective of advanced practice nursing regulation. International Nursing Review, 62(3), 421-429. https://doi.org/10.1111/inr.12193

Henni, S. H., Kirkevold, M., Antypas, K., \& Foss, C. (2018). The role of advanced geriatric nurses in Norway: A descriptive exploratory study. International Journal of Older People Nursing, 13(3), e12188. https:// doi.org/10.1111/opn.12188
International Council of Nurses (2015). Definition and characteristics of the role. Retrieved from http://international.aanp.org/Practice/ APNRoles

Kennedy-Malone, L., Penny, J., \& Fleming, M. E. (2008). Clinical practice characteristics of gerontological nurse practitioners: A national study. Journal of the American Academy of Nurse Practitioners, 20(1), 17-27. https://doi.org/10.1111/j.1745-7599.2007.00275.x

Kiljunen, O., Valimaki, T., Kankkunen, P., \& Partanen, P. (2017). Competence for older people nursing in care and nursing homes: An integrative review. International Journal of Older People Nursing, 12(3), e12146. https://doi.org/10.1111/opn.12146

Kringos, D. S., Boerma, W. G. W., Bourgueil, Y., Cartier, T., Dedeu, T., Hasvold, T., ... Pavlick, D. R. (2015). Diversity of primary care systems analysed. In D. S. Kringos, W. G. W. Boerma, A. Hutchinson \& R. B. Saltman (Eds.), Building primary care in a changing Europe (pp. 103-118). Copenhagen, Denmark: European Observatory on Health Systems and Policies.

Lafortune, C., Huson, K., Santi, S., \& Stolee, P. (2015). Community-based primary health care for older adults: A qualitative study of the perceptions of clients, caregivers and health care providers. BMC Geriatrics, 15, 57. https://doi.org/10.1186/s12877-015-0052-x

Lau, R., Stevenson, F., Ong, B. N., Dziedzic, K., Treweek, S., Eldridge, S., ... Murray, E. (2016). Achieving change in primary care Causes of the evidence to practice gap: Systematic reviews of reviews. Implementation Science, 11, 40. https://doi.org/10.1186/ s13012-016-0396-4

Laurant, M., van der Biezen, M., Wijers, N., Watananirun, K., Kontopantelis, E., \& van Vught, A. J. (2018). Nurses as substitutes for doctors in primary care. Cochrane Database Systematic Review, 7, CD001271. https://doi.org/10.1002/14651858.CD001271.pub3

LeClerc, C. M., Wells, D. L., Craig, D., \& Wilson, J. L. (2002). Falling short of the mark: Tales of life after hospital discharge. Clinical Nursing Research, 11(3), 242-263. https://doi.org/10.1177/1057380201 1003002

Maier, C. B., Aiken, L. H., \& Busse, R. (2017). Nurses in advanced roles in primary care: Policy levers for implementation. Paris, France: OECD Publishing.

Martin-Misener, R., Donald, F., Wickson-Griffiths, A., Akhtar-Danesh, N., Ploeg, J., Brazil, K., ... Taniguchi, A. (2015). A mixed methods study of the work patterns of full-time nurse practitioners in nursing homes. Journal of Clinical Nursing, 24(9-10), 1327-1337. https://doi. org/10.1111/jocn.12741

Melby, L., Obstfelder, A., \& Helleso, R.( 2018). "We tie up the loose ends": Homecare nursing in a changing health care landscape. Global Qualitative Nursing Research, 5, 1-11. https://doi.org/10.1177/23333 93618816780

Morilla-Herrera, J. C., Garcia-Mayor, S., Martin-Santos, F. J., Kaknani Uttumchandani, S., Leon Campos, A., Caro Bautista, J., \& MoralesAsencio, J. M. (2016). A systematic review of the effectiveness and roles of advanced practice nursing in older people. International Journal of Nursing Studies, 53, 290-307. https://doi.org/10.1016/j. ijnurstu.2015.10.010

OECD (2013). Health at a glance 2013: OECD indicators. Paris, France: OECD Publishing.

Perfetto, C., Holden, M., \& McNabney, M. K. (2018). Nurse practitioners as primary educators for medical trainees in geriatric medicine. Journal for Nurse Practitioners, 14(1), 45-52. https://doi. org/10.1016/j.nurpra.2017.10.016

Poghosyan, L., Nannini, A., Smaldone, A., Clarke, S., O'Rourke, N. C., Rosato, B. G., \& Berkowitz, B. (2013). Revisiting scope of practice facilitators and barriers for primary care nurse practitioners: A qualitative investigation. Policy, Politics \& Nursing Practice, 14(1), 6-15. https://doi. org/10.1177/1527154413480889

Qian, X., Russell, L. B., Valiyeva, E., \& Miller, J. E. (2011). "Quicker and sicker" under Medicare's prospective payment system for hospitals: 
New evidence on an old issue from a national longitudinal survey. Bulletin of Economic Research, 63(1), 1-27.

R Core Team (2018). R: A Language and environment for statistical computing. Vienna, Austria: R Foundation for Statistical Computing. Retrieved from https://www.r-project.org/

Report to the Storting No. 26 (2015). The primary health and care services of tomorrow - Localised and integrated (Vol. 26 (2014-2015)). Oslo, Norway: Norwegian Ministry of Health and Care Services.

Ruiz, M., Bottle, A., Long, S., \& Aylin, P. (2015). Multi-morbidity in hospitalised older patients: Who are the complex elderly? PLoS ONE, 10(12), e0145372. https://doi.org/10.1371/journal.pone.0145372

Sangster-Gormley, E., Martin-Misener, R., \& Burge, F. (2013). A case study of nurse practitioner role implementation in primary care: What happens when new roles are introduced? BMC Nursing, 12, 1. https://doi.org/10.1186/1472-6955-12-1

Sangster-Gormley, E., Martin-Misener, R., Downe-Wamboldt, B., \& Dicenso, A. (2011). Factors affecting nurse practitioner role implementation in Canadian practice settings: An integrative review. Journal of Advanced Nursing, 67(6), 1178-1190. https://doi. org/10.1111/j.1365-2648.2010.05571.x

Schober, M. (2016). Introduction to advanced nursing practice. Cham, Switzerland: Springer International Publishing.

Sheer, B., \& Wong, F. K. (2008). The development of advanced nursing practice globally. Journal of Nursing Scholarship, 40(3), 204-211. https ://doi.org/10.1111/j.1547-5069.2008.00242.x

Siedlecki, S. L., Butler, R. S., \& Burchill, C. N. (2015). Survey design research: A tool for answering nursing research questions. Clinical
Nurse Specialist, 29(4), E1-E8. https://doi.org/10.1097/NUR.00000 00000000134

Ter Maten-Speksnijder, A. J., Dwarswaard, J., Meurs, P. L., \& van Staa, A. (2016). Rhetoric or reality? What nurse practitioners do to provide self-management support in outpatient clinics: An ethnographic study. Journal of Clinical Nursing, 25(21-22), 3219-3228. https://doi. org/10.1111/jocn.13345

Walsh, A., Moore, A., Barber, A., \& Opsteen, J. (2014). Educational role of nurse practitioners in a family practice centre: Perspectives of learners and nurses. Canadian Family Physician, 60(6), e316, e318-321.

World Health Organization (2015). World report on ageing and health. Geneva, Switzerland: World Health Organization.

\section{SUPPORTING INFORMATION}

Additional supporting information may be found online in the Supporting Information section at the end of the article.

How to cite this article: Henni SH, Kirkevold M, Antypas K, Foss $C$. The integration of new nurse practitioners into care of older adults: A survey study. J Clin Nurs. 2019;28:29112923. https://doi.org/10.1111/jocn.14889 



\section{Appendices}

1. Interview guide

2. AGN questionnaire

3. Colleague and leader questionnaire

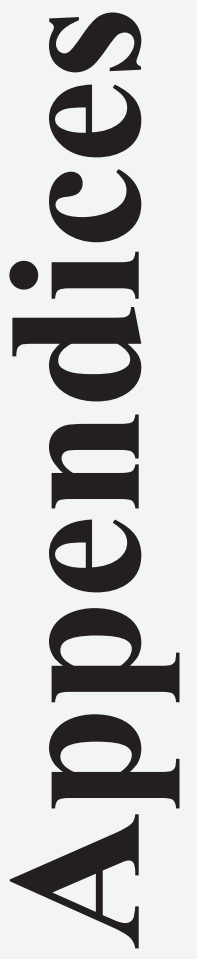





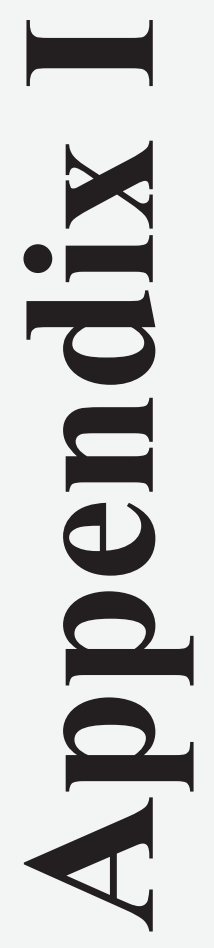





\section{Intervjuguide}

\section{Innledningsvis}

- Muntlig gjenta den skriftlige informasjon fra samtykkeerklæringen

- Avklare bruk av båndopptaker - ta i mot underskrevet samtykkeerklæring

Åpningsspørsmål: AGS er en ny utdannelse. Hvilke erfaringer har du gjort deg som ny «AGS'er» som du selv mener er viktige for den rollen og funksjonen du har nå?

\section{Temaer som tas opp underveis:}

Hvilke avklaringer/planlegging var gjort før du gikk inn i stillingen?

Yrkesrolle og funksjon

Dine / arbeidsplassens forventninger

Muligheter for utvikling

\section{Definisjon av yrkesrolle}

Har du stillingsbeskrivelse beregnet på AGS?

Overlapping av arbeidsoppgaver

Stemmer dine nåværende oppgaver med det du er utdannet for?

\section{Beskrivelse av tjenestemodell}

Organiseringen av helsehjelpen i organisasjonen

Fordeling av resurser og ansvar velegnet?

\section{Samarbeid og støtte}

Hvordan kan samarbeidet med andre yrkesgrupper beskrives?

Hvordan erfarer du at samarbeidspartnere ser på din stilling?

I hvilken grad:

-Opplever du støtte?

-Brukes du?

-Har du tillit?

\section{Avslutningsvis}

Er det noe annet du mener er viktig å få sagt som vi ikke har pratet om? 


\section{Demografiske variabler}

1. Kjønn

$\square$ Kvinne

$\square$ Mann

2. Alder

3. Antall år arbeidet som sykepleier

4. År uteksaminert fra master i avansert geriatrisk sykepleie

$\square 2016$

$\square 2015$

$\square 2014$

5. Arbeidskommune

6. Arbeidssted

$\square$ Kommunehelsetjenesten

Spesialisthelsetjenesten

$\square$ Annet, spesifiser:

7. Antall år arbeidet i nåværende stilling

8. Har du fått hjelp fra UiO til opprettelse av din arbeidsstilling som AGS?

$\square \mathrm{Ja}$

$\square$ Nei 


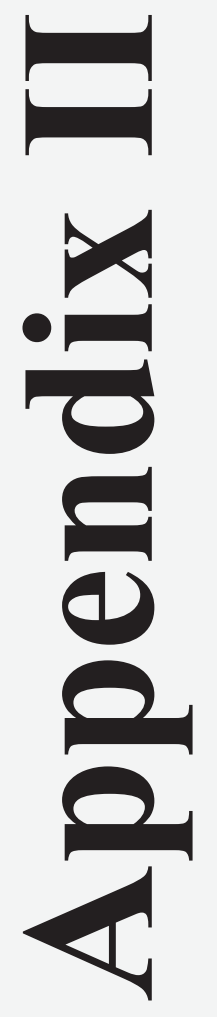





\section{Spørreskjema til uteksaminerte fra master i avansert geriatrisk sykepleie}

\section{Bakgrunnsopplysninger}

1. Hvilken enhet er du tilknyttet?

Nedtrekks liste med navn på de ulike kommunene/enhetene

2. Kjønn

Kvinne

Mann

3. Alder

4. Hvor mange år har du vært autorisert sykepleier?

5. Har du annen tilleggsutdannelse i tillegg til master i avansert geriatrisk sykepleie?

Sett gjerne flere kryss

Masterutdanning

Spesifiser:

Videreutdanning $\square$ Spesifiser:

Annet

$\square$ Spesifiser:

Ingen

6. Hvilket år ble du uteksaminert fra master i avansert geriatrisk sykepleie?

2014

2015

$2016 \square$

2017

7. Arbeider du nå som sykepleier, avansert geriatrisk sykepleier eller leder innenfor helsevesenet?

$\mathrm{Ja}$

Nei

Hvis nei, følgende tekst:

«Selv om du ikke jobber nå som sykepleier, avansert geriatrisk sykepleier eller leder innenfor helsevesenet er det ønskelig at du svarer på spørreskjemaet basert på dine tidligere erfaringer fra helsevesenet og det arbeidsstedet du sist var ansatt på» 


\section{Hvilken arbeidsplass er du ansatt på?}

Hvis du er ansatt på flere arbeidsplasser, kryss av på dem det gjelder

Hvis du ikke har fast ansettelsesprosent, anslå hva du tror den er

Hjemmetjeneste

Sykehjem/Aldershjem

Innsatsteam

Virtuell avdeling

Fastlegekontor i privat praksis

Fastlegekontor i offentlig praksis

Høyskole/Universitet

Tildelingskontor

Utviklingssenter for sykehjem og hjemmetjenester

Legevakt

Sykehus $\quad \square$ Spesifiser avdeling:

Annet

Spesifiser: $\square$ Ansettelsesprosent:

Antall år:

Ansettelsesprosent:

Antall år:

Ansettelsesprosent:

Antall år:

Ansettelsesprosent:

Antall år:

$\square$ Ansettelsesprosent: Antall år:

$\square$ Ansettelsesprosent: Antall år:

Ansettelsesprosent: Antall år:

Ansettelsesprosent: Antall år:

Ansettelsesprosent: Antall år:

Ansettelsesprosent: Antall år:

Ansettelsesprosent: Antall år:

Ansettelsesprosent: Antall år:

9. Har du endret arbeidssted etter utdanningen i avansert geriatrisk sykepleie?

$\mathrm{Ja}$

Nei

Hvis ja, spørsmål 10

Hvis nei, spørsmål 11

\section{Hvorfor endret du arbeidssted?}

Sett gjerne flere kryss

Fikk ikke lønnsjustering for masterutdanning

Manglende støtte fra leder

Manglende støtte fra kolleger

Rollen og funksjonen til AGS var for avgrenset

Rollen og funksjonen til AGS var for vid

Fikk ikke ny stillingsbetegnelse

Fikk ikke brukt kompetansen og ferdighetene fullt ut

Det dukket opp en spennende stilling et annet sted Annet 
11. Har du endret stillingsbetegnelse etter at du ble uteksaminert fra master i avansert geriatrisk sykepleie?

$\mathrm{Ja}$

Nei

12. Hva er din stillingsbetegnelse?

AGS

Sykepleier

Fagsykepleier

Ledende fagsykepleier

Kvalitetskoordinator

Avdelingsleder

Annet

$\square$ Spesifiser:

13. Hva er ditt ansettelsesforhold?

Fast

Vikariat $\quad \square \quad$ Antall måneder:

Midlertidig tilsatt i prosjekt $\quad \square \quad$ Antall måneder:

Annet $\square$ Spesifiser: ............ Antall måneder:

\section{Hvordan er stillingen din finansiert?}

På lik måte som andre sykepleiere på arbeidsplassen

Prosjektmidler eller tilskudd fra fylkeskommunen

Prosjektmidler eller tilskudd fra kommunen

Annet

Spesifiser:

Vet ikke

\section{Hva er arbeidstiden din?}

Tredelt turnus

Todelt turnus

Dag

Kveld

Natt

Annet

Spesifiser:

16. Har du en stillingsbeskrivelse på arbeidsplassen din som reflekterer din kompetanse som AGS?

$\mathrm{Ja}$

Nei 


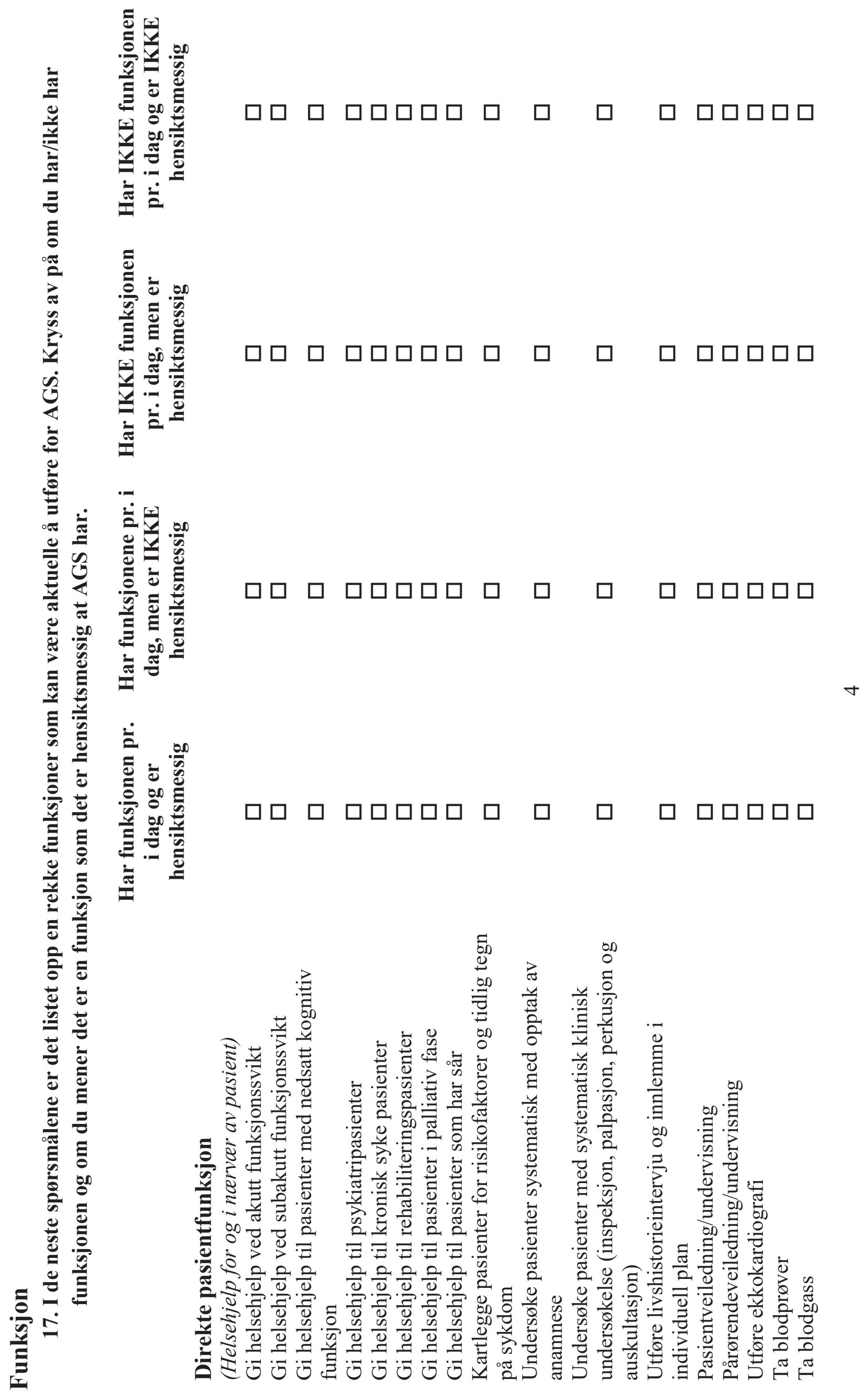




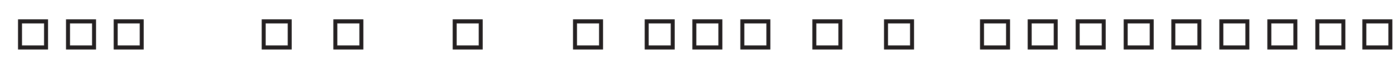

$\square$

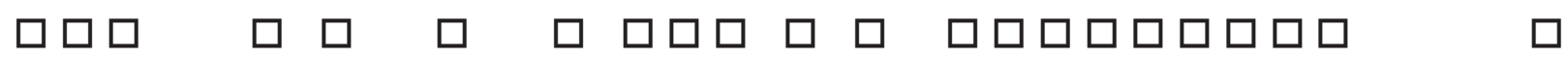

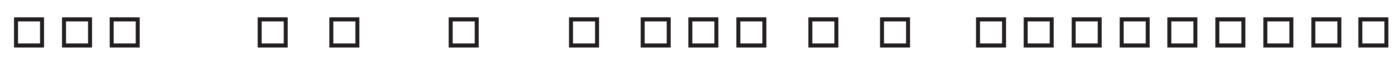

in

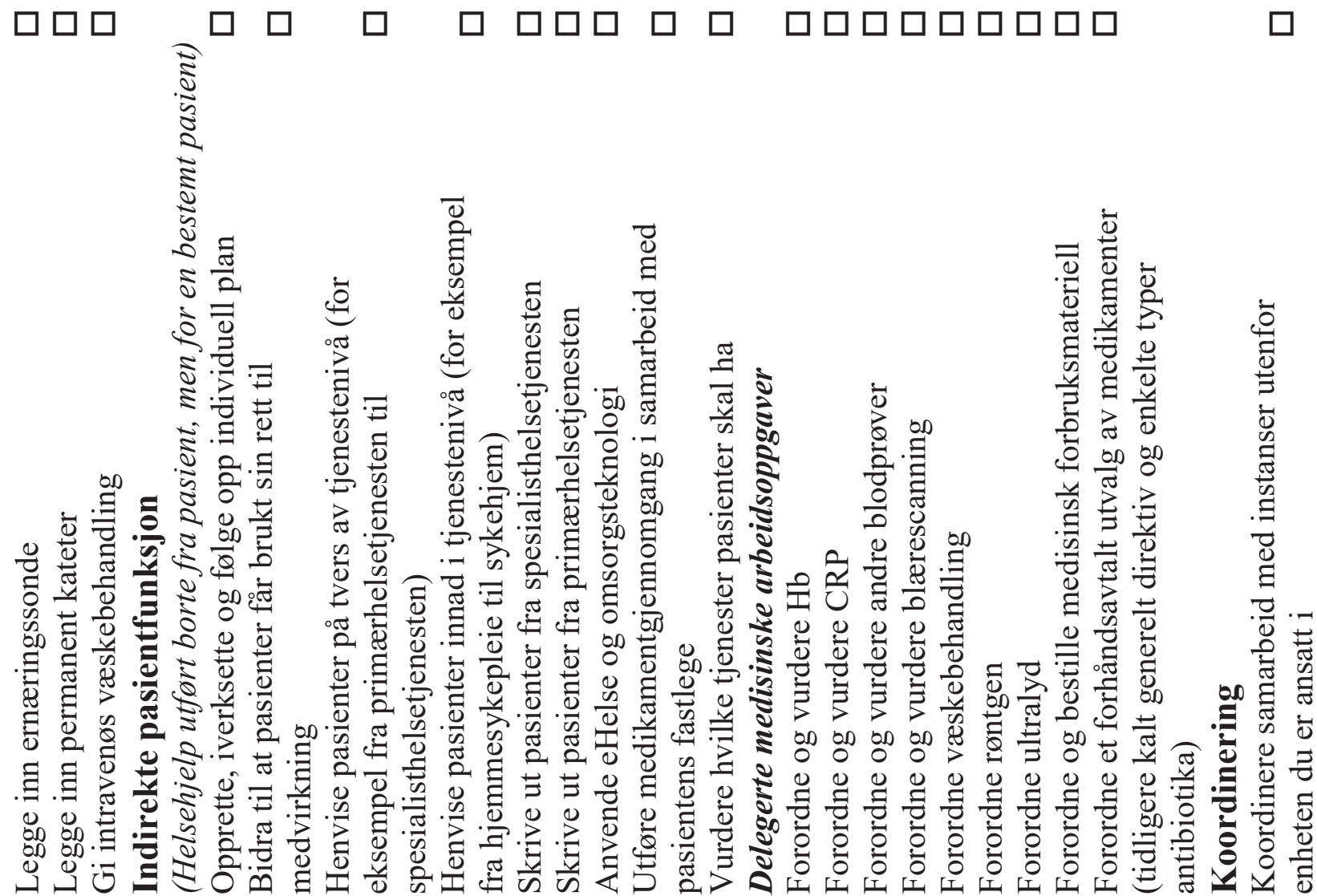




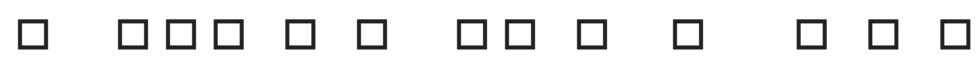

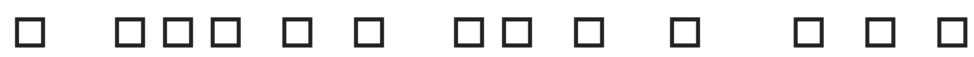

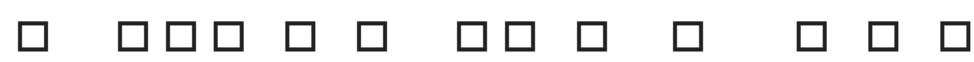

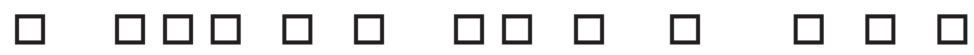

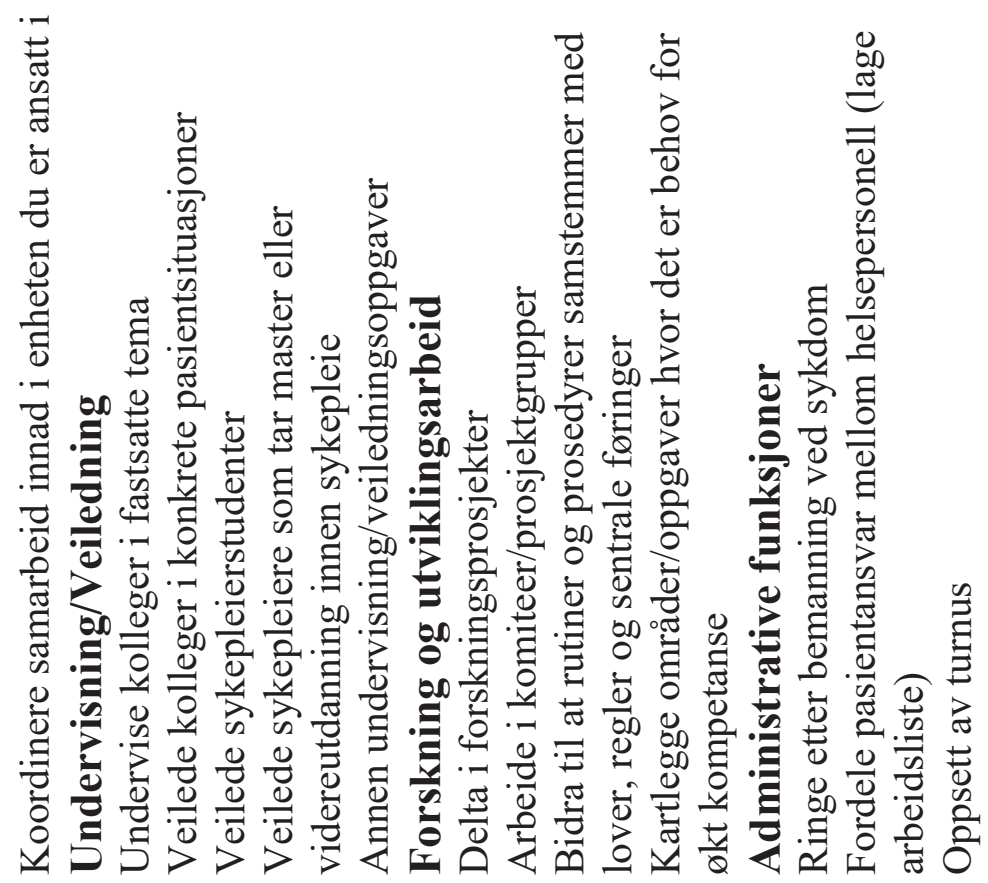


18. Hvis du har en rolle som AGS, er det klarlagt for deg hvilken funksjon AGS skal ha på arbeidsplassen din?

I høy grad

I noen grad

I liten grad

Overhodet ikke

Har ikke en rolle som AGS

Hvis «I høy grad, Har ikke en rolle som AGS», spørsmål 20

Hvis «I noen grad, I liten grad, Overhodet ikke», spørsmål 19

\section{Hvilken funksjon er uklar?}

Sett gjerne flere kryss

Direkte pasientfunksjon (helsehjelp for og i nærvær av pasient)

Indirekte pasientfunksjon (helsehjelp utført borte fra pasient, men for en bestemt pasient)

Koordinering

Undervisning/Veiledning

Forsknings og utviklingsarbeid

Administrative funksjoner

20. Opplever du at det er klarlagt for andre hvilken funksjon AGS skal ha på arbeidsplassen din?

I høy grad

I noen grad

I liten grad

Overhodet ikke

Hvis «I høy grad», spørsmål 22

Hvis «I noen grad, I liten grad, Overhodet ikke», spørsmål 21

\section{Hvilken funksjon er uklar?}

Sett gjerne flere kryss

Direkte pasientfunksjon (helsehjelp for og i nærvær av pasient)

Indirekte pasientfunksjon (helsehjelp utført borte fra pasient, men for en bestemt pasient)

Koordinering

Undervisning/Veiledning

Forsknings og utviklingsarbeid

Administrative funksjoner

22. Tenk tilbake på de fire siste ukene og oppgi hvilke arbeidsoppgaver du har brukt tiden din på?

Sett gjerne flere kryss

Direkte pasientfunksjon

Prosentandel

(helsehjelp for og i nærvær av pasient)

Indirekte pasientfunksjon

Prosentandel

(helsehjelp utført borte fra pasient, men for en bestemt pasient) 
Koordinering

Prosentandel

Undervisning/Veiledning

Prosentandel

Forsknings og utviklingsarbeid

Prosentandel

Administrative funksjoner

Prosentandel

Annet

Spesifiser:

Prosentandel

Hvis «Direkte pasientfunksjon», spørsmål 23

Hvis «Undervisning/Veiledning», spørsmål 27

Alle andre, spørsmål 28

23. Hvor mange pasienter møter du i løpet av en uke?

Hvis antallet varierer, anslå hva du tror det er $i$ en «vanlig» uke ...(Antall)

24. Hvor mange av dem er førstegangsbesøk? Ta med de pasientene som er kjent fra tidligere, men som har fătt ny henvisning (Antall)

25. Hvor mange minutter bruker du gjennomsnittlig hos pasienter ved førstegangsbesøk? ...(Antall)

26. Hvor mange minutter bruker du gjennomsnittlig hos pasienter når det ikke er førstegangsbesøk? ...(Antall)

27. Hvor mange timer bruker du gjennomsnittlig for å undervise kolleger per måned? ...(Antall)

28. I hvilken grad opplever du å få brukt følgende kunnskaps-/ferdighetsområder som du har lært i masterutdanningen i avansert geriatrisk sykepleie fullt ut?

$\begin{array}{lllll} & \begin{array}{l}\text { I høy } \\ \text { grad }\end{array} & \begin{array}{l}\text { I noen } \\ \text { grad }\end{array} & \begin{array}{l}\text { I liten } \\ \text { grad }\end{array} & \begin{array}{l}\text { Overhodet } \\ \text { ikke }\end{array} \\ \begin{array}{l}\text { Områder tilknyttet direkte } \\ \text { pasientfunksjon }\end{array} & \square & \square & \square & \square \\ \begin{array}{l}\text { Områder tilknyttet indirekte } \\ \text { pasientfunksjon }\end{array} & \square & \square & \square & \square \\ \begin{array}{l}\text { Områder tilknyttet koordinering } \\ \text { Områder tilknyttet }\end{array} & \square & \square & \square & \square \\ \begin{array}{l}\text { undervisning/veiledning } \\ \begin{array}{l}\text { Områder tilknyttet administrative } \\ \text { funksjoner }\end{array}\end{array} & \square & \square & \square & \square \\ & \square & \square & \square & \square\end{array}$

Hvis i «I høy grad» på alle, spørsmål 30 
29. Hva er årsaken til at du ikke får brukt kunnskapene og ferdighetene dine fullt ut?

Sett gjerne flere kryss

Måten avdelingen er organisert på

Rollen og funksjonen til AGS er for avgrenset

Rollen og funksjonen til AGS er for vid

Ikke trygg nok til å innta rollen

Manglende støtte fra leder

Manglende støtte fra kolleger

Ikke etterspurt av leder og/eller kolleger

Annet

Spesifiser:

\section{Forberedthet på rolle og funksjon}

30. Erfarer du at du er faglig forberedt på rollen og funksjonen som AGS?

I høy grad

I noen grad

I liten grad

Overhodet ikke

Hvis «I høy grad», spørsmål 33

Hvis «I noen grad, I liten grad, Overhodet ikke», spørsmål 31

31. Hva er du ikke forberedt på?

Sett gjerne flere kryss

Selvstendigheten som rollen innebærer

Mengden faglig kunnskap og ferdighet som kreves

Mangel på støtte fra leder

Mangel på støtte fra kolleger

Annet

Spesifiser:

32. Hva kan gjøres ved det du ikke er forberedt på?

Sett gjerne flere kryss

Teoretisk undervisning $\square$ Spesifiser tema/emne/mengde:

Praksis

$\square$ Spesifiser type/sted/mengde:

Annet

$\square$ Spesifiser:

\section{Organisering av helsetjenestene som gis}

33. Hvilken organisatorisk plassering har du på arbeidsplassen?

Direkte under enhets/distriktsleder, samme plassering som avdelingsleder

Direkte under avdelingsleder, samme plassering som sykepleier

Annet $\square$ Spesifiser:

34. Er den organisatoriske plasseringen slik at kompetansen din blir utnyttet best mulig?

I høy grad

I noen grad 
I liten grad

Overhodet ikke

\section{Hvordan kommer du i kontakt med pasienter?}

Sett gjerne flere kryss

Andre spør om jeg kan gi helsehjelp til pasienter

Ser alle pasienter som er skrevet ut fra sykehus

Ser alle nye pasienter

Fanger opp pasienter ved å lese journal

Fanger opp pasienter ved å delta på daglig rapport

Annet

Spesifiser:

Hvis «Andre spør om jeg kan gi helsehjelp til pasienter», spørsmål 36

Alle andre, spørsmål 37

36. Hvor ofte spør andre om du kan gi helsehjelp?

\begin{tabular}{|c|c|c|c|c|c|c|c|}
\hline & $\begin{array}{l}\text { Flere } \\
\text { ganger } \\
\text { daglig }\end{array}$ & $\begin{array}{l}\text { En gang } \\
\text { daglig }\end{array}$ & $\begin{array}{l}\text { Flere } \\
\text { ganger i } \\
\text { uken }\end{array}$ & $\begin{array}{l}\text { En gang } \\
\text { i uken }\end{array}$ & $\begin{array}{l}\text { Ca. hver } \\
\text { 14. dag }\end{array}$ & Sjeldnere & Aldri \\
\hline Pasienter & $\square$ & $\square$ & $\square$ & $\square$ & $\square$ & $\square$ & $\square$ \\
\hline Pårørende & $\square$ & $\square$ & $\square$ & $\square$ & $\square$ & $\square$ & $\square$ \\
\hline Tildelingskontor & $\bar{\square}$ & $\bar{\square}$ & $\bar{\square}$ & $\bar{\square}$ & $\bar{\square}$ & $\bar{\square}$ & $\bar{\square}$ \\
\hline Enhets/Distriktsleder & $\square$ & $\square$ & $\square$ & $\square$ & $\square$ & $\square$ & $\square$ \\
\hline Avdelingsleder & $\square$ & $\square$ & $\square$ & $\square$ & $\square$ & $\square$ & $\square$ \\
\hline Lege i privat praksis & $\square$ & $\square$ & $\square$ & $\square$ & $\square$ & $\square$ & $\square$ \\
\hline $\begin{array}{l}\text { Lege i offentlig } \\
\text { praksis }\end{array}$ & $\square$ & $\square$ & $\square$ & $\square$ & $\square$ & $\square$ & $\square$ \\
\hline Annen AGS & $\square$ & $\square$ & $\square$ & $\square$ & $\square$ & $\square$ & $\square$ \\
\hline Sykepleier & $\square$ & $\square$ & $\square$ & $\square$ & $\square$ & $\square$ & $\square$ \\
\hline Ergoterapeut & $\square$ & $\square$ & $\square$ & $\square$ & $\square$ & $\square$ & $\square$ \\
\hline Fysioterapeut & $\square$ & $\bar{\square}$ & $\square$ & $\square$ & $\bar{\square}$ & $\square$ & $\bar{\square}$ \\
\hline Helsefagarbeider & $\square$ & $\square$ & $\square$ & $\square$ & $\square$ & $\square$ & $\square$ \\
\hline Assistent & $\square$ & $\square$ & $\square$ & $\square$ & $\square$ & $\square$ & $\square$ \\
\hline
\end{tabular}

37. Erfarer du at du bruker mye tid på pasienter med spesielle utfordringer?

Utfordringene kan vare knyttet til pasientenes adferd, diagnose, medisinsk-og psykososiale behov og så videre

I høy grad

I noen grad

I liten grad

Overhodet ikke

38. Hvem rapporterer du faglig til?

Sett gjerne flere kryss

Enhets/distriktsleder

Avdelingsleder 
Annen AGS

Lege i privat praksis

Lege i offentlig praksis

Ergoterapeut

Fysioterapeut

Pasientens primærsykepleier

Tildelingskontoret

Andre

Spesifiser:

Rapporter ikke til enkeltpersoner, skriver i pasientjournal

39. I hvilken grad har du mulighet til å prioritere hvilke pasienter du skal gi helsehjelp til?

I høy grad

I noen grad

I liten grad

Overhodet ikke

\section{Samarbeid}

40. Hvem samarbeider du med?

Sett gjerne flere kryss

Enhets/distriktsleder

Avdelingsleder

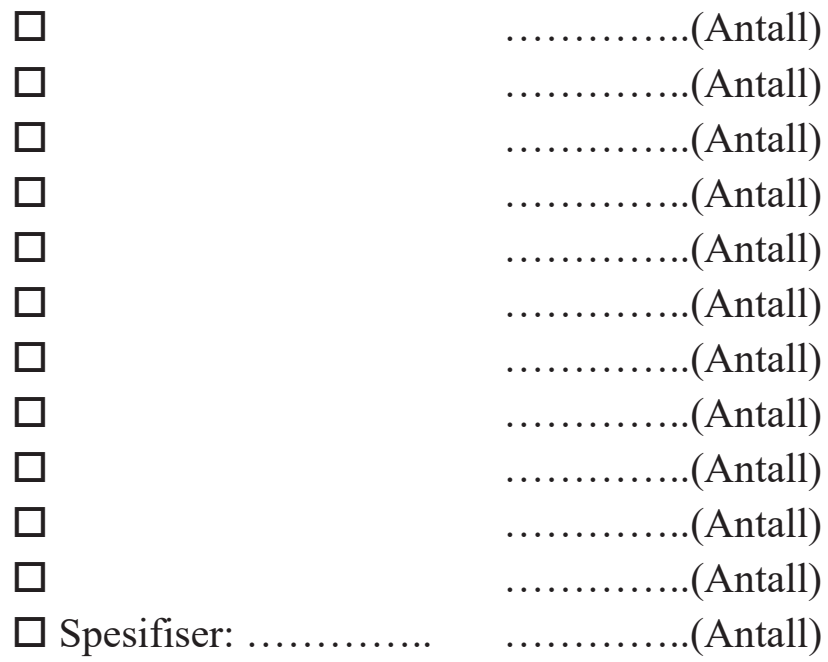

Annen AGS

Lege i privat praksis (Antall)

Lege i offentlig praksis (Antall)

Sykepleier (Antall)

Ergoterapeut (Antall)

Fysioterapeut (Antall)

Helsefagarbeider (Antall)

Tildelingskontoret (Antall)

Andre Spesifiser:

Oppfølgingsspørsmål til hver samarbeidspartner:

41. Hvor ofte samarbeider du med ...?

Flere ganger daglig $\square$

En gang daglig

Flere ganger i uken $\square$

En gang i uken

Ca. hver 14. dag

Sjeldnere

42. Hvordan foregår samarbeidet med ...?

Sett gjerne flere kryss

Avtalt møte

Ad-hoc samtale 
Telefon

Faks

E-post

Elektroniske meldinger

Post

Rapport

Videokonferanse eller lignende

Annet

Spesifiser:

43. Hvordan opplever du at samarbeidet er med ...?

Svært godt

Godt

Lite godt

Dårlig

\section{Andres holdninger til rollen og funksjonen til AGS}

44. Hvis du har opplevd å bli mott med tillit knyttet til rollen og funksjonen til AGS på arbeidsplassen, hvem har utrykt tillit?

Sett gjerne flere kryss

Enhets/distriktsleder ...(Antall)

Avdelingsleder (Antall)

Lege i privat praksis (Antall)

Lege i offentlig praksis ...(Antall)

Sykepleier ..(Antall)

Ergoterapeut (Antall)

Fysioterapeut ...(Antall)

Helsefagarbeider (Antall)

Assistent (Antall)

Ansatte på tildelingskontoret (Antall)

Andre Spesifiser: ...(Antall)

Har ikke opplevd å bli møtt med tillit

Hvis «Har ikke opplevd å bli møtt med tillit», spørsmål 48

Hvis alle andre svaralternativer, spørsmål 45

\section{Hva er tilliten relatert til?}

Sett gjerne flere kryss

Direkte pasientfunksjon (helsehjelp for og i nærvær av pasient)

Indirekte pasientfunksjon (helsehjelp utført borte fra pasient, men for bestemt en pasient)

Koordinering

Undervisning/Veiledning

Forsknings og utviklingsarbeid

Administrative funksjoner

Annet $\square$ Spesifiser: 
46. Hva har blitt gjort for å skape tillit?

Sett gjerne flere kryss

Vi har snakket om rollen og funksjonen til AGS

Jeg har undervist/veiledet kolleger

Jeg har samarbeidet med andre

Annet

Har ikke gjort noe for å skape tillit

47. Opplever du at tilliten er fremmende for rollen og funksjonen til AGS?

I høy grad

I noen grad

I liten grad

Overhodet ikke

48. Hvis du har opplevd å bli møtt med skepsis knyttet til rollen og funksjonen til AGS på arbeidsplassen, hvem har utrykt skepsis?

Sett gjerne flere kryss

Enhets/distriktsleder

Avdelingsleder ...(Antall)

Lege i privat praksis

Lege i offentlig praksis (Antall)

Sykepleier .(Antall)

Ergoterapeut ...(Antall)

Fysioterapeut (Antall)

Helsefagarbeider ...(Antall)

Assistent (Antall)

Ansatte på tildelingskontoret (Antall)

Andre

Spesifiser: (Antall)

Har ikke opplevd å bli møtt med skepsis

Hvis «Har ikke opplevd å bli møtt med skepsis», spørsmål 52

Hvis alle andre svaralternativer, spørsmål 49

\section{Hva er skepsisen relatert til?}

Sett gjerne flere kryss

Direkte pasientfunksjon (helsehjelp for og i nærvær av pasient)

Indirekte pasientfunksjon (helsehjelp utført borte fra pasient, men for en bestemt pasient)

Koordinering

Undervisning/Veiledning

Forsknings og utviklingsarbeid

Administrative funksjoner

Annet $\square$ Spesifiser:

\section{Hva har blitt gjort ved skepsisen?}

Vi har diskutert skepsisen og funnet en løsning

Vi diskuterer fortsatt skepsisen 
Har arbeidet bevisst for å skape tillit

Det har ikke blitt gjort noe vedrørende skepsisen

51. Opplever du at skepsisen er hemmende for rollen og funksjonen til AGS?

I høy grad

I noen grad

I liten grad

Overhodet ikke

\section{Oppsummering}

52. Totalt sett, i hvilken grad mener du at rollen og funksjonen til AGS bidrar positivt til helseog omsorgstjenester for eldre?

I høy grad

I noen grad

I liten grad

Overhodet ikke

53. Alt i alt, hva mener du er viktig for at AGS skal bidra positivt til helse- og omsorgstjenester for eldre?

Åpent svar:

54. Åpen kommentar: Her er du velkommen til å skrive det du mener er viktig Hvis dette er knyttet til et spørsmål eller svaralternativ, vennligst skriv hvilket Åpent svar:

Tusen takk for at du fullførte spørreskjemaet! 


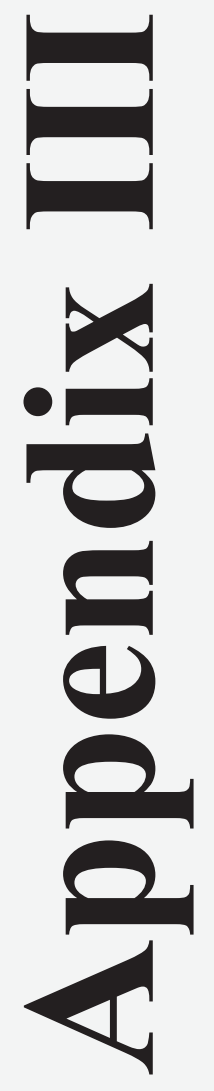





\section{Spørreskjema til ledere og kolleger som er tilknyttet samme enhet som en avansert geriatrisk sykepleier}

Rollen og funksjonen til avanserte geriatriske sykepleiere er ikke like godt kjent for alle. Spørreskjemaet er utformet slik at det skal være mulig å svare for alle uavhengig av kjennskap til avanserte geriatriske sykepleiere.

\section{Bakgrunnsopplysninger}

1. Hvilken enhet er du tilknyttet?

Nedtrekks liste med navn på de ulike kommunene/enhetene

\section{Kjønn}

Kvinne

Mann

\section{Alder}

4. Hvilken stillingsbetegnelse har du?

Enhets/Distriktsleder

Avdelingsleder

Lege

Sykepleier

Ergoterapeut

Fysioterapeut

Helsefagarbeider

Assistent

Saksbehandler

Annet

Spesifiser

5. Hvor mange år har du vært i nåværende stilling i enheten?

6. Hvilken arbeidsplass er du ansatt på?

Hvis du er ansatt på flere arbeidsplasser, kryss av på dem det gjelder Hvis du ikke har fast ansettelsesprosent, anslå hva du tror den er

Hjemmetjeneste

Sykehjem/Aldershjem

Innsatsteam

Virtuell avdeling

Fastlegekontor i privat praksis
Ansettelsesprosent:

Ansettelsesprosent:

Ansettelsesprosent:

Ansettelsesprosent:

Ansettelsesprosent: 
Fastlegekontor i offentlig praksis

Høyskole/Universitet

Tildelingskontor

Utviklingssenter for sykehjem og hjemmetjenester

Legevakt

Sykehus

Annet
Spesifiser avdeling:

$\square$ Spesifiser:
Ansettelsesprosent:

Ansettelsesprosent:

Ansettelsesprosent:

Ansettelsesprosent:

Ansettelsesprosent:

Ansettelsesprosent:

Ansettelsesprosent:

7. Hva er arbeidstiden din?

Tredelt turnus

Todelt turnus

Dag

Kveld

Natt

Annet

Spesifiser:

\section{Funksjon}

8. I de neste spørsmålene er det listet opp en rekke funksjoner som kan være aktuelle å utføre for AGS. Kryss av på om AGS har/ikke har funksjonen og om du mener det er en funksjon som det er hensiktsmessig at AGS har.

Direkte pasientfunksjon

(Helsehjelp for og i nærvær av pasient)

Gi helsehjelp ved akutt funksjonssvikt

Har funksjonen pr. i dag

Har ikke funksjonen pr. i dag

Vet ikke om har funksjonen

Er det hensiktsmessig at AGS har funksjonen?

$\mathrm{Ja}$

Nei

Gi helsehjelp ved subakutt funksjonssvikt

Har funksjonen pr. i dag

Har ikke funksjonen pr. i dag

Vet ikke om har funksjonen

Er det hensiktsmessig at AGS har funksjonen?

$\mathrm{Ja}$

Nei

Gi helsehjelp til pasienter med nedsatt kognitiv funksjon

Har funksjonen pr. i dag

Har ikke funksjonen pr. i dag

Vet ikke om har funksjonen 
Er det hensiktsmessig at AGS har funksjonen?

$\mathrm{Ja}$

Nei

Gi helsehjelp til psykiatripasienter

Har funksjonen pr. i dag

Har ikke funksjonen pr. i dag

Vet ikke om har funksjonen

Er det hensiktsmessig at AGS har funksjonen?

$\mathrm{Ja}$

Nei

Gi helsehjelp til kronisk syke pasienter

Har funksjonen pr. i dag

Har ikke funksjonen pr. i dag

Vet ikke om har funksjonen

Er det hensiktsmessig at AGS har funksjonen?

$\mathrm{Ja}$

Nei

Gi helsehjelp til rehabiliteringspasienter

Har funksjonen pr. i dag

Har ikke funksjonen pr. i dag

Vet ikke om har funksjonen

Er det hensiktsmessig at AGS har funksjonen?

$\mathrm{Ja}$

Nei

Gi helsehjelp til pasienter i palliativ fase

Har funksjonen pr. i dag

Har ikke funksjonen pr. i dag

Vet ikke om har funksjonen

Er det hensiktsmessig at AGS har funksjonen?

$\mathrm{Ja}$

$\mathrm{Nei}$

Gi helsehjelp til pasienter som har sår

Har funksjonen pr. i dag

Har ikke funksjonen pr. i dag

Vet ikke om har funksjonen 
Er det hensiktsmessig at AGS har funksjonen?

$\mathrm{Ja}$

Nei

Kartlegge pasienter for risikofaktorer og tidlig tegn på sykdom

Har funksjonen pr. i dag

Har ikke funksjonen pr. i dag

Vet ikke om har funksjonen

Er det hensiktsmessig at AGS har funksjonen?

$\mathrm{Ja}$

Nei

Undersøke pasienter systematisk med opptak av anamnese

Har funksjonen pr. i dag

Har ikke funksjonen pr. i dag

Vet ikke om har funksjonen

Er det hensiktsmessig at AGS har funksjonen?

$\mathrm{Ja}$

Nei

Undersøke pasienter med systematisk klinisk undersøkelse (inspeksjon, palpasjon, perkusjon og auskultasjon)

Har funksjonen pr. i dag

Har ikke funksjonen pr. i dag

Vet ikke om har funksjonen

Er det hensiktsmessig at AGS har funksjonen?

$\mathrm{Ja}$

Nei

Utfore livshistorieintervju og innlemme $i$ individuell plan

Har funksjonen pr. i dag

Har ikke funksjonen pr. i dag

Vet ikke om har funksjonen

Er det hensiktsmessig at AGS har funksjonen?

$\mathrm{Ja}$

Nei

Pasientveiledning/undervisning

Har funksjonen pr. i dag

Har ikke funksjonen pr. i dag

Vet ikke om har funksjonen 
Er det hensiktsmessig at AGS har funksjonen?

Ja

Nei

Pårorendeveiledning/undervisning

Har funksjonen pr. i dag

Har ikke funksjonen pr. i dag

Vet ikke om har funksjonen

Er det hensiktsmessig at AGS har funksjonen?

$\mathrm{Ja}$

$\mathrm{Nei}$

\section{Utfore ekkokardiografi}

Har funksjonen pr. i dag

Har ikke funksjonen pr. i dag

Vet ikke om har funksjonen

Er det hensiktsmessig at AGS har funksjonen?

$\mathrm{Ja}$

Nei

Ta blodprover

Har funksjonen pr. i dag

Har ikke funksjonen pr. i dag

Vet ikke om har funksjonen

Er det hensiktsmessig at AGS har funksjonen?

$\mathrm{Ja}$

Nei

\section{Ta blodgass}

Har funksjonen pr. i dag

Har ikke funksjonen pr. i dag

Vet ikke om har funksjonen

Er det hensiktsmessig at AGS har funksjonen?

$\mathrm{Ja}$

Nei

Legge inn ernaeringssonde

Har funksjonen pr. i dag

Har ikke funksjonen pr. i dag

Vet ikke om har funksjonen 
Er det hensiktsmessig at AGS har funksjonen?

$\mathrm{Ja}$

Nei

Legge inn permanent kateter

Har funksjonen pr. i dag

Har ikke funksjonen pr. i dag

Vet ikke om har funksjonen

Er det hensiktsmessig at AGS har funksjonen?

$\mathrm{Ja}$

Nei

Gi intravenos vaeskebehandling

Har funksjonen pr. i dag

Har ikke funksjonen pr. i dag

Vet ikke om har funksjonen

Er det hensiktsmessig at AGS har funksjonen?

$\mathrm{Ja}$

Nei

\section{Indirekte pasientfunksjon}

(Helsehjelp utført borte fra pasient, men for en bestemt pasient)

Opprette, iverksette og folge opp individuell plan

Har funksjonen pr. i dag

Har ikke funksjonen pr. i dag

Vet ikke om har funksjonen

Er det hensiktsmessig at AGS har funksjonen?

$\mathrm{Ja}$

$\mathrm{Nei}$

Bidra til at pasienter får brukt sin rett til medvirkning

Har funksjonen pr. i dag

Har ikke funksjonen pr. i dag

Vet ikke om har funksjonen

Er det hensiktsmessig at AGS har funksjonen?

$\mathrm{Ja}$

Nei

Henvise pasienter på tvers av tjenestenivå (for eksempel fra primarhelsetjenesten til spesialisthelsetjenesten)

Har funksjonen pr. i dag

Har ikke funksjonen pr. i dag 
Vet ikke om har funksjonen

Er det hensiktsmessig at AGS har funksjonen?

$\mathrm{Ja}$

Nei

Henvise pasienter innad i tjenestenivå (for eksempel fra hjemmesykepleie til sykehjem)

Har funksjonen pr. i dag

Har ikke funksjonen pr. i dag

Vet ikke om har funksjonen

Er det hensiktsmessig at AGS har funksjonen?

$\mathrm{Ja}$

Nei

Skrive ut pasienter fra spesialisthelsetjenesten

Har funksjonen pr. i dag

Har ikke funksjonen pr. i dag

Vet ikke om har funksjonen

Er det hensiktsmessig at AGS har funksjonen?

$\mathrm{Ja}$

Nei

Skrive ut pasienter fra primarhelsetjenesten

Har funksjonen pr. i dag

Har ikke funksjonen pr. i dag

Vet ikke om har funksjonen

Er det hensiktsmessig at AGS har funksjonen?

$\mathrm{Ja}$

Nei

Anvende eHelse og omsorgsteknologi

Har funksjonen pr. i dag

Har ikke funksjonen pr. i dag

Vet ikke om har funksjonen

Er det hensiktsmessig at AGS har funksjonen?

$\mathrm{Ja}$

$\mathrm{Nei}$

Utfore medikamentgjennomgang $i$ samarbeid med pasientens fastlege

Har funksjonen pr. i dag

Har ikke funksjonen pr. i dag

Vet ikke om har funksjonen 
Er det hensiktsmessig at AGS har funksjonen?

$\mathrm{Ja}$

Nei

Vurdere hvilke tjenester pasienter skal ha

Har funksjonen pr. i dag

Har ikke funksjonen pr. i dag

Vet ikke om har funksjonen

Er det hensiktsmessig at AGS har funksjonen?

$\mathrm{Ja}$

Nei

Delegerte medisinske arbeidsoppgaver

Forordne og vurdere $\mathrm{Hb}$

Har funksjonen pr. i dag

Har ikke funksjonen pr. i dag

Vet ikke om har funksjonen

Er det hensiktsmessig at AGS har funksjonen?

$\mathrm{Ja}$

Nei

Forordne og vurdere CRP

Har funksjonen pr. i dag

Har ikke funksjonen pr. i dag

Vet ikke om har funksjonen

Er det hensiktsmessig at AGS har funksjonen?

$\mathrm{Ja}$

Nei

Forordne og vurdere andre blodprover

Har funksjonen pr. i dag

Har ikke funksjonen pr. i dag

Vet ikke om har funksjonen

Er det hensiktsmessig at AGS har funksjonen?

$\mathrm{Ja}$

$\mathrm{Nei}$

Forordne og vurdere blarescanning

Har funksjonen pr. i dag

Har ikke funksjonen pr. i dag

Vet ikke om har funksjonen 
Er det hensiktsmessig at AGS har funksjonen?

$\mathrm{Ja}$

Nei

Forordne intravenos vaeskebehandling

Har funksjonen pr. i dag

Har ikke funksjonen pr. i dag

Vet ikke om har funksjonen

Er det hensiktsmessig at AGS har funksjonen?

$\mathrm{Ja}$

Nei

\section{Forordne rontgen}

Har funksjonen pr. i dag

Har ikke funksjonen pr. i dag

Vet ikke om har funksjonen

Er det hensiktsmessig at AGS har funksjonen?

$\mathrm{Ja}$

Nei

Forordne ultralyd

Har funksjonen pr. i dag

Har ikke funksjonen pr. i dag

Vet ikke om har funksjonen

Er det hensiktsmessig at AGS har funksjonen?

$\mathrm{Ja}$

Nei

Forordne og bestille medisinsk forbruksmateriell

Har funksjonen pr. i dag

Har ikke funksjonen pr. i dag

Vet ikke om har funksjonen

Er det hensiktsmessig at AGS har funksjonen?

$\mathrm{Ja}$

$\mathrm{Nei}$

Forordne et forhåndsavtalt utvalg av medikamenter (tidligere kalt generelt direktiv og enkelte typer antibiotika)

Har funksjonen pr. i dag

Har ikke funksjonen pr. i dag

Vet ikke om har funksjonen 
Er det hensiktsmessig at AGS har funksjonen?

$\mathrm{Ja}$

Nei

\section{Koordinering}

Koordinere samarbeid med instanser utenfor enheten AGS er ansatt $i$

Har funksjonen pr. i dag

Har ikke funksjonen pr. i dag

Vet ikke om har funksjonen

Er det hensiktsmessig at AGS har funksjonen?

$\mathrm{Ja}$

Nei

Koordinere samarbeid innad i enheten AGS er ansatt $i$

Har funksjonen pr. i dag

Har ikke funksjonen pr. i dag

Vet ikke om har funksjonen

Er det hensiktsmessig at AGS har funksjonen?

$\mathrm{Ja}$

$\mathrm{Nei}$

\section{Undervisning/Veiledning}

Undervise kolleger i fastsatte tema

Har funksjonen pr. i dag

Har ikke funksjonen pr. i dag

Vet ikke om har funksjonen

Er det hensiktsmessig at AGS har funksjonen?

$\mathrm{Ja}$

Nei

Veilede kolleger i konkrete pasientsituasjoner

Har funksjonen pr. i dag

Har ikke funksjonen pr. i dag

Vet ikke om har funksjonen

Er det hensiktsmessig at AGS har funksjonen?

$\mathrm{Ja}$

Nei

Veilede sykepleierstudenter

Har funksjonen pr. i dag

Har ikke funksjonen pr. i dag 
Vet ikke om har funksjonen

Er det hensiktsmessig at AGS har funksjonen?

$\mathrm{Ja}$

Nei

Veilede sykepleiere som tar master eller videreutdanning innen sykepleie

Har funksjonen pr. i dag

Har ikke funksjonen pr. i dag

Vet ikke om har funksjonen

Er det hensiktsmessig at AGS har funksjonen?

$\mathrm{Ja}$

Nei

Annen undervisning/veiledningsoppgaver

Har funksjonen pr. i dag

Har ikke funksjonen pr. i dag

Vet ikke om har funksjonen

Er det hensiktsmessig at AGS har funksjonen?

$\mathrm{Ja}$

Nei

\section{Forskning og utviklingsarbeid}

Delta i forskningsprosjekter

Har funksjonen pr. i dag

Har ikke funksjonen pr. i dag

Vet ikke om har funksjonen

Er det hensiktsmessig at AGS har funksjonen?

$\mathrm{Ja}$

Nei

Arbeide i komiteer/prosjektgrupper

Har funksjonen pr. i dag

Har ikke funksjonen pr. i dag

Vet ikke om har funksjonen

Er det hensiktsmessig at AGS har funksjonen?

$\mathrm{Ja}$

Nei

Bidra til at rutiner og prosedyrer samstemmer med lover, regler og sentrale foringer Har funksjonen pr. i dag

Har ikke funksjonen pr. i dag 
Vet ikke om har funksjonen

Er det hensiktsmessig at AGS har funksjonen?

$\mathrm{Ja}$

$\mathrm{Nei}$

Kartlegge områder/oppgaver hvor det er behov for okt kompetanse

Har funksjonen pr. i dag

Har ikke funksjonen pr. i dag

Vet ikke om har funksjonen

Er det hensiktsmessig at AGS har funksjonen?

Ja

Nei

\section{Administrative funksjoner}

Ringe etter bemanning ved sykdom

Har funksjonen pr. i dag

Har ikke funksjonen pr. i dag

Vet ikke om har funksjonen

Er det hensiktsmessig at AGS har funksjonen?

$\mathrm{Ja}$

Nei

Fordele pasientansvar mellom helsepersonell (lage arbeidsliste)

Har funksjonen pr. i dag

Har ikke funksjonen pr. i dag

Vet ikke om har funksjonen

Er det hensiktsmessig at AGS har funksjonen?

$\mathrm{Ja}$

Nei

Oppsett av turnus

Har funksjonen pr. i dag

Har ikke funksjonen pr. i dag

Vet ikke om har funksjonen

Er det hensiktsmessig at AGS har funksjonen?

$\mathrm{Ja}$

Nei

9. Hvis det er andre funksjoner som ikke er oppgitt ovenfor, vennligst skriv hvilke funksjoner du har behov for at en sykepleier med utvidet geriatrisk kompetanse utfører Åpent svar: 
10. Opplever du at det er klarlagt for deg hvilken funksjon AGS skal ha på arbeidsplassen din?

I høy grad

I noen grad

I liten grad

Overhodet ikke

Hvis «I høy grad», spørsmål 12

Hvis «I noen grad, I liten grad, Overhodet ikke», spørsmål 11

\section{Hvilken funksjon er uklar?}

Sett gjerne flere kryss

Direkte pasientfunksjon (helsehjelp for og i nærvær av pasient)

Indirekte pasientfunksjon (helsehjelp utført borte fra pasient, men for en bestemt pasient)

Koordinering

Undervisning/Veiledning

Forsknings og utviklingsarbeid

Administrative funksjoner

Kjenner ikke til funksjonen til AGS

\section{Forberedthet på rolle og funksjon}

12. Vet du hvem det er i enheten som har en master i avansert geriatrisk sykepleie?

$\mathrm{Ja}$

Nei

Hvis Ja, spørsmål 13

Hvis Nei, spørsmål 14

13. Kjenner du personen(e) som er AGS fra for personen(e) ble AGS?

I høy grad

I noen grad

I liten grad

Overhodet ikke

14. Hvordan har informasjonen om rollen og funksjonen til AGS vært gitt på arbeidsplassen din?

Sett gjerne flere kryss

Skriftlig informasjonsskriv

Muntlig av ledelsen

Muntlig av AGS

Har ikke blitt informert

Annet

Spesifiser:

Hvis «Har ikke blitt informert», spørsmål 16

Hvis alle andre svar, spørsmål 15 
15. Har du fått tilstrekkelig med informasjon?

Ja $\square$ Spesifiser:

Nei $\square$ Spesifiser:

16. Hvordan mener du at arbeidsplassen bør informere om at det finnes AGS og om hvilken rolle og funksjon personen(e) er tiltenkt?

Sett gjerne flere kryss

Skriftlig informasjonsskriv

Muntlig av ledelsen

Muntlig av sykepleieren som ha den utvidede geriatriske kompetansen

Annet $\square$ Spesifiser:

\section{Organisering av helsetjenestene som gis}

17. Hvilken organisatorisk plassering mener du at AGS skal ha på arbeidsplassen?

Direkte under enhets/distriktsleder, samme plassering som avdelingsleder

Direkte under avdelingsleder, samme plassering som sykepleier

Annet $\square$ Spesifiser:

18. Formidler du kontakt mellom pasient og AGS ved behov?

I høy grad

I noen grad

Overhodet ikke

Hvis «I høy grad, I noen grad», spørsmål 20

Hvis «Overhodet ikke», spørsmål 19

19. Hva er årsaken til at du ikke formidler kontakt mellom pasient og AGS?

Sett gjerne flere kryss

Vet ikke hvem som er AGS

Funksjonen og rollen til AGS er ukjent

Manglende ferdigheter hos AGS

Jeg har ikke behov for å formidle kontakt mellom pasient og AGS

Pasientene har ikke behov for at jeg formidler kontakt til AGS

Manglende kapasitet hos AGS

Har ennå ikke vært aktuelt å formidle kontakt mellom pasient og AGS

Annet $\square$ Spesifiser:

20. Bør AGS gi helsehjelp til pasienter med spesielle utfordringer?

Utfordringene kan vare knyttet til pasientenes adferd, diagnose, medisinsk- og psykososiale behov og så videre

I høy grad

I noen grad

I liten grad

Overhodet ikke

21. Opplever du at AGS påvirker din arbeidsdag? 
I høy grad $\quad \square \quad$ Spesifiser hvordan:

I noen grad $\quad \square \quad$ Spesifiser hvordan:

I liten grad $\quad \square \quad$ Spesifiser hvordan:

Overhodet ikke

22. Skal AGS ha mulighet til å prioritere hvilke pasienter de skal gi helsehjelp til?

I høy grad

I noen grad

I liten grad

Overhodet ikke

Vet ikke

\section{Samarbeid}

23. Har du samarbeidet med AGS?

$\mathrm{Ja}$

Nei

Hvis ja, spørsmål 29

Hvis nei, spørsmål 24

\section{Hvorfor har du ikke samarbeidet med AGS?}

Sett gjerne flere kryss

Vet ikke hvem som er AGS

Vet ikke hva AGS kan gjøre

Har ikke hatt behov for å samarbeide med AGS

Har ikke klart å få tak i AGS

Annet

$\square$ Spesifiser:

25. Kan du tenke deg å samarbeide med AGS?

$\mathrm{Ja}$

Nei

Hvis ja, spørsmål 27

Hvis nei, spørsmål 26

26. Hvorfor kan du ikke tenke deg å samarbeide med AGS?

Sett gjerne flere kryss

Kan ikke se behovet for å samarbeide

Har ikke tid til å samarbeide

Annet

Spesifiser:

Bli videresendt til spørsmål 33

27. Hvor ofte ser du for deg at du kunne samarbeide med AGS?

Flere ganger daglig

En gang daglig 
Flere ganger i uken

En gang i uken

Ca. hver 14. dag

Sjeldnere

28. Hvordan ser du for deg at samarbeidet med AGS skal foregå?

Sett gjerne flere kryss

Avtalt møte

Ad-hoc samtale

Telefon

Faks

E-post

Elektroniske meldinger

Post

Rapport

Videokonferanse eller lignende

Annet

Spesifiser:

Blir videresendt til spørsmål 33

29. Erfarer du at det er lett å få tak i AGS?

I høy grad

I noen grad

I liten grad

Overhodet ikke

30. Hvor ofte samarbeider du med AGS?

Flere ganger daglig

En gang daglig

Flere ganger i uken

En gang i uken

Ca. hver 14. dag

Sjeldnere

\section{Hvordan foregår samarbeidet med AGS?}

Sett gjerne flere kryss

Avtalt møte

Ad-hoc samtale

Telefon

Faks

E-post

Elektroniske meldinger

Post

Rapport

Videokonferanse eller lignende

Annet

Spesifiser: 
32. Hvordan opplever du at samarbeidet er med AGS?

Svært godt

Godt

Lite godt

Dårlig

\section{Oppsummering}

33. Totalt sett, i hvilken grad mener du at rollen og funksjonen til AGS kan bidra positivt til helse- og omsorgstjenester for eldre?

I høy grad

I noen grad

I liten grad

Overhodet ikke

Kjenner ikke til rollen og funksjonen til AGS

34. Totalt sett, i hvilken grad mener du at rollen og funksjonen til AGS er integrert på arbeidsplassen?

I høy grad

I noen grad

I liten grad

Overhodet ikke

35. Alt i alt, hva mener du er viktig for at AGS skal bidra positivt til helse- og omsorgstjenester for eldre?

Åpent svar:

36. Åpen kommentar: Her er du velkommen til å skrive det du mener er viktig Hvis dette er knyttet til et spørsmål eller svaralternativ, vennligst skriv hvilket Åpent svar:

Tusen takk for at du fullførte spørreskjemaet! 